\title{
Development of Human
} Factors Guidance for Human-System Interface Technology Selection and Implementation for Advanced NPP Control Rooms and Fuel Cycle Installations

Jacques V. Hugo

David I. Gertman

Magdy S. Tawfik

September 2013

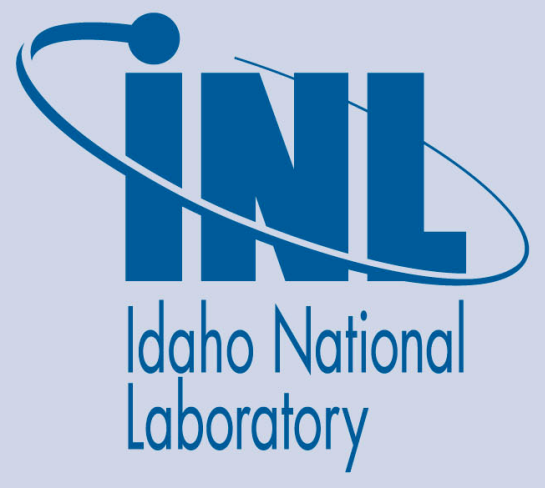

The INL is a U.S. Department of Energy National Laboratory operated by Battelle Energy Alliance 
INL/EXT-13-30118

\title{
Development of Human Factors Guidance for Human- System Interface Technology Selection and Implementation for Advanced NPP Control Rooms and Fuel Cycle Installations
}

\author{
Jacques V. Hugo \\ David I. Gertman \\ Magdy S. Tawfik
}

September 2013

Idaho National Laboratory

Human Factors, Controls and Statistics Department

Idaho Falls, Idaho 83415

http://www.inl.gov

Prepared for the

U.S. Department of Energy

Office of Nuclear Energy

Under DOE Idaho Operations Office

Contract DE-AC07-05ID14517 


\section{DISCLAIMER}

This information was prepared as an account ofwork sponsored by an agency of the U.S. Government. Neither the U.S. Government nor any agency thereof, nor any of their employees, makes any warranty, expressed or implied, or assumes any legal liability or responsibility for the accuracy, completeness, or usefulness, of any information, apparatus, product, or process disclosed, or represents that its use would not infringe privately owned rights. References herein to any specific co mmercial product, process, or service by trade name, trade mark, manufacturer, or otherwise, does not necessarily constitute or imply its endorsement, reco mmendation, or favoring by the U.S. Government or any agency thereof. The views and opinions of authors expressed herein do not necessarily state or reflect those of the U.S. Government or any agency thereof. 



\section{ABSTRACT}

This report characterizes a range of advanced HSI technologies and relevant performance measures. It also de scribes plans for further research required to formalize the technology classification framework in preparation for its submission to a selected standards organization. A second priority is a formal, quantitative model of innovation that can be used by DOE and planners to anticipate the introduction of advanced HSI in nuclear power plant control rooms. Much of the prior human factors inspired research stops at the interface and fails to provide a definitive process and integration of I\&C. The potential merger of two different approaches in this area is disc ussed and also why an integrated approach that ties I\&C and human factors together is warranted. The conclusion is that there is an urgent need for requirements and guidelines for HSI implementation at nuclear facilities to be formalized and this research should lead to the potential adoption of a national or international standard or guidance on the best methods to select and implement advanced technologies to achieve safe and efficient human-system interactions. 


\section{ACKNOWLEDGEMENTS}

Parts of this report are based on Hugo, J. (2013) "Human-System Interfaces for a new generation of nuclear plants" In "Handbook of Small Modular Reactors" M. Carelli and D. Ingersoll (Eds.), currently in press at Woodhead Publishing, Cambridge, UK. 


\section{CONTENTS}

ABSTRACT iii

ACKNOWLEDGEMENT S. iv

CONTENTS V

ACRONYMS vii

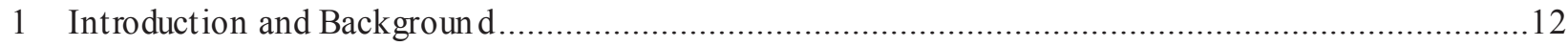

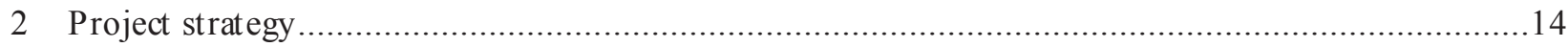

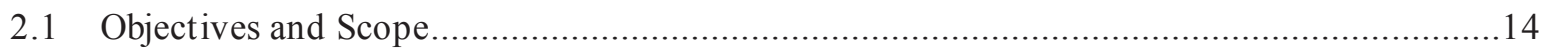

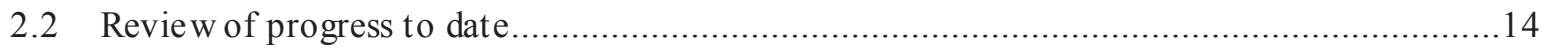

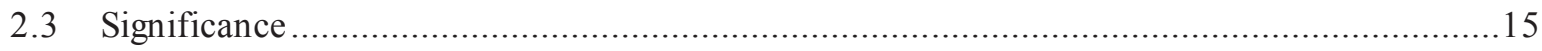

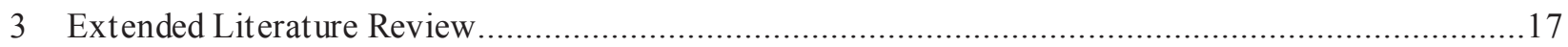

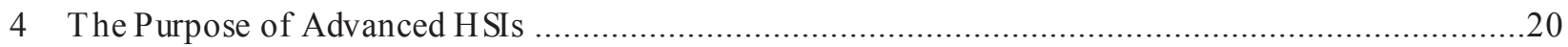

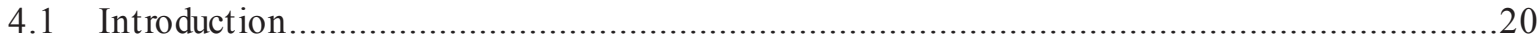

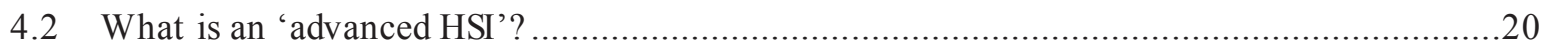

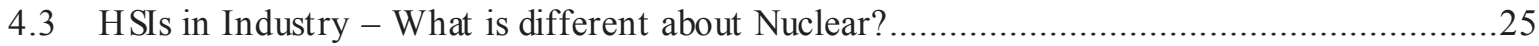

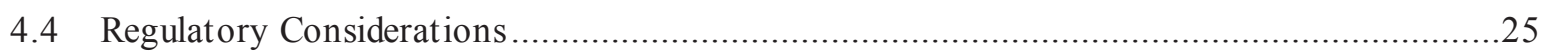

4.5 The state of HSI technology in existing nuclear power plants ........................................26

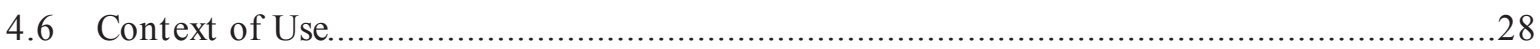

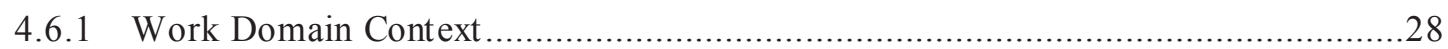

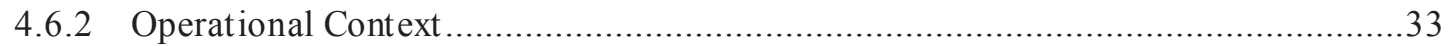

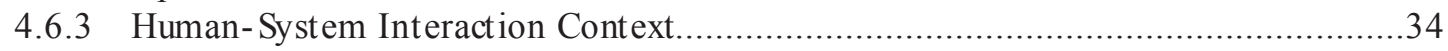

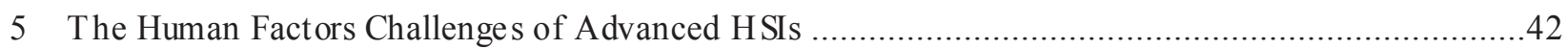

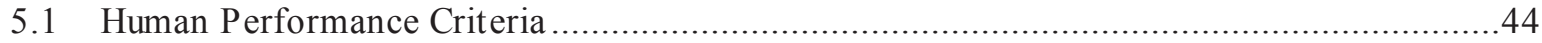

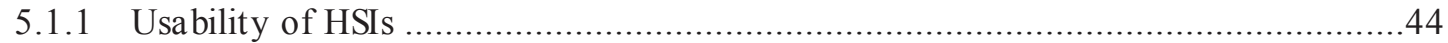

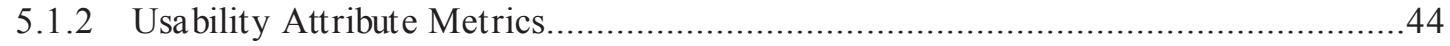

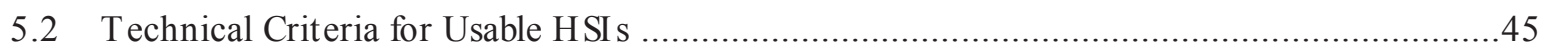

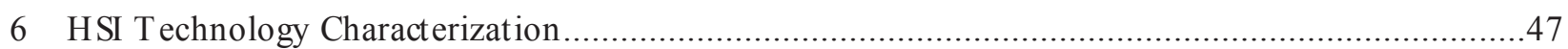

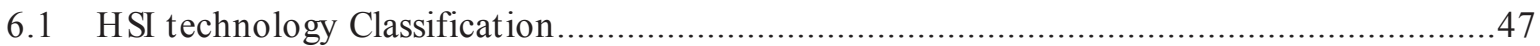

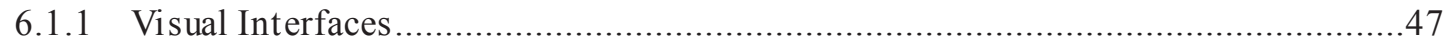

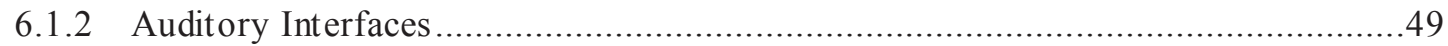

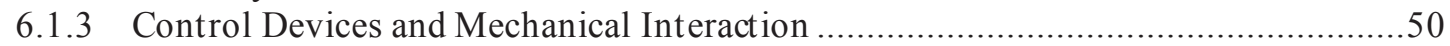

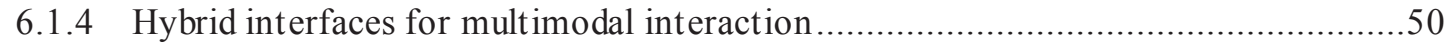

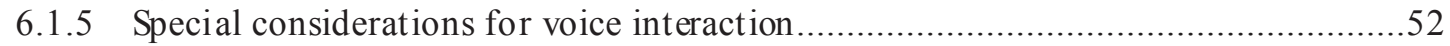

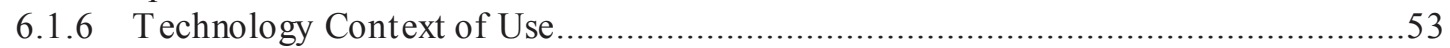

6.2 Conceptual Mapping of Functions to HSI Displays and Controls ....................................57

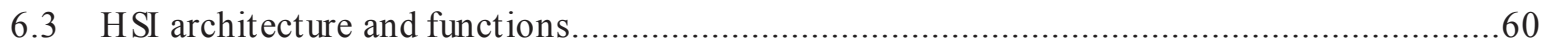

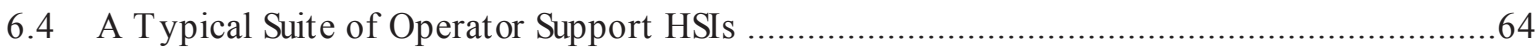




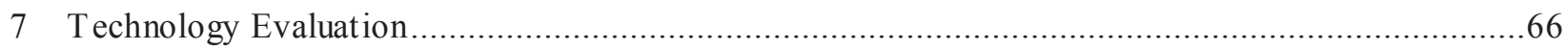

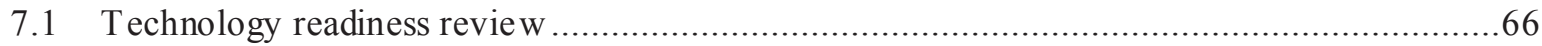

7.2 Evaluation of the Smart Technologies SMART Board ....................................................67

7.3 Evaluation of the Emotiv Epoc Neuroheadset .................................................................... 70

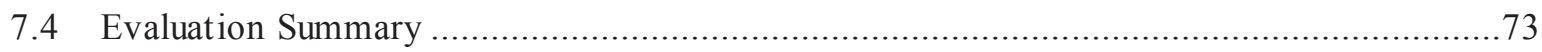

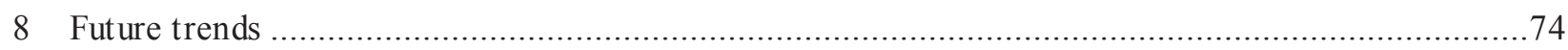

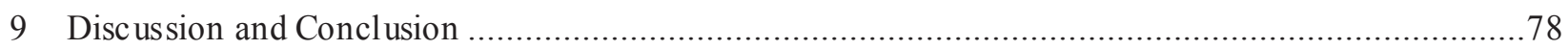

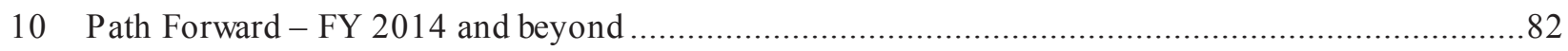

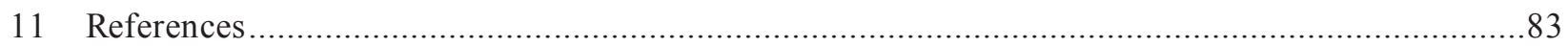

\section{FIGURES}

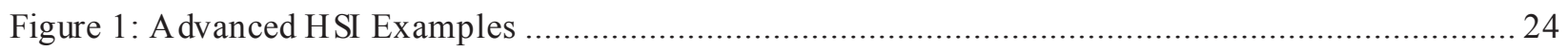

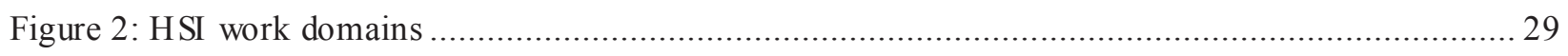

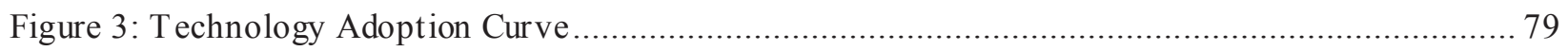

\section{TABLES}

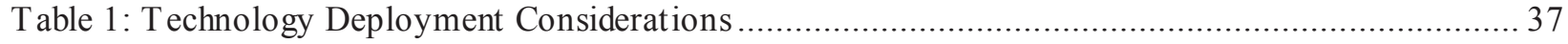

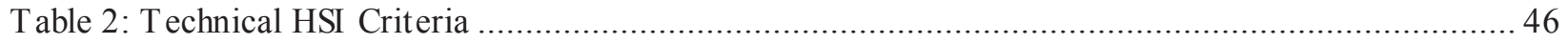

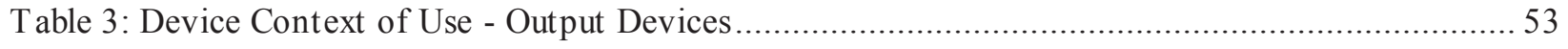

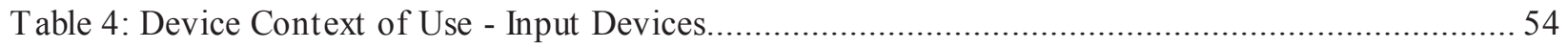

Table 5: Device Context of Use - Hybrid Input/Output Devices................................................. 55

Table 6: Advanced Technology Context of Use - Specialized Applications......................................... 56

Table 7: Ergonomic Comparison of Interaction Devices............................................................ 58

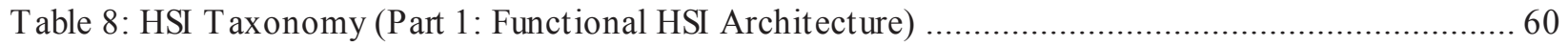

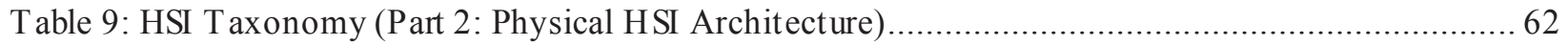

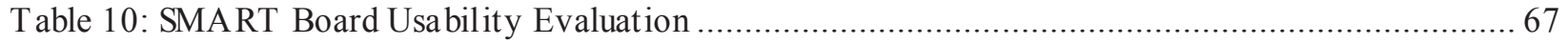

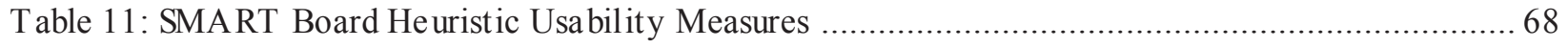

Table 12: Epoc Neuroheadset Usability Evaluation ...................................................................... 70

Table 13: Headset Heuristic Usability Measure s ...................................................................... 71

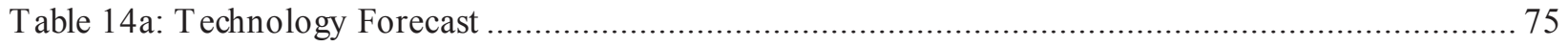




\section{ACRONYMS}

ANSI

AR

A SI

A ST M

BCI

BDBE

DBE

DOE

EOF

FOAK

GP S

HF

HFE

HSI

HMD

HVAC

I\&C

IEEE

INCOSE

INL

ISO

LCD

LCS

LED

LWR

NASA

NEET

NFPA

NPP

NRC

OLED

O\&M
American National Standards Institute

Augmented Reality

Advanced Sensors and Instrumentation

American Society for Testing and Materials

Brain-Computer Interface

Beyond Design Basis Event

Design Basis Event

US Department of Energy

Emergency Operating Facility

First-Of-A-Kind (Engineering)

Glo bal Positioning Sy stem

Human Factors

Human Factors Engineering

Human-System Interface

Head-mounted Display

Heating, Ventilation and Air Conditioning

Instrumentation and Control

Institute of Electrical and Electronics Engineers

International Council on Systems Engineering

Idaho National Laboratory

International Standards Organization

Liquid Crystal Diode

Local Control Station

Light Emitting Diode

Light Water Reactor

National Aeronautics and Space Agency

Nuclear En gineering Enabling Technology

National Fire Protection Association

Nuclear Power Plant

Nuclear Regulatory Commission

Organic Light Emitting Diode

Operations and Maintenance 
OSHA Occupational Safety and Health Administration

PDA

Personal Digital Assistant

PPE

Personal Protective Equipment

RFID

Radio Frequency Identification

SA

Situation Awareness

SACRI

Situation Awareness Control Room Inventory

SAGAT

Situation Awareness Global Assessment Technique

SEP

Sy stems Engineering Process

SMR

Small Modular Reactor

TRL

Technology Readiness Level

VDU

Visual Display Unit

VR

Virtual Reality 


\section{Preliminary Report on the Development of Human Factors Guidance for Human-System Interface Selection and Implementation for Advanced NPP Control Rooms and Fuel Cycle Installations}

\section{Introduction and Background}

The growing demand for clean and reliable energy in recent years has stimulated resurgence in the interest in nuclear energy. Energy utilities in the United States in particular are under increasing pressure to improve the competiveness of nuclear plants. Designers of the new generation of plants are also under pressure due to the need to offset capital cost by reducing operating and maintenance (O\&M) costs. It is generally accepted that the new generation of nuclear power plants, especially designs like integral pressurized water reactors, liquid metal cooled reactors, fast sodium cooled reactors, high temperature gas-cooled reactors and other advanced reactor designs, will make use of state-of-the-art technologies in many areas of the plant. Although future plants may be highly automated, there is little doubt that humans will continue to play an important role. The need for shared or collaborative control in fut ure plants, especially in advanced multi-modular reactors, is guaranteed to demand advanced technologies. Advances in instrumentation, control, and human machine interface technologies will significantly change the nature of the interaction between operators and the system, and they can also enhance human reliability and control room safety. For example, it is expected that automation and digital technologies like advanced human-system interfaces (HSIs) will contribute to lower O\&M cost by reducing the need for human control. However, there is very little proof of concept in the nuclear industry for the use of this type of technology. Without such proof of concept demonstrations, even in replica, simulated environments, there may be little impetus for advanced technology adoption. As a result, the anticipated benefits expected from these new technologies may not be realized. This situation may be exacerbated by the lack of guidance for the selection and implementation of these technologies for upgraded plants or new builds. This will be a significant challenge for design en gineers and human factors analysts because implicit in the adoption of different automation strategies is a change in the role of operators. Safety and reliability requirements will require that operators are still able to intervene when necessary and otherwise oversee automation in many aspects of plant operation. Guidance is needed to ensure that advanced HSI technologies are deployed where beneficial and will support reliable and safe plant operation.

New technologies like large, high-resolution displays, handheld and wearable devices and augmented reality systems are already being introduced in other industries and can be expected to become important options for the nuclear industry too. These new tech nologies offer human support capabilities unheard of in existing conventional nuclear plants and this represents just one of the important feat ures that will make the next generation of power reactors unique. Designers will be able to exploit these capabilities to achieve enhanced monitoring, improved situation awareness and more efficient response planning, coordination and communication among human teams, some of whom may be remotely located, and also 
between humans and intelligent automation. The analysis, design and selection of advanced humansystem interfaces is an important part of power plant engineering activities and de signers need to consider these capabilities in the context of current regulations, expectations of personnel roles and responsibilities, an d combined multi-unit operations.

Determining the optimal interaction modalities for different operational contexts is also a key requirement for future system design. This requires accounting for spatial and physical work space characteristics and collaborative functions among crew members. This includes coordination of work activities, adapting their use of HSI technologies to different work settings, and how to achieve shared situation awareness of ongoing evolutions to maintain plant safety. Designers will also consider alternative perceptual and interaction modalities offered by new technologies like touch and voice interaction. Ultimately they have to determine how new technology characteristics affect human performance and therefore the need for advanced capabilities to support new power plant requirements, such as reducing O\&M costs by reducing the number of labor-intensive activities that are needed to operate and maintain the plant. This leads to questions about the need for, and rational implementation of adaptive automation, computational intelligence, operator support systems, and other methods of reducing complexity, to optimize human automation interaction. Where appropriate nuclear operating experience of advanced technologies is lacking, designers will require access to standards and recommendations on the best methods to select and implement advanced technologies to achieve safe and efficient human-system interactions. 


\section{Project strategy \\ $2.1 \quad$ Objectives and Scope}

In spite of all the requirements that will be imposed on designers of anew generation of nuclear plants to verify and validate their choice of technologies, there is already ample evidence in other industries of the benefits of advanced technologies in specific work environments and operational contexts. These HSIs offer support for substantial improvement in the safety and economics of all nuclear power plants (NPPs). The new and upgraded power plants and associated facilities that are the subject of this research promise to be safer and more economical plants that will reach the market in the next decade in various co untries. That is just one reason why the adoption of the HSIs de scribed here is a lo gical approach in current small modular reactors (SMRs) and other advanced designs. Nevertheless, designers cannot simply assume that any new technology would contribute to safety or better human performance. Addressing issues of automation, function allocation, error reduction and overall operat or efficiency is still a major challenge. To address those challenges three main topics are disc ussed in this chapter:

1. The technical characteristics of HSIs for a new generation of NPPs and the human factors considerations associated with them.

2. Development of implementation and design strategies and special considerations for the selection and deployment of advanced technologies in NPPs, whether, modernized, new, conventional, or first-of-a-kind. This includes strategies for the integration of human factors and regulatory aspects into systems engineering processes.

3. Description of typical future trends, that is, how technologies are likely to develop over the next ten to fifteen years and how this will affect design choices for the nuclear industry.

\subsection{Review of progress to date}

The plan for this phase of the project included the following tasks:

\begin{tabular}{|c|c|c|}
\hline $\begin{array}{c}\text { Task } \\
\text { Number }\end{array}$ & Des crip tion & Status \\
\hline 1 & $\begin{array}{l}\text { Develop and implem ent a prioritization schem e to focus the } \\
\text { topics for system atic res earch required to develop a } \\
\text { technical basis and guidance for technology selection and } \\
\text { implementation. }\end{array}$ & $\begin{array}{l}\text { The DOE Technology Readiness } \\
\text { Level schem e was adapted and } \\
\text { applied to the ranking of the } \\
\text { technologies identified in this study. }\end{array}$ \\
\hline 2 & $\begin{array}{l}\text { Develop a preliminary technology selection fram ework for } \\
\text { pursuit of empirical research }\end{array}$ & $\begin{array}{l}\text { Topics for further investigation were } \\
\text { identi fied and des cribed in Appendix } \\
\text { A. }\end{array}$ \\
\hline 3 & $\begin{array}{l}\text { Select and acquire material for experiments need ed to } \\
\text { develop measures of human performance in the presence of } \\
\text { speci fic technologies. }\end{array}$ & $\begin{array}{l}\text { Due to funding limitations, this task } \\
\text { was limited to the evaluation of the } \\
\text { Emotiv Neuroheads et and the SMART } \\
\text { Board. }\end{array}$ \\
\hline 4 & $\begin{array}{l}\text { Define the crit eria needed for implem entation of advanced } \\
\text { HSIs in NPP control rooms and in the plant with } \\
\text { consideration of functionality, safety, operability, usability, } \\
\text { practicality, availability, and expected cont ext of use. }\end{array}$ & $\begin{array}{l}\text { The results were captured in the } \\
\text { technology charact eristics matrix, } \\
\text { Appendix A. }\end{array}$ \\
\hline
\end{tabular}




\begin{tabular}{|c|c|c|}
\hline $\begin{array}{c}\text { Task } \\
\text { Number }\end{array}$ & Des crip tion & Status \\
\hline 5 & $\begin{array}{l}\text { Applying previ ously developed criteria, sel ect and evaluate } \\
\text { a seri es of high impact HS I devi ces and supporting so ff ware } \\
\text { for experimental deploym ent in the Hum an Systems } \\
\text { Simulation Laboratory (HSSL). This includes candidate } \\
\text { technologi es for NPP control ro om implem entation, such as } \\
\text { touch screen panels, large screen overviews, hand-held } \\
\text { devices, and head-mounted display devices to visualize } \\
\text { control room operations. }\end{array}$ & $\begin{array}{l}\text { Topics for further investigation were } \\
\text { identified and des cribed in Section } 10 \\
\text { and in Appendix A. }\end{array}$ \\
\hline
\end{tabular}

As shown above, this project has made significant progress in the classification of Advanced Human Sy stem Interfaces (HSIs) for a future generation of nuclear energy installations. This classification characterizes technologies in terms of the context of use, that is, the actual conditions under which a given product is likely to be use d by specific people in a variety of working situations and environments. The characterization includes definitions of operational scenarios, a taxonomy of the families of input, output and hybrid devices, the context of operator interaction with devices in diverse environments, and the human performance characteristics with selected devices under various operating conditions. This characterization was necessary to establish the technical basis for the future design and selection of advanced HSIs. The results to date have demonstrated how advanced HSIs c an be defined and classified in terms of three dimensions:

1. The work environment where the device is used, also called the work domain context.

2. The condition of the plant or system at the time when a specific task has to be performed, also called the operational context.

3. The nature of the device use d to perform a task and its suitability for the task at hand, which includes the characteristics of human mental and physical performance requirements in specific operating situations, also called the human-system interaction context.

These results will support the further gap analysis of the current state of technologies in the nuclear industry, compared to current best practice in other industries, with special emphasis on the development of technology selection criteria to best support human performance in advanced concepts of operations.

\subsection{Significance}

New HSI technologies have the potential to significantly improve human performance in a wide variety of applications, and work domains. At present the impact is seen predominantly in domestic and commercial applications (for example, a large variety of handheld devices like tablets and smart phones). Similar devices are also beginning to find their way into several industrial applications, for example maintenance, field diagnostics, stock control, point of sale, and many more. However, in spite of their potential to contribute to reliable operator performance in the control room (and in other locations where technology might be employed to support operations), these devices have yet to be adopted by the nuclear industry. This backlog in the nuclear industry is partly due to a lack of well-defined selection criteria to ensure that displays and controls adequately support operator job requirements and to ensure operational 
safety. Selection guidance is needed for higher-level operational and human performance issues, such as ensuring that chosen technologies support situation awareness, contribute to reduction of workload, and support balanced task allocation.

The experience gained from this phase of the project and the continued research will be relevant to all NPP I\&C and HSI digital upgrades and new designs. Because up grades and new designs will rely to a much greater extent on digital technologies and employ newer and more kinds of automation, technology neutral, decision-centered and performance-based approaches are needed that permit the selection of the best available technologies for eventual qualification for system operation, upgrades, maintenance and replacement. Because of the broad application potential of these technologies, even small improvements in efficiency across the application domains can yield significant benefits for human and system reliability, resilience, usability and productivity. The approaches developed during this project will also help to ensure that the most suitable technologies can be deployed and that strategies for upgrade and replacement are sound and meet regulatory guidance. 


\section{Extended Literature Review}

The literature review reported in the September FY12 milestone report [34] was extended to identify additional and updated information on new technologies. As indicated in that report, several commercial sources were identified, but research on the role and impact of new HSI technologies in the nuclear industry was non-existent.

This again confirms the urgent need to provide guidance for NPP utilities wishing to implement new HSI technologies. The rapid rate of development of consumer devices al so confirms that many advanced HSI technologies currently available and being developed are potentially suitable for modern control room application.

The most recent sources are disc ussed briefly below:

- Integration of HSIs for Control Room Modernization: The design of new as well as upgraded control rooms is a complex process that involves many human factors considerations that must be integrated with many engineering processes. NUREG-0711 (O'Hara et al. 2012 [61]) describes the Human Factors Engineering Program from a regulatory perspective, but it provides only limited guidance on integrating human factors requirements with the Systems Engineering Process as described in IEEE 1220-2005 [37]. Similarly, NUREG-0700 ('Human-System Interface Design Review Guidelines' [55]) contains a large number of criteria for the review of existing HSI implementations, but it does not provide guidance on the selection of advanced HSI, nor does it provide criteria for the integration of specific technologies in defined operational contexts. The first steps towards developing a process for implementing an engineering process for control room modernization that include human factors requirements in conformance with NURE G-0711, were taken during the Duke Energy project in 2012 and 2013 [33]. That report describe d the human factors requirements involved in a modernization project, but it did not address the selection of HSIs. Similar research was conducted at the Halden Reactor Project on the development of an integrated concept for control room modernization projects and current new builds (Hurlen et al. 2013 [35]). The report described the key principles that form the foundation for design work and the purpose and behavior of individual HSI elements, and how they are integrated and coordinated as a whole. However, the report focused primarily on display concepts for the control room (such as 'Information Rich Displays' and 'Task-based Displays') and did not examine any human factors issues a ssociated with the target technologies. Other Halden Work Reports focused on different design concepts and prototypes that have been implemented and evaluated in the Halden experimental control room facility. Many of those concepts go far beyond traditional type displays and utilize advanced computer graphics and animations, but also do not consider the human factors aspects of the physical technology and the implications for modernization projects (Braseth et al. 2009 [5]).

- Large group-view display (non-interactive). These displays are generally good for displaying the operational "big picture" and especially to promote high-level SA. They are also good for team coordination/ communication. Typical devices are mounted in a fixed location, unless they are mounted on a wheeled frame, which provides limited mobility, although this mode of use is not 
suitable for control rooms. (Czerwinski et al. 2006 [13]; Wallace et al. [82]). No recent literature was found on the use of large displays in NPP control rooms.

- Bone conduction audio. Headphones that employ bone conduction have been available since the early 1960 s, but have only recently become popular consumer devices because they are now more compact and can provide high-fidelity sound, especially where external noise is a concern. In power plant operations they can provide real-time information in busy-hands busy-eyes tasks because they can maintain sound clarity in very noisy environments because the eardrum is bypasse d and so und is passed directly to the inner ear. For this reason they are well suited to specialized communication needs, such as for underwater or high-noise environments. Another advantage is that they can be used with hearing protection. The only significant disadvantages are that bone conduction is less suitable for perception of stereo sound, some implementations require more power than normal headphones, and they provide only a reduced frequency bandwidth, with higher frequencies. (Stanley and Walker 2009 [77])

- Haptic output (narrow-range vibratory alert): This is a family of devices that provide simple tactile feedback to users on discrete events, such as alarms. A typical example is found in modern cellular phones that can vibrate on incoming calls or messages. Many studies have examined the feasibility and effectiveness of tactile information presentation in the context of rather simple tasks and environments. It was proven especially valuable in the aviation domain where it is use to provide navigational or spatial gui dance to pilots. The technology provides real-time alerts when visual or audio sources are not available or where there is too much interference. It is good for fast localization and response, but can provide only transient information and a limited range of discriminable stimuli. (Sklar and Sarter, 1999 [76]; Hameed et al. 2009 [25])).

- Haptic input and output (wide range physical stimulus): These technologies use highly specialized hardware and software. They allow users to operate devices through the sense of touch and reduce reliance on visual interaction. Operators can "feel" the state and even the shape of a system. It can be integrated into displays, hard controls, hand-held devices an d virtual reality systems (e.g. vibratory alerts and force feedback). Most users need extensive training and practice to use devices effectiv ely. The development of these devices needs a lot of human factors analysis to ensure appropriate precision of touch. (Robles-De-La-T orre 2006 [66]).

- Hand-held display, hand-held computers and wearable computing devices: This family of technologies has become pervasive in most commercial and industrial environments but has seen only limited penetration in the nuclear domain. The devices are relatively cheap, portable, light and versatile, can be carried in backpack, briefcase or pocket, are easy to use and provide rapid access to information almost anywhere. Some devices, such as wrist-worn computers can be combined with vibratory and audio alerts. There are a few drawbacks, however. Devices need to be carried by hand or stored or mounted on the body. Unless they are provided with a reliable voice command interface, they can only be operated by hand. The small keyboards limit their use to actions that require minimal typing. Displays have significant power requirements, especially when complex graphics or video material must be displayed; this limits battery life. In addition, the small display size limits rea dability 
and offers reduced visibility in bright light. They are also difficult to use with gloves. Although most devices offer wireless connectivity, this is limited in certain plant areas. Finally, the use of handheld devices competes with other visual requirements and this may inhibit situation awareness and lead to loss of contextual comprehension. ( Lewis et al. 2008 [47]).

- Virtual/Augmented reality (AR) (multidimensional) information display: This technology uses computer vision and object recognition to superimpose task information on the user's view of the real task environment, allowing the user to interact with information in real time. It uses head-mounted devices co upled with display technologies like retinal displays for immersive or semi-immersive display. By linking the displays to a head-mounted camera, virtual labels can be superimposed on the view of the real component, for example, to clarify operating instructions for a technician performing maintenance on a system. It can also be use t to evaluate designs of physical environments or syst ems before manufacture. This is a complex technology, but it is developing rapidly and is making an appearance in some advanced engineering environments. Most devices still require cumbersome headge ar and in some applications may require construction of controlled environments containing position sensors and actuators. One of the most well-known examples of augmented reality is the Google Glass ${ }^{\mathrm{TM}}$ device announced in 2013. This is a device that can connect wirelessly to the Internet and the wireless service on a user's cellphone. The glasses respond when a user speaks, touches the frame or moves the head. A similar device but one designed more for industrial environments is the Motorola Golden-I device that combines several of the features mentioned above. (Manjoo 2012 [49]; Metz, 2012 [50]; Wood, R.T. et al. 2003 [83]).

The conclusion from this review was that there remains a large gap in the availability of human factors guidance for the selection and deployment of HSI technology for specific work domains in new NPPs as well as upgraded workplaces (that is, control rooms, local control stations, workshops, laboratories, etc.). 


\section{The Purpose of Advanced HSls}

\subsection{Introduction}

The primary purpose of the HSI is to provide the operator with a means to monitor and control the plant and to restore it to a safe state when adverse conditions occur. The implementation of devices that successfully accomplish this objective will also satisfy the five important human performance goals that all contribute to the safe and efficient operation of the plant: 1) reduce complexity, 2) reduce error and improve human reliability, 3) improve usability, 4) reduce operator workload, and 5) improve situation awareness.

Achieving these objectives relies heavily upon the most effective information and communication technologies available. Such technologies have the potential to improve many of the shortcomings of the old generation of analogue HSIs found in most NPPs (that is, 'hard controls and instruments' consisting of buttons, switches and gauges). However, such improvements require a focus on the human factors principles involved in the interaction between humans and machines. Advanced automation systems are be ginning to allow a more dynamic collaboration between humans and systems and we can no longer regard the complex relationship between humans and systems as 'people versus technology', which was often the result of the classical function allocation approach. That outdated approach was based on attempts to implement the 'HABA-MABA (humans are better at - machines are better at)' principles derived from Fitts' List (Hoffman et al., 2002 [27]). Rather, it is now more appropriate to consider the total socio-technical system as a 'joint cognitive system.' Woods and Hollnagel (2006) [84] and Lintern (2007) [48] describe a cognitive system as one that performs the cognitive work functions of knowing, understanding, planning, deciding, problem solving, analyzing, synthesizing, asse ssing, and judging, as they are fully integrated with perceiving and acting. In a particular work environment in the power plant, the ent ity that performs perceiving and acting functions would be the human agent. This implies that the control room and the entities within it could be characterized as a joint cognitive system that functions in a distributed way and involves relevant parts of the environment, the physical, mental and cultural processes of people, and the technical artifacts. The joint cognitive system viewpoint emphasizes the cognitive functions that human operators and techno logies accomplish in collaboration. It allows human factors analysts and designers to analyze the system on different levels of detail, starting from the entire socio-technical system of the NPP, down to specific functions of an HSI that would have the ability to support the operator's cognitive functions. ${ }^{1}$

\subsection{What is an 'advanced HSI'?}

The US Nuclear Regulatory Commission's (NRC) review guidance on human-system interfaces, NUREG-0700, defines the HSI as 'that part of the nuclear power plant through which personnel interact to perform their functions and tasks. Major HSI s include alarms, information displays, controls, and procedures.' (O'Hara et al., 2002 [58]). The HSI is use d to manipulate a device or system, to request and display stored data, or to actuate a single process or various pre-programmed command routines. HSI s

An extended discussion ofFunction Allocation will be found in the report INL/EXT-13-30117 (2013) “Development of a Technical Basis and Guidance for Advanced SMR Function Allocation”. 
can be organized into workstations consisting of consoles and panels and the arrangement of workstations and supporting equipment could be organized into physical work areas such as a main control room, remote shutdown station, local control station, technical support center, and emergency operations facility. The HSI could also be characterized in terms of the environmental conditions in which the HSIs are use d, including radiation, temperat ure, humidity, ventilation, illumination, and noise.

The NUREG-0700 definition is generally valid for HSIs currently in use, but it does not take into account the latest advances in HSI hardware and software. ${ }^{2}$ In contrast, Guida an d Lamperti (2000 [23]) describe an advanced HSI as one that can support the implementation of advanced interaction features, such as natural dialogue, flexible languages, multi-media communication, user-a dapted interaction, cooperative behavior, explanation and justification, intelligent help, etc.

The scope of this project is to a large extent determined by how the term 'Advanced Human-System Interface Technology' is defined. Characterization of new and advanced HSI s is difficult due to the very broad nature of the terms 'advanced' and 'new technology'. It would be infeasible to address all the different types of selection procedures that would be necessary for all types of new technology. In an attempt to define the boundaries for the current research, the following criteria were applied:

Firstly, defining what is 'new', secondly, defining what is the 'technology' that is new, and thirdly, what is 'advanced':

1. There are three classifications of the term 'new' which are: new to mankind, new to the nuclear industry, or new to specific nuclear power utilities.

2. There are two forms of 'new technology': a new design concept that is developed to become a product, or a new industrial process. (This would include the process of human interaction with such technology).

3. There are two forms of 'advanced': Far ahead in the development of the state-of-the-art, or relatively unknown and not yet generally accepted by either the utilities or the regulator, or both. Specific reference will be made later in this report to the relationship between "advanced" and "technology readiness".

It will be shown that "advanced HSIs" for the nuclear industry include all three classifications and this report will focus on new technologies that are either new de sign concepts or technologies associated with new in dustrial processes within the field of nuclear power that are only new to the US utilities. The reason for this decision was firstly because the methodology of new technology selection should be generic enough to enable comparison of any type of HSI technology. Secondly, despite the adopted methodology being able to deal with uncertainty, it can only be realistically applied when there is enough information available about the possible technologies to be able to at least make an educated guess about certain criteria for comparison.

As explained in the September 2012 report [34], an HSI is by definition a crosscutting technology, that is, most general-purpose HSI s can be used in any environment where a human needs to interact with a controllable process or device. All HSIs are designed to serve as interface between the human and the

\footnotetext{
${ }^{2}$ At the time ofwriting NUREG-0700 was being prepared for a revision.
} 
process, and therefore the HSI can be described as the user's "handle" on the device, the "front end", or the "affordance". This assumes, of course, that the HSI is well-designed and matched to the capabilities as well as the limitations of the user. The same principle also applies to special-purpose HSIs, which include a wide range of state-of-the-art display and control technologies that may be deployed in conjunction with advanced sensors and instrumentation to satisfy the needs of current NPP modernization efforts as well as new NPP designs. The "handle" of devices in this environment can be as simple as a control panel with a number of buttons and physical controllers, or it can be as complex as a device that detects and translates the user's brain waves into discrete commands that control one or more processes or machines.

The following are regarded as the general characteristics of an Advanced HSI:

\section{- Hardware features}

The physical characteristics of new HSIs include devices that support multimodal interaction, such as touch screens, gesture interaction, speech recognition and synthesis, haptic input and output (that is, technologies that use touch and tactile feedback to enable human-system interaction), and even direct body-machine interfaces (biosensors). Advanced display and interaction features already available and un der development make use of hand-held devices, head-mounted displays, lar ge overview displays, three-dimensional (3-D) displays (with or without glasses), motion, and position tracking. To support such extensive interaction capabilities, the whole system is typically driven by highperformance numerical and graphics processors for demanding applications such as high-resolution displays and computationally intensive applications like real-time processing and trending of large amounts of plant data.

\section{- Software criteria}

The main characteristic of new HSI software platforms is that it typically forms part of the plant's Distributed Control System (DCS) software. The DCS is the system that is used for overall plant I\&C integration and automation and the HSI forms part of the 'front end' that enables the operator to interact with the plant through a hierarchy of controls and displays. This system typically allows development of the functionality and displays of the HSI without the need for low-level programming, while allo wing some end-user customization. It also supports full object-orientation and component-based programming, which ensures consistency of functionality, layout and appearance of objects throughout the HSI. Systems like this also support standardized documentation and code handling formats like XML. In advanced applications, as disc ussed later, it would support advanced computational methods like neural/semantic networks, pattern recognition, and also realtime and faster-than-real-time simulation.

\section{- Functional criteria}

Functional features of advanced HSIs include standardized as well as user-configurable displays. However, the most import ant feature would be the organization of the whole HSI as an operatorcentric or task-based system with embedded operator support, including various levels of computerbased procedures. Due to the inherent complexity of advanced automation systems, the HSI must support intuitive navigation through a display architecture derived from proper task analysis, coupled 
with a functional breakdo wn and rational function allocation. Advanced HSIs would also provide error-tolerant and resilient operation, support adaptive automation schemes and provide integrated multimedia communication.

The following are a few typical examples of emerging advanced techn ologies:

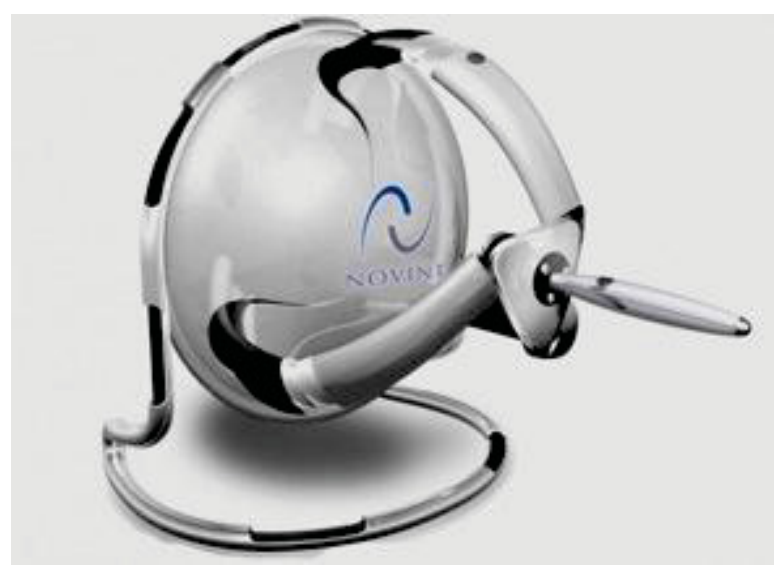

Haptic 3-D con troller

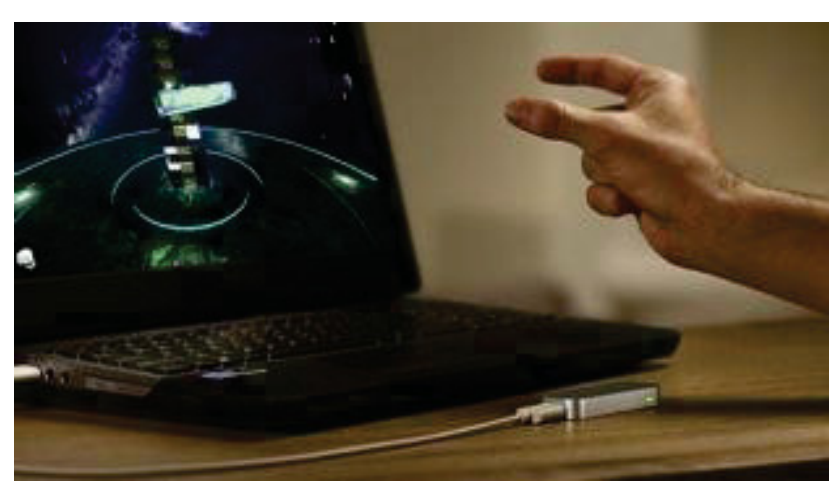

Gestu re cont roller

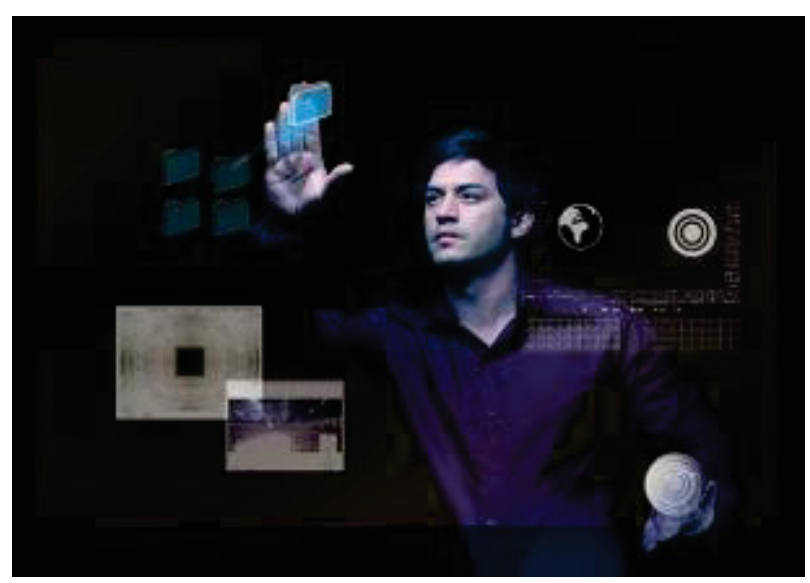

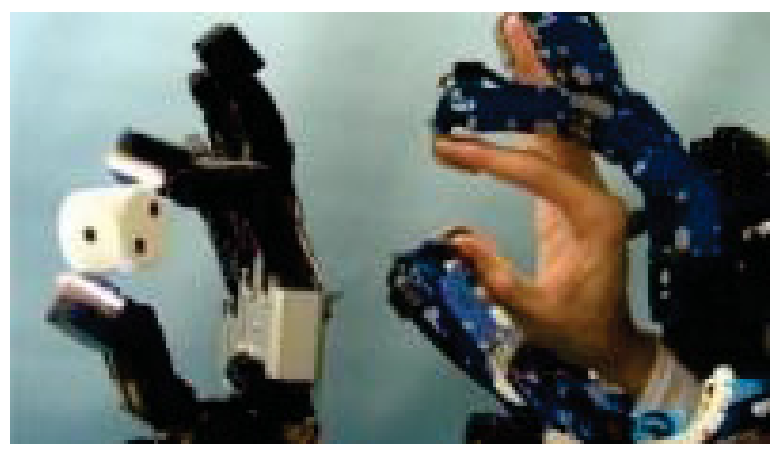

Glove and ex oskeleton controllers

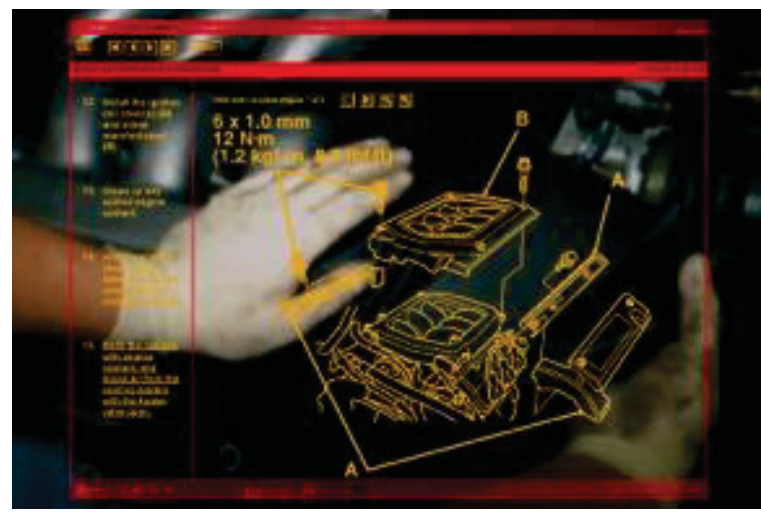

Augmented Reality display

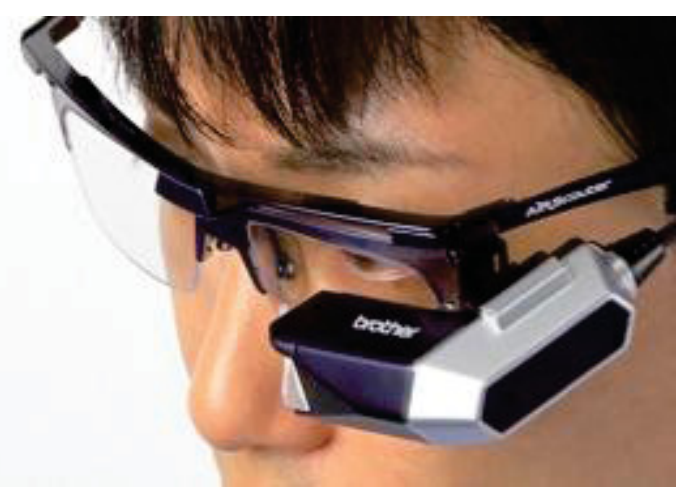


Gestu re control co mbined with holographic display

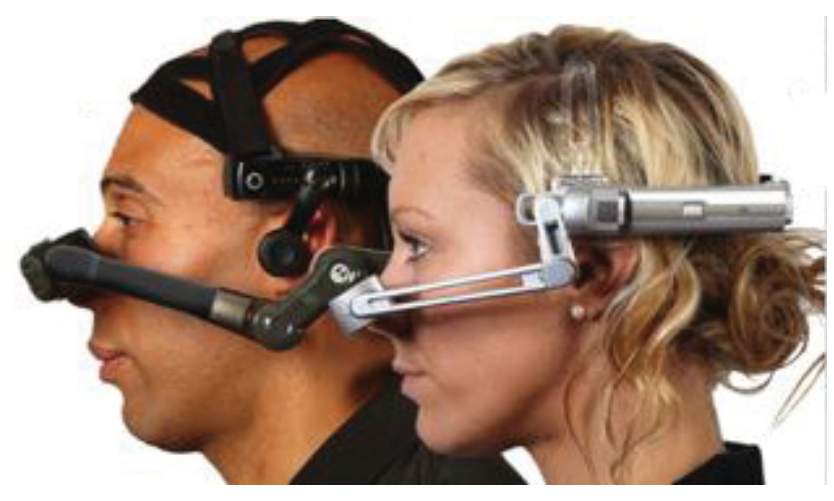

Golden-I Industrial W ea rable Co mputer H eadset

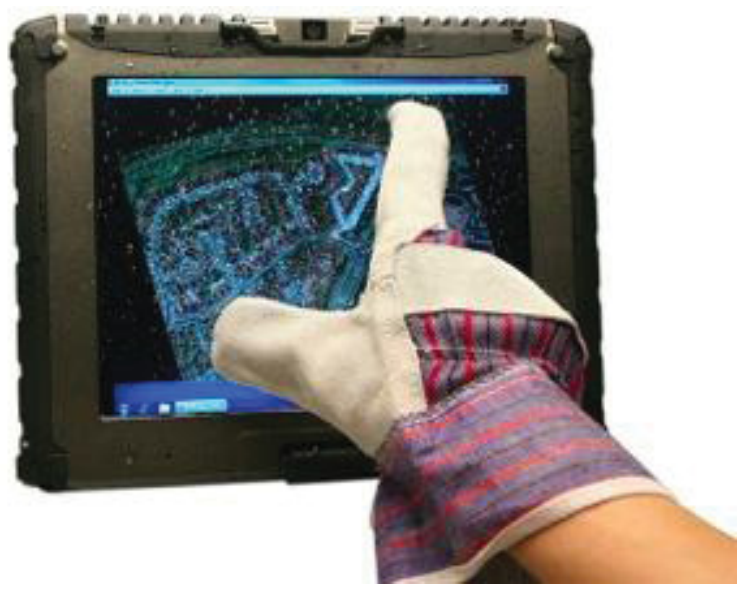

Ruggedized, glove compatible tou ch display

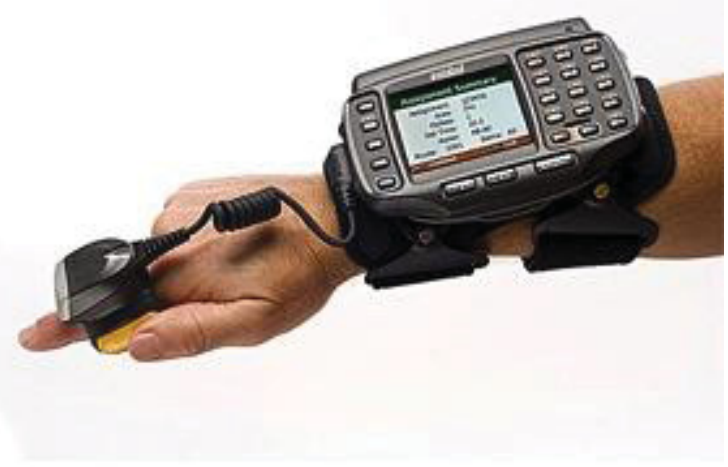

Wrist computer with scanner

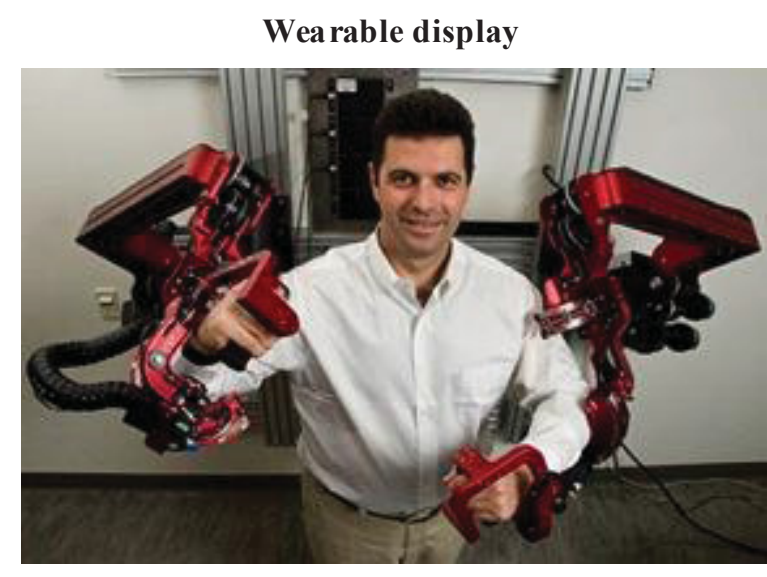

Ex oskeleton manipulator

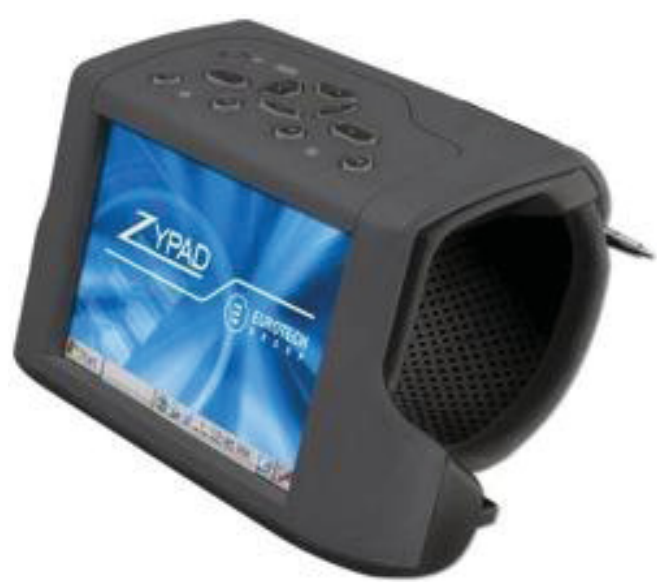

Wrist-worn display

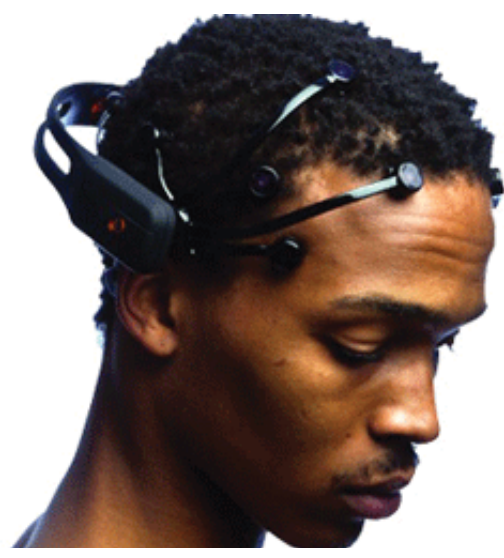

Brain-computer interface

Figure 1: Advanced HSI Examples

Most of these devices are already a commercial reality and are therefore potential candidates for operator use in the future. However, the question is not whether they can be used by operators, but where, why and what wo uld be the impact on human and operational performance? These are the questions that this report is addressing. 


\subsection{HSIs in Industry - What is diffe rent a bout Nuclear?}

There are several reasons why the treatment of HSIs in the nuclear industry is different from other industries. For example, there are probably more regulations, guidelines and standar ds for the consideration of human factors than in most other process industries. SMRs in general and non -light water reactor (non-LWR) designs in particular face even more challenges. For example, due to the emphasis on new technologies, higher levels of automation, new function allocations and the quest for minimal staffing and lower O\&M costs, designers need to cope with a large number of rules, regulations, standards and guidelines. These include, for example, codes of federal regulations like 10 CFR 50.54, the Standard Review Plan for safety analyses (NUREG-0800), the requirements for the review of an organization's human factors engineering program (NUREG-0711), gui delines for human-system interface design, such as NUREG-0700 ('Human-Sy stem Interface Design Review Guidelines'), ISO 11064 ('Ergonomic Design of Control Centers') and IEC 60964 ('Nuclear Power Plants - Control Room Design'), and requirements for the integration of Human Factors Engineer ing (HFE) in other engineering processes as described in IEEE 1023 ('IEEE Recommended Practice for the Application of Human Factors Engineering to Systems, Equipment, and Facilities of Nuclear Power Generating Stations and Other Nuclear Facilities'). There are also many regulations dealing with Occupational Health and Safety, building regulations, and several more.

All of these regulatory and best practice expectations lead to probably the biggest challenges that designers of new NPPs face: the integration of human factors in the systems engineering process throughout the project lifecycle. Because a large part of advanced reactor design wo uld be first -of-a-kind (FOAK) engineering, human factors engineers need to cope with many organizational, technical, regulatory, and methodological questions that are new to the nuclear industry.

Because of all of these requirements, we can expect as much, if not more, regulatory oversight for advanced NPP design projects in the form of regular, mandatory audits, quality and safety management requirements and intensive verification and validation of, for example, HSI de sign s, human performance with operating procedures, and so on. Regulators will also expect to see evidence of human factors work in provisions made to protect the public, workers and the environment. This includes, for example, attention to Situation Awareness, Safety Culture, Human Reliability, Workload and Performance Shaping Factors. All of this contributes to long lead times, not only for engineering and de sign, but particularly for the licensing processes.

It should also be emphasized that HFE practitioners in the nuclear industry are not excluded from scrutiny and public opinion. It is thus also important for HFE people to show how they contribute to safet y to counter misconceptions about hazards (opinions often based on incomplete or outdated information, or disinformation by antagonists).

\subsection{Regulatory Considerations}

Current NRC regulations were developed to support traditional large NPP LWR designs. Current requirements related to the human role in the plant deal primarily with avoiding human error and improving human reliability in normal and abnormal operational conditions. This includes requirements 
for control room staffing, criteria for evaluation of HSIs, and conducting human factors engineering activities in the power plant. Some provision is currently made for new designs, for example for minimum staffing of the NPP, as described in the Code of Federal Regulations, 10 CFR 50.54. However, most new reactor designs, and particularly SMR designs, differ substantially from traditional designs in a number of aspects, including size and number of reactors, inherent passive safety systems, fuel type, and coolant type, among others. These differences present un ique issues in terms of licensing and regulation.

Although current NRC guidance provides a general framework for conducting design-specific reviews, the review of control room and HSI design s as well as staffing plans and potential exemption requests is expected to be challenging for future plants that plan to use advanced HSIs. This is because of the differences between the new reactor design s and previously lic ensed reactor designs and also beca use of a lack of research and design data to provide an adequate technical basis for decisions. The NRC has identified a number of differences bet ween advanced reactor design and operating philosophies and the designs for larger reactors currently licensed or being evaluated for licensing. These differences include different operat or tasks, such as operating multiple units in different modes of operation. A major challenge will be to identify tasks that could substantially affect operator workload and how these could be supported by advanced HSIs. Of particular importance will be new requirements for minimum inventory (that is, the minimum number of indicators and controls needed for the operator to maintain situation awareness during upset conditions such as DBEs and BDBEs.

For the human factors engineer it is essent ial to resolve regulatory issue s regarding the use of new HSI s as early as possible. Early resolution will enable designers to incorporate appropriate changes during the development of their concepts of operation, designs, task analyses, and staffing plans before submitting a design review or license application. It will also support the NRC staff's review of the design and license applications.

\subsection{The state of HSI te chnology in existing nuclear power plants}

Many new reactor design s, and especially SMRs, are still in the conceptual or preliminary design phase and typically very little information for HSI design and device selection is available early in the project life cycle. Nevertheless, it is possible to generalize the characteristics of much of HSI technol ogy that wo uld be used in advanced NPPs. This is not so much because of similarities in new designs, but rather because of the state-of-the-art in HSI technology. In the past there was a certain degree of customization of instruments and controls (I\&C) for specific control rooms, but this customization was more in the layout of the control room and the control boards. Most of the instruments and controls (traditional 'light box' alarm annunciators, panel-mounted switches, knobs, dials an gauges) were devices that were designed to strict industry standards for reliability and robustness. However, for the foreseeable future we can expect implementation of devices initially designed for consumer and commercial use, but that are fast becoming standard in many industries: high-resolution flat panel displays, touch screens, wireless handheld computers that can serve as both input and display devices, and a range of static and mobile devices designed to improve supervisory control, improve situation awareness an d enhance operator performance and reliability. 
In most industries we find that advanced automation systems have the potential to enhance the safety of workers and equipment, enhance monitoring of process variables through improved sensing, control and display capabilities, increase system reliability, resilience and availability, and reduce the need for human operators for functions that can be achieved more efficiently through automation.

In contrast, the nuclear industry has yet to reap the full benefits of advanced technologies. There are several reasons for this backlog, but at the same time there are many reasons why a transition to advanced technology is not only inevitable, but also highly desirable. Even a brief examination of the current stateof-the-art of emerging instrumentation and control (I\&C) and also human interface technologies would quickly reveal the reasons for this trend.

In most existing plants, surveillance, testing, inspection and monitoring of plant performance are all dependent on human operat ors and are all labor intensive activities. This is not surprising, given the current state of technology in the majority of older plants. Traditional I\&C and display technology in most plants older than twenty years consists of fixed analogue devices, as mentioned above. The control boards and panels in the control room are typically arranged in a horseshoe configuration and very often the controls use d for control actions and the gauges where the results of such actions must be observed are widely separated on the boards and panels throughout the control room. The result is that the operator has to move around a lot to collect information from diverse sources. At the same time, the operat or has to keep a lot of information in his or her head while performing a procedure. Under abnormal or emergency conditions this can produce significant workload and stress, and it is easy to see how this kind of HSI could become a potential source of human error. Indeed, there is ample evidence of the critical importance of well-designed HSI s from the accidents at Three Mile Island, Chernobyl and Fukushima Daiichi, both of which had inefficient analogue HSIs.

Innovations in HSI technologies have the potential to alleviate or even eliminate many of the problems associated with analogue I\&C. Various strategies to upgrade I\& C systems, including modernization of control rooms, are beginning to emerge (Korsah et al., 2009 [44]). These strategies range from the most common 'like-for-like' replacement of systems (for example, replacing alarm light boxes with flat panel monitors that still display alarms as conventional alarm tiles), to comprehensive human factors engineering studies combined with systems engineering projects that consider all technical and human aspects of the new or upgraded sy stems. Since most new reactor designs will employ first -of-a-kind technology (FOAK, that is, technology that has not been use $\mathrm{d}$ in the older generation of NPPs), they have the opport unity to avoid the problems of outdated I\&C and HSI s (obsole scence, unavailability, costly maintenance, and so on). However, there are still significant risks associated with FOAK design s. These risks include challen ges of integration, inadequate consideration of the changing role of the operator, coupled with the possible need to define new models of human-automation collaboration, the need for integrated system validation, and many more.

Advanced technologies cannot be placed in the hands of the operat or without considering how this will affect his or her task and performance. This means that designers should be intimately familiar with the characteristics of technologies, not only individual devices, but also devices coupled, integrated or interfaced with other new as well as older devices. An understanding of how the introduction of new 
technologies may affect operat or behavior and performance is crucial to the success of an NPP development project in the short term, and the safe and efficient operation of the plant in the long term.

\subsection{Context of Use}

The nature of HSIs for advanced reactors can be better understood if they are characterized in terms of the context of use, that is, the actual conditions under which a given product is use $\mathrm{d}$ in a variety of working situations and environments.

It is necessary to bound the context of use to determine unambiguo us definitions and classifications for design and selection of HSIs. Thus, the definition of the context of the operational scenario and the context of the interaction with the operator with devices must also be accounted for in the design and selection of advanced HSIs. This also involves simplifying the problem space. For much of the technology that this research will consider, the HSIs will be defined and classified in terms of the three dimensions or contexts described on page 14, Section 2.1:

1. The work domain context.

2. The operational context.

3. The human-system interaction context.

\subsubsection{Work Domain Context}

The Work Domain Context can be defined in terms of the physical, structural, logical or functional characteristics that distinguish different areas in the plant where work is performed and where humans interact with technology.

Eight distinct work domains can be identified where advanced HSIs will play an important role in most NPPs. Some of these are dedicated and enclosed areas; other areas inside or outside the plant have variable bo undaries within which functions are performed:

- Main Control Room - This is an enclosed area, often in close proximity to the reactor and turbine building.

- Local Control Stations throughout the plant, typically consisting of one or more small control panels.

- Materials and Waste Fuel Handling. Forklifts, cranes and similar tools are typically found in these domains.

- Refueling operations, using specialized equipment to handle radioactive materials.

- Maintenance inside and outside the plant, using a range of conventional and specialized tools.

- Outage Control Centre, characterized by many desktop computers, large displays, printers, planning boards and communication equipment.

- Fuel processing installations, characterized by specialized equipment to handle hazardous materials, such as robotic manipulators.

- Technical Support Centre. This center is typically somewhere on site and like the Outage Control Centre would have large displays, but also limited HSIs that provide access to some of the displays found in the control room. 
- Emergency Operations Facility. This facility is located at a more remote location outside the plant perimeter and would also have access to data from the control room.

Most of these domains have a greater or lesser de gree of interdependence, overlap or redundancy, as shown in the following diagram:

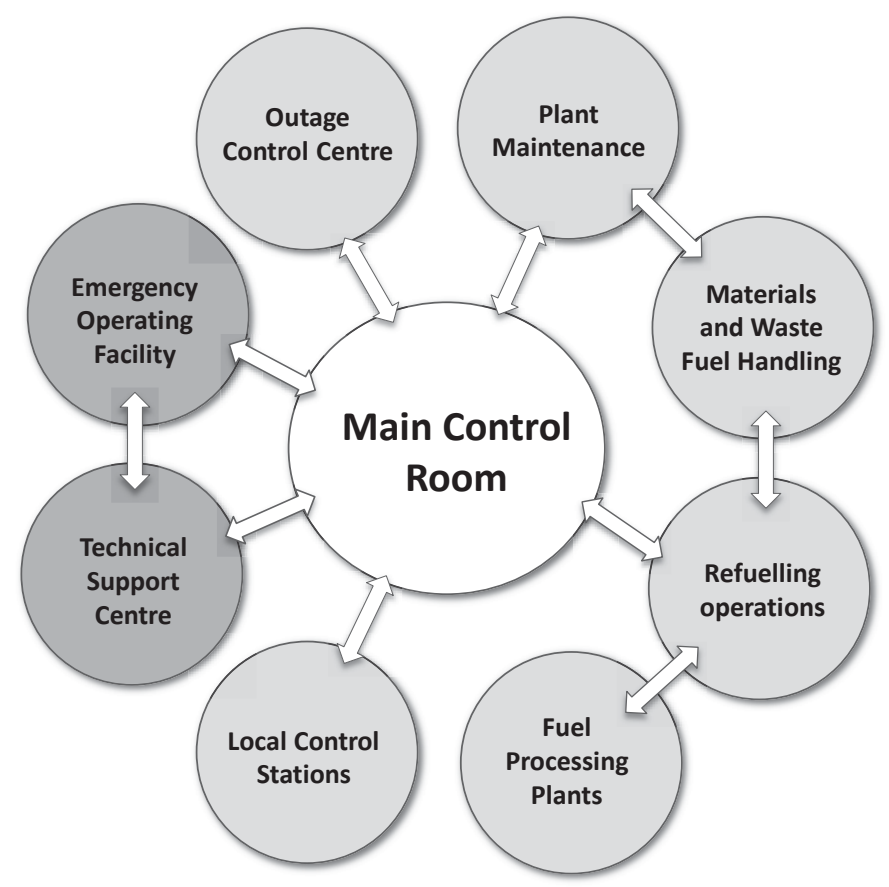

Figu re 2: HSI work domains

This diagram indicates that the control room dominates in terms of range and number of HSI s applied in that environment. The arrows indicate the potential links or overlaps between domains. Five related work domains, some of which may functionally overlap with each other or with the main control room, are the local control stations throughout the plant, HSIs used for materials handling, refueling operations, fuel and waste handling, and HSIs used in maintenance and outage management. A sixth domain, fuel processing plants, could feature strongly in future at plants using fast breeder reactors and fuel reprocessing. The interfaces between the control room and the overlapping domains consist primarily of status displays an d communication devices. These interfaces enable the operating crew to maintain situation awareness of all activities throughout the plant and during all con ditions.

Two other domains interface with the control room only during upset or emergency conditions: the Technical Support Centre and the Emergency Operations Facility.

The most important domains are described briefly below. 


\subsubsection{Control and monitoring centers}

Plant control and monitoring functions are performed in two main areas - the Main Control Room and Local Control Stations:

\section{Main Control Room}

A control room is generally un derstood to be the nerve center of the plant and it often forms part of a control center that could also house some of the work domains shown in Figure 2, for example, the Technical Support Centre and the Outage Control Centre. The Main Control Room (MCR) in older NPPs is de dicated to the control of a single unit; new plant designs, and especially SMRs with their compact footprint, are more likely to have a single MCR for multiple modules (see 'Multi-module Control Rooms' below). Some emerging designs envisa ge a single control room for up to twelve modules. This kind of control room will be larger than today's control rooms for a single unit, but due to the level of integration and automation, they may actually reduce the complexity of the overall $\mathrm{I} \& \mathrm{C}$ architecture by allowing common systems to share a single operator console, or through the ability to monitor and control a single unit with only a small number of displays (O'Hara et al., 2008).

It is normally assumed that a central control room is necessary as part of a strategy to rationalize plant operations, to minimize duplication of equipment, and to optimize the capability of automation systems. Central control rooms for modern plants are also considered to enhance communication between units, enable better coordination of plant-wide operations and maintenance and more effective response to upsets.

As indicated in an earlier section, an important consideration for new designs wo uld be the location of the control center. Traditionally, the main control room is located somewhere on the 'nuclear island', which normally consists of the containment and primary systems, includin g reactor, steam generator and primary coolant systems. Because the nuclear island is se ismically qualified and provides back up systems like electrical supply and heating, ventilation and air conditioning (HVAC), this was typically the choice for the location of the control room. In fact, this is still one of the strictest criteria for control room habitability described in NUREG-0800 (the NRC's Standard Review Plan) [56].

As mentioned before, it is assumed that new reactors will use more passive safety designs like negative temperature coefficient of reactivity, natural circulation of coolant, or less need for active controls and fewer active protection systems like forced cooling sy stems. Designers should now determine if requirements for seismic qualified control systems and HSIs will change and if this means that the control room need not be on the nuclear island. Designers should also determine if the availability and reliability of wireless technology and fiber optics is sufficient justification for having the main control room remote from the reactors. Other important considerations would be if the need for operator response to certain events would still force location of the control room to be near the reactor. Due to the current strict NRC regulations (see NURE G-0696) [54], proving these new concepts of operation is likely to be an importance challenge for designers. 


\section{Multi-module control rooms}

Unlike large NPPs that typically have one control room for each unit, compact plant design s like SMRs are more likely to operate multiple modules from a single central control room. Plants that employ multimodule control rooms will inherit a number of characteristics from NPP control rooms as we know them today. As in the past, the primary purpose of the control room and the HSIs within it will still be to enable the operator to control the plant safely and effectively. They are also used to monitor and direct complex operational activities, such as optimizing the combined output of the modules or units.

The most likely characteristics of multi-module control rooms would include:

- The need for a high level of automation, integration and synchronization of systems, and optimization of output. This sugge sts a single control room from where a minimum crew can manage the entire plant, while still being able to control and monitor the operation of individual modules and systems.

- The use of advanced HSIs to simplify the display of complex system functioning and to minimize the safety-critical, potentially high consequence nature of the control task.

- The change in the central role of the control room operator to system supervisor.

- The existence of new regulatory measures to govern the control room procedures and interface technologies.

\section{Local control stations}

NUREG-0700 defines a local control station (LCS) as 'A place outside of the main control room where operators interact with the plant. Local control stations may include multifunction workstations and panels, as well as operator interfaces, such as controls (e.g. valves, switches, and breakers) and displays (e.g. meters and VDUs)'. NUREG/CR-6146 [6] identifies multifunction and single-function LCSs:

- A multifunction LCS is any operator interface used for process control not located inside the control room and not consisting solely of manually-operated valves or circuit breakers.

- A single-function LCS is defined as any operator interface, excluding multifunction control panels, that is not located in the control room. This type includes all controls (valves, switches, breakers) and display s (meters, gauges, monitors) operated or consulted durin g normal, abnormal, or emergency operations.

We can expect that many manual actions that were common with local control stations will be replaced by automated control to eliminate many of the discrete controls mentioned above. Instead, operat ors will be able to use remote digital controls and more advanced displays to control and monitor local processes.

\subsubsection{Materials and wa ste fuel handling}

In nuclear plants, as in almost all industrial plants, there is always a lot of materials handling that requires various common and also sophisticated tools. HSIs for materials handling include large as well as simple overhead cranes, forklifts, and even programmable robotic systems.

Advanced HSIs will play an increasingly important role in fuel and materials handling systems, especially for handling hazardous materials like low- an d high-level radioactive waste. Several technologies are 
becoming prominent in new means to improve reliability and safety in hazardous applications. These include graphic visualization for remote controls that will take traditional methods of materials handling to a new level. Devices envisaged include robots or remote-controlled machines, haptic manipulators for hot cell work, augmented reality and eye- and position-tracking systems for tasks such as planning for surveillance and maintenance in plant areas where environmental conditions such as radioactivity, heat, cold, dust, or toxic materials would prevent or limit human access. In addition to visual monitoring and materials handling systems, HSI s would have the ability to notify operators immediately if there is a problem in the system, including jams, misaligned sensors or valves, worn bearings, or related issues that cause system degradation. These kinds of technologies will thus offer significant benefits for system as well as human performance.

\subsubsection{Outage Control Centre}

Some of the biggest challenges during large plant outages are to manage the multitude of resources and maintain a high level of situation awareness to ensure the continued safety of plant personnel and to ensure that equipment is protected. Some nuclear utilities have refined the outage process to a fine art, but all struggle with the need to manage the complex communication processes during outages. Multimedia and wireless communication technologies are already proving to be an indispensable boon to outa ge teams and this is likely to become a standard feature of outage management in future. In particular, the need for collaboration and information sharing is satisfied by a range of information displays in the outage control center. Large interactive displays (called 'smart boards') and collaborative work support systems allow real-time access to information, schematics, procedures, and all kinds of scheduling and resource information. This is augmented by a variety of handheld information and communication devices like tablets, smartphones, handheld computers, barcode readers and cameras.

Advanced HSIs and communication devices will also help to eliminate or reduce distractions in the control room caused by maintenance personnel traffic, noise, nuisance ala rms and non-critical activities, while helping the operators to maintain situation awareness. For the maintenance teams, technologies mentioned above will help to minimize down time, and improve communication and resource management.

\subsubsection{Emergency Operations Facility and Technical Support Centre}

Many of the advantages mentioned for Outage Control Centers also apply to the Emergency Operations Facility (EOF) and the Technical Support Centre (T SC).

The EOF is normally outside the safety perimeter of the power plant and it serves as management and coordination center for the emergency staff that will operate from there in the event of an emergency at the plant. Advanced HSI s will help to manage information about important plant parameters and radiological conditions in the plant and its immediate surroundings.

The T SC is an on-site facility located close to the control room - according to NUREG-0696 the T SC must be located within a two-minute walk of the main control room. During upset and emergency conditions it provides technical support to plant management and the reactor operating personnel located 
in the control room. Advanced HSIs with diagnostic features will be important here too to help T SC personnel analyze the plant conditions before and throughout the course of an accident.

\subsubsection{Operational Context}

The Operational Context is defined as the operating mode or state of the plant and could include all possible conditions such as defueled, cold sh utdown, hot shutdown or full power operation. It also includes Anticipated Operating Occurrences (e.g., reactor scram, turbine trip or loss of off-site power), Design Basis Events (e.g., accident conditions such as steam generator tube rupture or large pipe break), and Beyond Design Basis Events (e.g., emergency conditions leading to radioactive releases and injury to workers or public). This context also includes the tasks of the operat or under those conditions, the environmental characteristics of the situation in which HSIs are used to operate the plant, and the use of procedures corresponding to the plant condition or the nature of the evolution.

The four typical categories of conditions that could be associated with operator tasks and the HSIs they wo uld use during those conditions can be characterized as follows:

- Normal Operations, which includes all planned transitions from one operating mode to the next and wo uld cover all conditions from a defueled reactor where only maintenance functions can be performed, to full power operation where operators would monitor all syst ems and maintain the safe condition of the plant, while ensuring optimal power production. The HSIs that are used during these conditions would be the standard displays and controls, including systems use to monitor the safety condition of the plant and safety-related systems.

- Anticipated Operating Occurrences (AOOs) that typically include very frequent events expected to occur several times a year, such as reactor scram, turbine trip or loss of off-site power, to events that are as rare as once in a hundred years during the life of a single reactor, such as small steam generator tube leaks. HSI s use d during these conditions wo uld be the same as for normal operations, but operators may also use additional systems to diagnose the nature and cause of events an $\mathrm{d}$ to obtain performance data not normally needed during normal operations.

- Design Basis Events (DBEs) cover radioactive releases that are not expected to occur during the lifetime of a single NPP, but may be encountered during the lifetime of a population of NPPs of similar design. Such events could be caused by severe accident conditions such as steam generator tube rupture or large pipe break leading to uncontainable releases to atmosphere. HSIs used to mitigate such conditions wo uld be the same as for normal operations and AOOs, but due to the infrequent nature of such events, it would be desirable to support operators with advanced HSIs that provide procedural support, diagnostic functions and operational advice.

- Beyond Design Basis Events (BDBEs) are low-probability events that are not expected to occur during the lifetime of a large fleet of NPPs. Such events wo uld include emergency conditions leading to radioactive releases and injury to workers or public. Due to their improbable nature, it is not normally possible to design HSIs specifically for such events, however, recent experience from the Fuk ushima Daiichi accident indicated the importance of providing reliable, resilient systems that 
wo uld ensure that operat ors are always able to determine the condition of the plant and its safety systems.

\subsubsection{Human-System Interaction Context}

The Human-System Interaction Context is a special context of use that describes the human interaction modalities in relation to the classes of physical and functional configuration of devices and how they are interfaced with each other and with the systems that they operate. In general, the HSI must support human use in specific contexts, that is, it must be usable for its assigned function and environment during all plant operating modes including startup, shutdown, refueling operations, maintenance and during plant disturbances.

One of the design goals for advanced HSI implementation is to support operator and team situation awareness. This includes the development of operat or interfaces and application of automation concepts use d to heighten operator perception of and control over plant processes and systems while improving reliability and performance. Ensuring situation awareness (SA) can be challenging. With advanced plants there is a high degree of complexity and associated data and information that, if not presented in a proper and meaningful way, can contribute to compromised situation awareness. If the crew doe s not know how to navigate the system to find the right data, particularly during off normal events, then stress, confusion and error are likely to result.

SA is comprised of three parts, perception, comprehension and prediction, all of which need to be supported by the proper HSI (Endsley 1996 [19]). If information is not perceived, then the operator's perception of the situation is likely to be flawed. This can happen whenever information is not presented properly, that is, accurately, at the right time, with the right semantic content, in the right place, and using the right medium. For example, a natural language speech recognition system is likely to be useless in a high noise environment where the signal-to-noise ratio is unfavorable. Digital display s that present information to a precision of 5 and 6 decimal places where less precision is required are likely to overload the operator, or slow down comprehension and response time.

Comprehension is combining, interpreting, and deriving meaning from data and information so that it can be acted upon in the context of goals and objectives. Therefore, to support comprehension, the HSI has to be designed to allow the operat or to derive operational meaning and significance from the current operational situation.

Linked to the 3 dimensions of SA are the temporal aspects associated with events. Time is explicitly linked to comprehension and projection. This is because real world events unfold in a dynamic manner where information changes can determine how much time is available for the operat or to act. Although advanced NPP designs hold strong promise of a long time horizon for operator decision making and action selection, the complications arising from events affecting systems common to multiple plant units or for multiple events at the same unit, sugge sts that comprehension of the time available is quite important. In terms of the HSI, this means that the system feedback for equipment and process status and acknowle dgement of operat or input needs to be timely and accurate. One of the strong design directions 
for advanced HSIs should be that it cues the operator to information needed for supervisory control and actions to be taken. (Endsley and Garland, 2000 [20])

The replacement of conventional HSIs with advanced HSI s needs to ensure that the new HSI has the ability to compensate for situations where other cues have become unavailable. This is because there are usually multiple cues available in the environment; if the replacement HSI removes redundant cues that aid perception and comprehension, the designer must ensure that the operat or will receive sufficient information through the HSI. For example, operators' ability to recognize patterns in operational conditions and alarms in the control room is a strong factor supporting SA. Because implementation of some advanced technologies is not likely to impact control rooms within the next fifteen years, it is diffic ult to specify how interaction modalities like voice actuation, augmented reality, and touch swipe interfaces should be integrated to maintain or replace the benefits of pattern recognition supplied by alarm locations on the control room panels.

One of the challenges for implementation of advanced HSI $s$ in the short and longer term is to ensure that it supports collaboration and not implemented solely with the performance requirements of a single operator in mind. All advanced designs in one way or another will reduce, but not eliminate, the crew as a key operational element. Therefore, the implementation of advanced HSI s must also seek to support this collaboration. This is particularly important with devices such as large screen overviews currently being promoted as collaborative workspaces.

A second challen ge is the goal of continually improving information quality and presentation so that the operator's reaction is near reflexive. However, this may result in a general degradation of knowle dge regarding the process or why events are occurring in the way that they do. A third challenge for advanced HSIs and the maintenance of operator and crew situation awareness involves ke eping the operator aware of and informed regarding any actions taken by an automated agent. This includes making sure that the operator perceives or is aware of the action being taken and comprehends the meaning of that action. For example, if the automation system were to reconfigure a sensor network, the operator should know that it was occurring, why it occurred, and what the operational implications of that action constitute.

Operational situation assessment results in situation awareness. Searching for cues is part of the situation asse ssment process. The operator's searches for information may be directed by certain goals, or be a response to salient cues that can help invoke certain goals that are linked to mental models. The mental models further help to direct the search. Endsley (1996 [19]) proposes that these searches are a series of top-down and bottom-up approaches between which operators quickly and unconsciously switch. In the case of introducing advanced HSI s into first-of-a-kind advanced reactors, it is fair to ask, "Are the cues that we provide as part of the environment compelling? What is the operator and crew' s mental model of an advanced HSI and the function it provides? What do the cues mean, what goals or mental models do they point to? Also, "What 'intelligence' is there behind the HSI?" "What is its reliability and relationship to other supporting systems?"

Many of these issues involving enhanced SA and advanced HSIs remain as re search questions and should be addressed in future phases of this project. 


\subsubsection{Interaction modalities}

One of the requirements that demands considerable in sight into the nature of human-system interaction and operational requirements is to determine the optimal interaction modalities for different operational contexts. This needs to take into account spatial and physical work space characteristics and collaborative functions such as crew-system coordination, contextual adaptation, and means of communication to support shared situation awareness. Designers would also have to consider alternative perceptual and interaction modalities offered by new technologies like touch and voice interaction to simplify information access, communication, and decision-making and to reduce errors. Ultimately they have to determine how new technology characteristics affect human performance and therefore the need for advanced capabilities to support new power plant requirements, such as reducing ope rational and maintenance costs by reducing the number of operators needed to manage control room tasks. This requirement leads to questions abo ut the need for adaptive automation, computational intelligence, operator support systems, and other methods of reducing complexity, to optimize human-automation interaction. Where appropriate nuclear operating experience of advanced technologies is lacking, designers will need up-to-date guidance. standards and research results to resolve these issues.

In the past it was easy to classify HSIs as either input (keyboards, switches, mice, etc.) or output devices (displays, gauge s or printers). With the convergence of modern HSIs it is not that simple anymore - many devices are now combining input and output on the same device (tablets, smartphones, etc.). Even distinguishing between hardware an d software is becoming increasingly difficult because many devices have embedded software and the device is rather considered in terms of the functions that the user can perform with it. It is now more sensible to classify HSI s in terms of the mode of interaction, or 'interaction modality'.

Interaction modality can be described as a means of communication between the human and the system or device. The term 'communication' implies the process of exchanging information between the human and the system primarily through the visual, auditory, speech and touch senses. All HSI technologies can therefore be categorized according to the human sense for which the device is designed. Most dev ices rely on only two or three of the most common senses used to obtain information from the environment: vision, hearing and touch. Some technologies can combine these senses into one device; more advanced devices can also enable interaction through other senses, such as speech, smell, motion or even kinesthesia or proprioception $^{3}$. When multiple modalities are available, that is, when more than one sense can be used for some tasks or parts of tasks, the system is said to offer multi-modal interaction functions. A system that is based on only one modality is called uni-modal.

When technology types are categorized in terms of the human sense for which they are designed, it is possible to classify interaction modality as either:

- Input - perceiving information produced by the system through a device that allows a human to observe it by means of one or more senses, such as visual, auditory, or tactile, or

3 Kinesthesia is the subliminal awareness of the position and movement of parts of the body by means o fproprioceptory organs in the muscles and joints (Hale, 2006). 
- Output - performing an action with a specific device that would cause the system to perform a function. This output in turn becomes the input to the system in the form of discrete actuations (for example, key presses) or continuous actions (using a mouse or similar device to select or manipulate objects on a display).

Based upon primary senses use in interacting with a device, HSIs can now be divided into three categories: Visual, Auditory, and Mechanical Motion. Devices associated with these modalities wo uld be either input or output devices (that is, devices accepting user input or providing output to the user), or hybrid devices where both input and output are combined in the same device.

In the control room and any of the operational domains described earlier, a multimodal interface acts as a facilitator of human-system interaction via two or more modes of input that go beyond the traditional keyboard and mouse. Multimodal HSIs can incorporate different combinations of speech, gesture, gaze, touch, and other non-conventional modes of input. Touch and gesture have become the most commonly supported combinations of input methods, as seen in the rapid development of tablets and smartphone devices (Oviatt, 2003 [62]). These are already making an appearance in control rooms for non-control applications, like procedure following and calculations, but they are likely to become much more prominent in future NPPs, provided that they can be proven reliable.

These combined modalities open up a vast world of possibilities to interact with the work environment. It is already possible, for example, to interact with displays, not only with both hands, but also with all fingers simultaneously or by various combinations of 'hand waving.'

\subsubsection{Technology Context of Use}

Base d on the description above, it is now possible to define three classes of technology: output technologies for visual or audio perception, mechanical control devices for providing input to a system, hybrid devices for multimodal interaction. It is also possible to identify a fourth class, based on specialized applications that combine one or more of the hardware technologies with advanced software.

These contexts are further elaborated for a wide range of technologies in Section 6.1.

Other considerations include the technical, physical and organizational constraints that might influence the selection of specific technologies:

Ta ble 1: Technology Deployment Conside rations

\begin{tabular}{|l|l|}
\hline \multicolumn{1}{|c|}{ Technical } & \multicolumn{1}{c|}{ Des crip tion } \\
\hline Standalone / networked & $\begin{array}{l}\text { Does the choi ce reflect a concern reg arding hack ers or } \\
\text { viruses? Are any tasks envision ed that requi re a conn ection } \\
\text { among us ers or systems? Is there a need to share resources } \\
\text { among comput ers? }\end{array}$ \\
\hline Supporting software required & $\begin{array}{l}\text { What is the level of support required for supporting soffware? } \\
\text { Should the soft ware be ven dor suppli ed? What internal } \\
\text { support is required? What is the total li fe cycl e cost of } \\
\text { ownership? }\end{array}$ \\
\hline Hardware required & $\begin{array}{l}\text { What is the level of support required for supporting } \\
\text { hardware? Will vendor maint en ance be provided? What is }\end{array}$ \\
\hline
\end{tabular}




\begin{tabular}{|c|c|}
\hline & $\begin{array}{l}\text { others' ex perien ce regarding the reliability of the hardware? } \\
\text { What is the ability to obtain reliable measures of } \\
\text { performance? How will off-no rmal events affect system } \\
\text { performance? Is operating experience review av ailable? Can } \\
\text { this hard ware be integ rat ed with leg acy systems? Do es the } \\
\text { human int erface with this hardware? If so, do es the interface } \\
\text { follow IEC or NUREG } 0700 \text { guidelines? }\end{array}$ \\
\hline Additional hardware / so ftware resources required & $\begin{array}{l}\text { Are any additional hardware or devices required to fully } \\
\text { implement the HSI, e.g., printers, special keyboards, } \\
\text { scanners, touch screens, etc.? }\end{array}$ \\
\hline Type of net work connection required & $\begin{array}{l}\text { If net working is required, what are the cap acity requi rem ents, } \\
\text { e.g. high-speed conn ections, firewalls, en cryption, etc.? } \\
\text { What type of s ecurity provisions exist such as fire wall, } \\
\text { encryption, password protection, use of biom etri cs? Are VPN } \\
\text { connections required (e.g., from TSC)? What type of } \\
\text { switch es and routers are to be considered? Do they need to be } \\
\text { prog ramm able? }\end{array}$ \\
\hline Physical/Functional & Des crip tion \\
\hline Standard Office & $\begin{array}{l}\text { If the task is perform ed in a stan dard office, what are the size } \\
\text { and ergon omic requi rem ents for layout, lighting and } \\
\text { ergo nomic furniture to accommo date the required HS Is? } \\
\text { What are the number and typ o of personnel needing office } \\
\text { space? What are their comm unication requi rem ents? What } \\
\text { sort of computer and data base access are required? Will } \\
\text { offices m eet ANSI and OSHA stand ard s for work place and } \\
\text { habitability? }\end{array}$ \\
\hline Labo rat ory or class room & $\begin{array}{l}\text { What sort of au dio visual equipm ent is needed, microphones, } \\
\text { headsets, and other recording devices? Is cont rollable lighting } \\
\text { planned for? Are fixed desks or recon figurable arrang ements } \\
\text { to be preferred? Is the visual line of sight uno bstructed for } \\
\text { students? How many personnel will be in training at any one } \\
\text { time? Are sm art boards required? Should the class room have } \\
\text { intern et access and larg e screen projection cap ability? What } \\
\text { are the lighting lev els and desirable acoustics? (S ee } \\
\text { ANSI/ ASA S12.60-2010 for acoustic requirements). Is } \\
\text { distance learning likely to be part of the educational process? } \\
\text { Do procedures from vendors exist for chemical safety and } \\
\text { security? How is em ergency planning for fire, flood, and } \\
\text { earthquake to be det ermined, i.e., What is the process? What } \\
\text { is the result ofloss of power on system s and process es? What } \\
\text { pers onnel requirements exist for leading security and safety } \\
\text { and review of procedures? What engin eering controls are } \\
\text { propos ed and what is the operating experi ence for similar } \\
\text { facilities? }\end{array}$ \\
\hline Simulator & $\begin{array}{l}\text { Is the proposed simulator an upgrade, i.e., part of } \\
\text { modernization or a simulator for a new facility? How will } \\
\text { fi delity with the reference plant be ensured? Maintain ed? } \\
\text { Assuming a modernization, US plants are required to have a } \\
\text { simulator; do es re-hosting of the computer involve a different } \\
\text { operating system or changes to the simul ation envi ronm ent? } \\
\text { What plat form is being us ed to develop the HSI? How was it } \\
\text { determined? Was a function al requirements docum ent } \\
\text { written? Has a syst em been established to track resolution for }\end{array}$ \\
\hline
\end{tabular}




\begin{tabular}{|c|c|}
\hline & $\begin{array}{l}\text { identi fi ed simulator or soft ware problems? What will be the } \\
\text { basis for scenario det ermination? What is the proposed } \\
\text { avail ability of the simulator and How was this determined? } \\
\text { Are there plans for an instructor station upgrade/replacement? } \\
\text { Input/output system replacement? Replacem ent /upgrade of } \\
\text { audio and video and other data recording systems? Has a } \\
\text { training needs an alysis been perform ed? What are the } \\
\text { simulator op erational requirem ents and how was this } \\
\text { determined? Is the simulator to be used for procedures } \\
\text { validation or en gineering design change validation? Is there } \\
\text { provision for when regulatory requirements cause change in } \\
\text { the plant that require changes to the simulator as well? Are } \\
\text { solutions reached scal able so that equipment can be add ed? Is } \\
\text { acceptance test schedul ed and planned for in accordance with } \\
\text { INCOS E systems engineering guidance? }\end{array}$ \\
\hline Control Rooms & $\begin{array}{l}\text { If the task is perform ed in a control ro om, remote shutdown } \\
\text { facility, techni cal support cent er, etc., what are the functional } \\
\text { and ergon omic requi rem ents to support the task? } \\
\text { Does the cont rol room acquisition pro cess in cluding up grad es } \\
\text { to the HSI take into consid eration equipm ent obsol escence, } \\
\text { long-term maint ain ability, spare parts av ailability and cost, } \\
\text { impact of equipm ent out of s ervi ce tim e, requi red computing } \\
\text { power, and likelihood of the ven dor being in business in the } \\
\text { future? How were techni cal solution s determin ed? Are } \\
\text { solutions reached scal able so that equipment can be add ed? }\end{array}$ \\
\hline Field work place (local cont rol station, etc.) & $\begin{array}{l}\text { If the tas } \mathrm{k} \text { is perform ed in the field, what are the functional, } \\
\text { safety and ergonomic requirements to support the task? }\end{array}$ \\
\hline Auditory Environment & $\begin{array}{l}\text { How have expect ed noise levels been det ermined and what is } \\
\text { the expected range in } \mathrm{dB} \text { ? What type of communi cation } \\
\text { requi rements exist and how will technology support } \\
\text { appropriate signal to noise levels? Is hearing protection } \\
\text { required, if so, where and for what tasks? What personnel risk } \\
\text { is involved? }\end{array}$ \\
\hline Thermal Environm ent & $\begin{array}{l}\text { What is the ran ge of temperature for the various workplace } \\
\text { locations? What are the HVAC requirem ents? What } \\
\text { precautions are in place for protection of pers onnel and } \\
\text { equipm ent? What temperature indication has been provided } \\
\text { to reduce pot ential for heat stroke? What personnel risk is } \\
\text { involved? What are time limits for personnel working in a } \\
\text { therm ally hot area? }\end{array}$ \\
\hline Visual Environm ent & $\begin{array}{l}\text { What cont rol over the lighting en vironment exists? Is } \\
\text { portable lighting a requi rem ent for inspections? What type of } \\
\text { HSI is envision ed? Are variable contrast and illumination } \\
\text { controls provided? What are the potential solutions for visual } \\
\text { pres ent ation of in form ation? }\end{array}$ \\
\hline Stability of Environment & $\begin{array}{l}\text { Does the task environ ment requi re devices or equipm ent to } \\
\text { protect the op erator from vib ration or ex cessive motion? } \\
\text { Could the work envi ronm ent be subj ect to flo oding? Is there } \\
\text { provision for easy work er egress from the en vironment? }\end{array}$ \\
\hline Posture required of user & $\begin{array}{l}\text { Are the postures required at local stations or in the field of } \\
\text { duration(s) leading to localized muscle fatigue and } \\
\text { discom fort? Do es postural ex ertion have the pot ential to } \\
\text { result in injury? Has technology been con sidered to reduce } \\
\text { these effects? Have whole body, should er and b ack-relat ed }\end{array}$ \\
\hline
\end{tabular}




\begin{tabular}{|c|c|}
\hline & $\begin{array}{l}\text { manual tasks been assess ed for potential leading to } \\
\text { discom fort? What technology or change in design has been } \\
\text { identi fied to reduce this incidence? }\end{array}$ \\
\hline Necess ary furniture / resources & $\begin{array}{l}\text { Is any special furniture or supporting structures (wheels, } \\
\text { stands, braces, shelves, etc.) need ed to fully implement the } \\
\text { HSI? }\end{array}$ \\
\hline Amount of avail able space & $\begin{array}{l}\text { Are workers likely to find themselves working in confined } \\
\text { spaces? IfPPE are required, are they likely to be even more } \\
\text { restrict ed in their movem ents? Is any floo ding of con fined } \\
\text { spaces possible? If so what pro cedural and technology -based } \\
\text { controls are being considered to reduce overall risk? }\end{array}$ \\
\hline Health hazards & $\begin{array}{l}\text { As a function of technology deploym ent could personnel find } \\
\text { themsel ves at risk of exposure to chemical sources, flam e and } \\
\text { heat, or chemi cal hazards? Is any work to be perform ed in or } \\
\text { around inert gas sources? If so, what engin eered controls } \\
\text { exist? What is the method for providing immediate medical } \\
\text { relief? }\end{array}$ \\
\hline Protective cl othing need ed & $\begin{array}{l}\text { How have the protective clothing and equipm ent needs for } \\
\text { pers onn el including emerg ency res pond ers been det ermin ed? } \\
\text { Are prot ective clothing easily accessed by pers onn el? Does } \\
\text { clothing make us e of advan ced mat erials? If so, how were } \\
\text { these m aterials test ed? Do es clothing m eet the American } \\
\text { Society for Testing and Materials (ASTM) and Nation al Fire } \\
\text { Protection Asso ciation (NFPA) guidelines? How was the } \\
\text { range of pot ential conditions requiring protective clothing } \\
\text { determined? How is clothing to be maint ained? What are the } \\
\text { associat ed perform ance requirem ents for this clothing? What } \\
\text { are the hum an perform an ce requi rem ents and how are they } \\
\text { impacted by the clothing sel ected? Could personnel be in a } \\
\text { part of the plant subj ect to structural coll aps e? What sort of } \\
\text { debris could be in the work area? What sort of protection } \\
\text { including clothing is offered? Is the PPE easily donn ed and } \\
\text { do ffed and does it allow unencum bered use of HS Is? }\end{array}$ \\
\hline Organi zational & Des crip tion \\
\hline Policy & $\begin{array}{l}\text { Does the org ani zation have specific polici es about anything } \\
\text { that rel ates to the us ers' interaction with the product? }\end{array}$ \\
\hline Aims & $\begin{array}{l}\text { Does the org ani zation have any speci fic aims or objectives } \\
\text { that rel ate to the way op erato rs would interact with the } \\
\text { product (e.g. eliminate paperw ork)? }\end{array}$ \\
\hline Culture & $\begin{array}{l}\text { Is there an ything noteworthy about the organizational } \\
\text { disposition to in formation technology that may affect the way } \\
\text { operators interact with the system (e.g. all operators are } \\
\text { expect ed to be 'computer-literate')? }\end{array}$ \\
\hline Procedures & $\begin{array}{l}\text { Are there any org anization al procedures that will affect the } \\
\text { way us ers int eract with the product (e.g. passwords may } \\
\text { never be written down)? }\end{array}$ \\
\hline Mode of communication & $\begin{array}{l}\text { Does organizational communication take place in a particular } \\
\text { way that will affect the usage of the product (e.g. all } \\
\text { communication is rigidly hierarchical)? }\end{array}$ \\
\hline User monitoring in progress & $\begin{array}{l}\text { Does the org ani zation monitor the operator's work, and if so, } \\
\text { to what ext ent do es this monitoring affect the operators' } \\
\text { interactions with the system (e.g. requests for help are }\end{array}$ \\
\hline
\end{tabular}




\begin{tabular}{|l|l|}
\hline & monitored so operators prefer to minimize these)? \\
\hline Feedback on job given & $\begin{array}{l}\text { Does the org ani zation provide feedback to the op erators on } \\
\text { their us age of the system s involved in their work? }\end{array}$ \\
\hline
\end{tabular}




\section{The Human Factors Challenges of Advanced HSls}

Ever since the Three Mile Island accident, human factors issues were lar gely associated with the design of the main control room. The possibilities to apply human factors engineering principles to improve human performance were limited to a great extent by the constraints of discrete, analogue instruments and controls. However, due to new capabilities offered by technologies like advanced sensors an d automation systems, new NPP designs are now expected to introduce fun damental changes, not only in the design of the control room, but also in the role of the operat or and the tools they use to monitor and control the plant. This could be regarded as a natural evolution for the industry, but it will require engineers and designers to rethink many tried and tested concepts and assumptions. For example, control center structures need to be remodeled to make provision for new types of console and panel layouts, large screen displays, new comm unication media, and even different crew structures. This will require a cl ear shift in the definition of the control room, its controls and instruments, its support structures and also the location of the control room in the plant.

Technically, it has become possible to control the plant from a remote location, but it will be a challen ge to prove the reliability of such a scheme un der all operational conditions. In addition to the changes in the physical and functional architecture of control rooms, we can also expect to see changes in the allocation of operational functions to humans and systems. The mere fact that future operators will deal with computer-based 'soft controls' and a multitude of high-resolution displays will already change their roles and mode of interaction with the plant. Where we today understand the operating crew as consisting of reactor operat ors, senior reactor operators and supervisors whose roles are largely determined by operating procedures, future operating crews may be regarded rather as part of the joint human technology system, which in turn is part of the bigger socio-technical system of the plant. The reason for this lies in how the operator's responsibilities and interaction with the plant will change. The shift will be more than just a role change due to increasing levels of automation, or an in creasing supervisory role where operators' primary function will be to monitor plant status and only to intervene if actual operation deviates from setpoints. Rather, there are now increasing possibilities for operators to perform 'predictive control' by examining past data, predicting future behavior of processes by means of extrapolation and real-time simulation, and performing corrective actions before an event is likely to occur.

A further shift in the role of the operator will be an increase in the scope of responsibility and collaboration. For example, the scope of control and monitoring functions could increase from just operations, to include maintenance, production planning, and even design and optimization.

All of these changes represent a paradigm shift for the nuclear industry, and it is almost entirely because of the advancement of automation and HSI technology. The changes have immediate implications for engineers who have to reconcile technological requirements with human abilities and limitat ions. There can be little doubt that automation is key to achieving cost-effective operations in future nuclear energy systems, but humans will continue to play as important a role in future systems as in today's safe NPPs. We can expect a different sort of human-system interaction than that of today's plants, but one in which the operator and crew are able still to intervene when necessary and otherwise oversee automation in 
many aspects of plant operation. This will require development of more 'intelligent' forms of automation and adaptive interface capabilities to facilitate near-autonomous operation as well as efficient humansystem collaboration.

The following are some of the most important considerations that need to be included in power plant engineering and design strategies:

- The joint human-technology system must be defined in terms of the dynamic allocation of functions between the humans and the automation system.

- The human-technology system is not static and will require new rules and procedures for allo wing a minimum number of operators to control multiple modules concurrently. Even for single module plants, it is possible that higher levels of automation will require fewer operators in the control room. However, regulators are unlikely to accept an unconventional staffing design without some kind of proof of concept. For new plants, this proof could be in the form of simulations or predictive computational models that provide reliable data on operator performance under various plant conditions (Persensky et al., 2005 [63]).

- Task support requirements - due to the dynamic nature of the collaborative human-system relationship and the variable levels of complexity at different levels of automation, there will be variable requirements for task support. In principle, the lower the level of automation, the more the operator's involvement in plant control and thus the more support is required, especially for nonroutine tasks. HSIs that are designed to optimize human performance need to be concerned with fundamental collaborative functions such as coordination, adaptation, and communicating shared awareness within the total socio-technical system. This goes beyond the present usage of computerized procedure systems, decision support, databases, data mining systems, and various devices to deliver this information to the user. The usability requirements for task support systems, especially those that use new HSI s, must include mea sures of the trust the operator places in the technology. (Hugo, 2004 [29]).

These considerations suggest that HSIs can be examined from many different perspectives, but when we consider the challenges of emerging po wer plant designs, there are two main themes that seem to influence most considerations for future implementation:

- New HSI technologies offer innovative interaction modalities such as ge sture control, augmented reality, remote control and telepresence. Designers need to provide, or obtain, sufficient evidence that these new concepts are conducive to usability and will support improved human performance.

- The applicability of advanced HSIs in the nuclear field is a particularly interesting question because the nuclear industry has been relatively stagnant for a long time. As a result, practices, standards, procedures and technologies have become so entrenched that utilities, vendors, regulators and other stakeholders have to make extraordinary efforts to justify and validate the use of new technologies. Even if those technologies had already shown proof of concept in other industries, the strict regulations and standards of the nuclear industry make implementation of any new technology an exceptional challenge. 
The rest of the report will cover the most important aspects of HSI technology, starting with a description of the architecture or taxonomy of HSIs as they are typically deployed in 'modern' power plants. Following sections will also describe the range of technologies becoming available to designers, the technical capabilities they offer to support human performance, and the use and potential of a range of non-traditional HSIs, such as virtual and augmented reality systems, haptic devices and ge sture controllers.

\subsection{Human Performance Criteria}

\subsubsection{Usability of HSIs}

The ability of the human-system interface or HSI to support human performance requirements for NPP control rooms is directly related to the usability of that interface, which includes the context in which it is be used. Usability is both a condition as well as the extent to which the system user, i.e., operator, is able to conduct work through the HMI efficiently, effectively, reliably and to his or her satisfaction.[39] The features of the HSI design should work together to help the user satisfy the system and human performance requirements of the job.

The International Standard I SO-9241-11 [39] specifies gui dance on usability, including techniques for asse ssment, and it deals with the extent to which a product can be used by specified users to achieve specified goals with effectiveness (task completion by users), efficiency (task in time) and satisfaction (responded by user in term of experience) in a specified context of use (users, tasks, equipment \& environments). Although the context of use for this document is not explicitly directed toward SMRs or even toward HSI for varied modalities, this section contains a number of guiding principles that would be useful in providing a framework for obtaining and measuring or evaluating usability, and therefore specific criteria for human performance in a defined context. As indicated in ISO 9241-11, usability can be measured in terms of: the features of the product, by analysis of the process of interaction, and by measurin g efficiency, effectiveness, and satisfaction. It is implied, though not prescribed, that minor changes in the environment or task demands do not result in diminished efficiency or effectiveness.

A number of principles for usability exist; however, they must be placed within the context of the demands of the work environment. General design principles for usability can be summarized and used to determine usability metrics as presented in the list below.

\subsubsection{Usability Attribute Metrics}

- Learnability - An interface should offer appropriate affordances to make it easy to use from the first time the user interacts with it.

- Functionality presented to the user should be limited to exactly what the user requires to achieve their goal.

- Efficiency - The number of steps it takes for a user to complete a task should be minimized - key tasks should be made as efficient as possible.

- Memorability - The interface should be easier to use each time the user interacts with it.

- Comfort - the use of the interface should not produce un due physical exertion, stress or movements that are unnatural. 
- Error Recovery - In a perfect user interface, users should never be allo wed to make a mistake (Juan g and Rabiner, 2004 [42]); other approaches include error tolerant design and aspects of error prevention.

- Simplicity - Routine tasks should be easy and less common tasks should be possible.

- Expectancy - It should be easy for the user to predict what would happen when they interact though the HSI.

- Complexity -Avoid unnecessary functionality and complexity

- Satisfaction - Freedom from discomfort, a positive attitude and willin gness to keep on using the system.

- Consistency - The response and appearance of different parts of the HSI should be consistent and predictable.

- Importance - More important information should be more visible (salient) than less important information.

- Aesthetic - The at tractiveness of the design should contribute to usability.

\subsection{Technical Criteria for Usable HSIs}

One of the major changes for HSI over the last 10 years has been the development of the touch screen. This has been the main driving force behind the popularity of mainstream consumer devices like smart phones, tablets and some laptops. As mentioned before, this family of HSIs is also slowly being introduced in the control rooms of new and upgraded power plants.

Typically, the touch screen input device is the human hand or finger, but a stylus is commonly available for tablets for more accurate input. The advantage of not having to use a stylus is that it reduces the need for an additional device. Within the pressure sensitive area, the amount of contact ar ea is sensed, instead of the amount of pressure. Touch screen implementation that allows the angle of approach (relative to the finger and screen surface) to be calculated can be used to allow the finger to function as joystick. Touch screens that allow for calculation of friction can use this information as a force vector to be use $\mathrm{d}$ in increasing flow, etc. To be comprehensive, the design of the touch screen interface should take into account the variability in hand sizes and the ergonomic placement of the device(s) should be such that the display is both well within the visual field and reach envelop of the operator.

The touch screen is rapidly making previous interaction techniques obsolete. For example, menus and buttons that are common in most software applications are making way for direct interaction methods on the touch screen (Rogers et al. (2005 [68]). Due to the rapid access and response of touch screen-based applications, many of the human age-related usability problems of windo ws and mo use-based interaction due to spatial ability and general slowing of reaction time are reduced significantly with touch screens (Salthouse, 1992 [69]).

In addition to the operational and human performance contexts, described in this report, there are also several technical considerations that affect human performance and would therefor e influence the selection of HSIs. The following hardware, software and functional criteria need to be considered: 
Ta ble 2: Technical HS I Criteria

\begin{tabular}{|c|c|}
\hline Interaction requirement & Typical device cha ract eris tics \\
\hline \multicolumn{2}{|c|}{ Hardware Criteria } \\
\hline $\begin{array}{l}\text { Multimodal interaction - touch, gesture, speech, tactile } \\
\text { feedback }\end{array}$ & $\begin{array}{l}\text { Touch screens, gesture controll ers, voice reco gnition \& } \\
\text { synthesis, haptic input and output. Also direct } \\
\text { body/machine interfaces (s ensors). }\end{array}$ \\
\hline Multidimensional in formation access & $\begin{array}{l}\text { Hand-held computers, heads-up and head-mounted } \\
\text { displays, retinal displays, large overview displays, 3D } \\
\text { displays (with or without glasses), motion and position } \\
\text { tracking. }\end{array}$ \\
\hline $\begin{array}{l}\text { Simulation and modeling of real objects or abstract } \\
\text { concepts }\end{array}$ & $\begin{array}{l}\text { - High-performance num eri cal and graphics process ors } \\
\text { for deman ding applications such as high-resolution } \\
\text { displays and computationally intensive applications. } \\
\text { - Reduced need for low-level programming }\end{array}$ \\
\hline \multicolumn{2}{|c|}{ Software Criteria } \\
\hline $\begin{array}{l}\text { Dealing with complexity in operational, design, } \\
\text { maintenance and managerial tasks }\end{array}$ & $\begin{array}{l}\text { - Full object-orientation and compon ent-bas ed } \\
\text { programming. } \\
\text { - Supports XML-bas ed documentation. } \\
\text { - Supports advanced com putational methods, e.g. } \\
\text { neural/s emantic net works, pattern recognition, real- } \\
\text { time and faster-th an -real-time simulation). } \\
\text { - User-con figurable displays }\end{array}$ \\
\hline \multicolumn{2}{|c|}{ Functional Criteria } \\
\hline $\begin{array}{l}\text { Systems and applications must be designed to fit the } \\
\text { operator's task and support their ability to perform a task } \\
\text { with effectiveness, efficiency, safety and satis faction. }\end{array}$ & $\begin{array}{l}\text { - Task-based system with em bed ded operator support } \\
\text { (including com puter-bas ed procedures) and intuitive } \\
\text { navigation (displ ay architecture bas ed on an } \\
\text { abstraction hierarchy and supporting op erator's } \\
\text { mental model). } \\
\text { - Provide error-tolerant and resilient op eration. } \\
\text { - Support ad aptive autom ation schem es (i.e. } \\
\text { vari able/mixed initiative - function allocation). } \\
\text { - Provide advanced int eraction features, such as natural } \\
\text { dialogue, flexible languages, multimedi a } \\
\text { communication, user-adapt ed interaction, cooperative } \\
\text { behavior, explan ation and justi fication, intelligent } \\
\text { help, etc. }\end{array}$ \\
\hline
\end{tabular}




\section{HSI Technology Characterization}

The nuclear industry is expected to invest millions of dollars over the next ten to twenty years in the implementation of new technologies for use in power plant upgrades, modernization and new construction. It is becoming increasin gly difficult to identify the most appropriate technology alternatives, especially those that may be affected by human factors requirements. This is mainly because the number of available technologies is increasing and these new technologies are increasingly complex. However, the correct selection of technologies is not only vital to ensure operational safety and effectiveness, it could also create significant competitive advantage for utilities and ensure that they remain successful in the energy economy.

\subsection{HSI technology Classification}

There are many different ways to classify HSI technology, depending on the context, as described before. The terms 'human-system interface' and 'human-system interaction' both suggest that either a technology-centric or a human-centric classification would be possible.

This section provides a simple taxonomy that describes both perspectives, including the key advantages and disadvantages of each.

\subsubsection{Visual Interfaces}

HSIs that employ vision as interaction modality are the most common devices to present information to the operator. This mode of interaction is uni-directional only (device to observer). New developments use cameras and sensors to detect user gaze and motion and use this to create an interactive dimension for displays. Examples are already found in entertainment-related devices like Microsoft's Xbox ${ }^{\circledR}$ Kinect, Nintendo ${ }^{\circledR}$ Wii, Sony PlayStation ${ }^{\circledR}$ Move and the Leap Motion ${ }^{\circledR}$ gesture controllers. Other devices use gaze detection to determine where the user is looking and use this data to display contextual information or to enable users to navigate through the system by gaze only.

While standard desktop flat screen displays will continue to be the most common means to display information for everyday use, a variety of advanced visual devices are becoming attractive options for textual, graphical and video information. Three types can be identified, ranging from large screen displays that are already available, to more sophisticated technologies that will be available in consumer markets within the next few years.

\section{- $\quad$ Large Screen Displays}

Large, high-den sity, high-resolution, high-definition displays are already common in consumer and commercial markets and many process and manufacturing in dustries are also using a variety of these displays. Typical applications include multi-monitor configurations, tiled flat panels and also projection-based systems that can display images several meters wide. (Ni et al. 2006 [53]). In conventional NPP control rooms the implementation of these large displays present numerous technical difficulties, mainly because of the lack of space in an area that was originally designed for large, hardwire consoles and panels without any digital displays. This is where designers of new plants have a distinct advantage: they can design state-of-the-art control rooms without trying to 
retrofit advanced HSI s into cramped spaces. Although large displays may seem an attractive option to overcome the distributed nature of information typical of older control rooms, designers need to consider that this will not necessarily address the fundamental question of ensuring that operators benefit from increased size and resolution. Vendor hype often leads designers to assume too easily that large displays will automatically outperform small ones (ibid.). Before equipping a control room with a multitude of large displays, human factors engineers should un derstand un der what conditions increased size and resolution may be advantageous and how they may contribute to situation awareness. In many cases a number of standard-size displays on the operator's workstation may be more effective than a large overview display.

\section{- Wearable displays}

Wearable and head-mounted displays of various types have been prototyped and tested by the military for many years. Devices range from large, heavy, full-immersion, head-mounted virtual reality displays used for specialist training, to lightweight, see-through devices used for augmented reality applications. This technology is now finally becoming a commercial reality also in consumer markets. Devices like Google Glass would offer significant opportunities to simplify common control room tasks, like continually monitoring alarm annunciators while performing other tasks, or having computer-based procedures available with a simple voice command.

Virtual reality has a long history in visualization of, and interacting with, three-dimensional environments. This is not only a powerful technology for visualizing and verifying designs long before they are built, but when combined with wearable devices like augmented reality headsets that superimpose virtual objects and information on the user's view of the real world, they enable operators to perform tasks in a virtual 3-D environment without the need for printed documentation or other support. In this way, information about the user's surrounding real world also becomes interactive and digitally manipulable. This technology is already being used in some in dustries to support maintenance and assembly tasks.

\section{- Three-dimensional displays}

A number of technologies that enable users to view objects and environments in three dimensions are becoming common in the consumer as well as professional media markets. They range from reasonably simple devices that require the user to use glasses to view images, to sophisticated volumetric holographic displays.

So-called 3-D displays or stereo displays present normal two-dimensional (2-D) images offset laterally by a small amount and displayed separately to the left and right eye. Both of these 2 -D offset images are then combined in the brain and create the perception of depth. Various types of devices can be used with television sets, gaming devices and movies.

Another technique, called 'the polarized 3-D system' uses two superimposed images that are viewed through two polarizing filters that are oriented differently. The filter passes only that light that is similarly polarized and blocks the light polarized differently, enabling each eye to see a different 
image. This produces a three-dimensional effect by projecting the same scene into both eyes, but depicted from slightly different perspectives.

Holographic display technology has the ability to create the illusion of three-dimensional objects in volumetric space by engaging all four visual functions: binocular disparity4, motion parallax5, accommodation6 and convergence 7 .

Holographic devices are developing fast, but will be out of reach of the average consumer for several more years. Also, all of the advanced 3-D display technologies still have limitations, especially in display quality and resolution. It is unlikely that we will see real $3-\mathrm{D}$ or holographic displays in the nuclear industry within the next twenty years.

\subsubsection{Auditory Interfaces}

Audio-based interaction between human and HSI is not new but it is now developing rapidly to provide more powerful and reliable means of obtaining information or performing control actions. Alarm sounds are the most common use of audio technology and most control rooms use coded and modulated soun ds to enable operators to distinguish different conditions.

Speech recognition is also not a new technology and it has been applied in many systems with varying degrees of success. Speech recognition has never been used in control rooms, but this technology is also becoming more accurate and reliable. However, although important advances have been made, especially in the ability of such systems to recognize natural language, it remains one of the least reliable interaction methods. Research has shown that even in the best systems, recognition is typically subject to an error rate of $5-10 \%$ and with background noise it is even worse, with error rates of $20-40 \%$ (Shneiderman, 2002 [74]). This makes this kind of interface slow and unreliable and unlikely to be use $\mathrm{d}$ in mission -critical applications. However, research continues and this may eventually become an option for 'busy hands, busy eyes' applications. Both speaker-independent and speaker-dependent speech recognition with backgro und noise cancellation might become more viable options for certain types of control commands in future, especially for fieldwork and maintenance where hands-free operation is often desirable.

Another auditory device that may become important for voice communication, for example between the control room and field operators in the plant, especially in noisy areas, is bone conduction audio. This technology provides real-time information in 'busy-hands busy-eyes' tasks. It maintains sound clarity in very noisy environments because the eardrum is bypassed and so und is passed directly to inner ear. It is especially important where there is a need to enhance the presentation of written or graphical information and to notify users about a particular condition without the need for a display. It is also useful where coded audio signals may convey more information than a single alarm tone, or for operators with some hearing impairment.

4 The difference in i mage location of an object seen by the left and right eyes, resulting from the eyes' horizontal separation (parallax). The brain uses binocular disparity to extract depth information fro $m$ the two-dimensional retinal images.

5 Displacement or difference in the apparent position ofan object viewed along two different lines ofsight.

6 The process by which the eye changes optical power to maintain a clear image (focus) on an object as its distance varies.

7 The simultaneous inward movement o fboth eyes toward each other, usually in an effort to maintain single binocular vision when viewing an object. 


\subsubsection{Control Devices and Mechanical Interaction}

In older control rooms, Discrete Control Input Devices (that is, devices that depend upon mechanical motion) are still the most common means for the operator to interact with the plant's systems. These devices are limited to relatively primitive devices like buttons, switches and levers. As I\&C and HSI technology evolves it is becoming possible to control plant components by means of direct manipulation devices like a computer mouse, joystick, or trackball. As computing power continues to increase, we can expect to see even more sophisticated devices finding their way into the control room and other work areas. In the not too distant future we can expect to see fixed as well as mobile devices that allow not only direct interaction through touch and force feedback, but also indirect interaction through ge sture, speech and gaze.

\subsubsection{Hybrid interfaces for multim odal interaction}

\section{- Gesture interaction}

Gesture interaction is a way for computers to interpret purposeful human motions, thereby creating a bridge betwe en machines and humans that allows a richer interaction experience than the primitive input methods of keyboard and mouse. Using gesture reco gnition, operators can literally point a finger at the computer screen to interact directly with objects, without actually touching the screen. This technology is still in its infancy but several devices and applications are beginning to appear. Devices similar to the Xbox Kinect and the Leap Motion gest ure controller are likely to become mainstream options very quickly. In the short term, this probably will not make conventional input devices such as mice, keyboards and even touch-screens redun dant, but will be added to the range of HSIs to allow operators more flexibility in interacting with plant systems. For an extensive discussion of gesture interaction, the reader is referred to the work of Bill Buxton, a Microsoft researcher (Buxton, 2011 [8])

\section{- Haptic in te raction}

A range of advanced sen sors embedded in HSIs allow operators to expand their ability to sense the state of the environment and the behavior of artifacts within the environment by means of haptic devices or 'tangible interfaces'. Such devices take advantage of the sense of touch to convey a range of information by applying forces such as vibration, force feedback and by sensing location and motion. This tactile stimulation can be use d to assist in the detection of changing conditions or orientation of objects that the operator cannot handle manually due to hazards such as heat or radiation. In more advanced devices it can create the illusion of virtual objects and the ability to control them in a computer simulation, to control such virtual objects, and also to enhance the remote control of machines and devices (telerobotics). Again, the reader is referred to Buxton's work (ibid., chapters $7,8,9,13,14$ )

A common example of haptic interaction in the form of vibratory feedback is found in the Sony, Xbox and Nintendo game controllers mentioned before. Haptic devices may also incorporate tactile sensors that measure forces exerted by the user on the interface. (Jones and Sarter, 2008 [41]). It is 
easy to imagine how operators wo uld be able to use a device like this to 'feel' the bearing vibration of a turbine while monitoring the spin-up process!

\section{- Brain interaction}

Recent state-of-the-art developments promise to offer interaction possibilities considered impossible just a few years ago. For example, direct brain-machine interaction has long been considered science fiction (think of the 1984 novel Neuromancer by William Gibson, or the 1999 movie The Matrix), but it is fast becoming a reality. Increasing computing capability and the ability of materials that allow man ufacture of small, cheap and accurate sensors have stimulated a rapidly gro wing interest in the development of intelligent interfaces in which information derived from psychophysiological and video-based measure s of a human is used directly to inform, interact with, or control computer-based systems. Powerful signal processing techniques and devices are now available at reasonable cost to implement in near-real time a wide range of spectral, neural network, and dynamic systems algorithms to extract information about psychological state or intent from multidimensional brain activity signals, eye-tracking and facial data, and other psychophysiological and/or behavioral data. Neural human-sy stems interface technology can use operator state information to give operator feedback, to control adaptive automation or to perform brain-actuated control. Even simple gameoriented devices like Emotiv Systems' Neuroheadset and Insight devices demonstrate impressive capabilities to control devices and software.

With devices like this designers can dramatically enhance interactivity and the level of immersion in the application by, for example, enabling the system to respond to a user's facial expressions and adjusting the application's behavior dynamically in response to user emotions such as frustration or excitement, and enabling users to manipulate objects in an application or even turn them on or off or change their state by simply using the power of their thoughts. This is reality and no longer science fiction; it is not too hard to imagine that these devices will find their way into certain application in industry within twenty years.

\section{- In telligent and Adaptive HSIs}

Although the term 'intelligent' is perhaps a misnomer in HSIs, it is nevertheless an important development. This is a class of technology that mimics certain aspects of human reasoning and behavior. Such systems employ statistical and probabilistic methods in conjunction with neural networks, databases, rules and a variety of sensors to approximate human traits of reasoning, knowledge, planning, learning, communication, perception, and the ability to manipulate abstract or concrete objects (Ehlert, 2003 [24]). Software systems that are able to perform such functions could be called intelligent software agents. When this forms part of the HSI, such an agent wo uld act in collaboration with the operator, for example, to detect certain patterns of operator responses in his or her use of the HSI, such as the need to perform a calculation. It would then either autonomously perform the function for the operator, or submit the result to the operator for approval. More sophisticated agents equipped with cameras and sensors could even detect stress and workload from the operator's voice and facial expression and offer to activate specific operat or support functions. However, this kind of technology is not likely to find its way into the control room in the near future. 
Other sensor technologies that are already common in many industries are now also slo wly being deployed in the nuclear industry, For example, RFID tags (radio-frequency identification) and GP S (global satellite positioning systems) are being used to locate personnel as well as components in the plant, especially during maintenance outages.

\subsubsection{Special considerations for voice interaction}

Of the technologies disc ussed in this report, voice interaction is often considered one of the most natural way s of communicating and it would therefore seem reasonable to give preference to natural speech as a method to interact with systems. With this in mind, research and development of speech-enabled technologies has been ongoing for decades and has recently been extended to intelligent agents. However, speech remains one of the most challenging technologies to perfect. Although there has been much made about the potential for the hands free voice activation of controls or directing information search, real world implementation of voice control for control room operations is fraught with challenge, not the least of which is the difficulty of natural language interpreters to process spontaneous speech. (Robbe-Reiter et al., 2006 [65]). One solution is to use voice activation while employing a lexicon limited to common control room commands. However, recent review of the literature sugge sts that spontaneous speech is effective, in part, because it is often accompanied by gesture. To replicate that multi-modality form of communication is not easy. Unless the application for verbal activation were restricted to limited navigation, verification, and control actions, the system interface soft ware wo uld have to be responsive to the great variability in individual verbal interaction styles including: phrasing, accent, pace, timing and others. Additionally, we know that speakers can easily utter non-grammatical constructs and ill-formed sentences. Further, the software recognition would have to be effective for instances such as when two speakers be gin to speak (or attempt control) at once, when the voice levels are too low and where the system will want to identify the speaker and the amount of authority they have. There are some instances where a control action must be authorized or initiated by a shift supervisor as opposed to other crewmem bers. As a practical problem, when there is a high degree of noise present in the control room, i.e., a low signal to noise level, the system may have to be able to identify and boost the gain on corresponding speech elements while suppres sing or neutralizing unimportant background frequencies. The use of speech as an input device would also have to be noted for in procedures. The current procedural approach often specifies cabinets of panels upon which actions are to be taken. The procedures wo uld need to be rewritten and tested for a disembodied voice directing control actions from any number of control room locations.

From a usability perspective there are instances when speech-based control may be preferred such as when during equipment failure the habitability of the control room may come into question or certain alternative indirect input media such as trackball, pen, or mouse are unavailable. Robbe-Reiter et al. [65] point out that the operator's response to speech recognition failures may be an important determinant regarding the perceived ease of use and perceived usefulness of the overall system. For example, are operators likely to reformulate their verbal commands or give up and search for alternate means by which to interact with the system? In addition, it is difficult to prove that verbal interaction within the context of carrying out additional concurrent tasks does not actually lead to increased co gnitive workload. 
Early speech recognition systems relied upon acoustic and phonetic recognition algorithms, but more sophisticated speech recognition systems now use statistical methods such as Hidden Markov models (HMM). Juan g and Rabiner (2004 [42] note that not only should there be allowance for recognition and understanding errors on the part of the software, but there should also be reco gnition of the need for dialog bet ween the user and the machine to reach a shared understanding. If we were to consider the use of a highly sophisticated voice recognition system, it raises the question of whether such a system should support a mixed-initiative, mixed-dialog sy stem. Thus, it seems that unless a limited lexicon were to be mapped to a small subset of system applications (e.g. provide approval of hold points, reduce flow, align valves, start/stop pumps, or to execute macro control over a sequence), the application of this technology on a wider basis is still too immature to be used in critical control room tasks such as control activation.

\subsubsection{Technology Context of Use}

As indic ated above, this research has considered advanced HSIs in terms of three classes of technology

- output technologies for visual or audio perception;

- input technologies that use electromechanical means control devices;

- hybrid devices for multimodal interaction;

- $\quad$ specialized applications that use advanced software.

The typical applications of these technologies can now be summarized (See also Appendix A for a more comprehensive analysis of each technology class):

Table 3: Device Context of Use - Output Devices

\begin{tabular}{|c|c|}
\hline Device Description & Typical Context of Use \\
\hline $\begin{array}{l}\text { 3D Audio (surround sound): The use of audio devices } \\
\text { that manipulate the sound produced by stereo speakers, } \\
\text { surround-sound speakers, speaker-arrays, or } \\
\text { headphones. This frequently involves the virtual } \\
\text { placem ent of sound sources anywhere in } 3 \text {-dimensional } \\
\text { space, including behind, above or below the listen er. }\end{array}$ & $\begin{array}{l}\text { Where envi ronm ent al sounds provide important } \\
\text { in form ation on the performance or status of syst ems or } \\
\text { process es. }\end{array}$ \\
\hline $\begin{array}{l}\text { Bone conduction audio: The conduction of sound to the } \\
\text { inner ear through the bon es of the skull. Bone } \\
\text { conduction transmission can be used with individuals } \\
\text { with norm al or impai red hearing. }\end{array}$ & $\begin{array}{l}\text { Where it is necess ary to enh an ce the pres ent ation of } \\
\text { written or graphical in fo rm ation and to noti fy users } \\
\text { about a parti cular condition without the need for a } \\
\text { display. Also where coded audio signals may convey } \\
\text { more in form ation than a single alarm tone. May be } \\
\text { help ful for operators with some hearing impairment. } \\
\text { There is some evidence that with stereo bone phones } \\
\text { laterali zing signals to left or right locations can be } \\
\text { difficult. }\end{array}$ \\
\hline $\begin{array}{l}\text { Des ktop flat panel displays: A display using light- } \\
\text { emitting diodes (LEDs) and org ani c light-emitting diode } \\
\text { (OLED), plasma panels, thin film el ectrolumin escent } \\
\text { panels (TFE), and liquid crystal (LCD) panels. }\end{array}$ & $\begin{array}{l}\text { Normal operating tasks, setting up system, and diagnosis } \\
\text { of fault conditions. }\end{array}$ \\
\hline $\begin{array}{l}\text { Haptic output (na rrow-range vibra to ry alert): A } \\
\text { tactile feedback technology that takes advantage of the } \\
\text { sens e of touch by applying forces, vibrations, or motions } \\
\text { to the user. }\end{array}$ & $\begin{array}{l}\text { Where fast localization of the source of a condition is } \\
\text { requi red and when visual or audio sources are not } \\
\text { avail able or too much int erference in the envi ronm ent. }\end{array}$ \\
\hline Haptic output (wide range physical sti mulus): Wide- & Use as a telepresence interface for remote manipulation \\
\hline
\end{tabular}




\begin{tabular}{|c|c|}
\hline Device Description & Typical Context of Use \\
\hline $\begin{array}{l}\text { range haptic devices allow users to touch, feel and } \\
\text { manipul ate three-dim ensional obj ects in virtual } \\
\text { environm ents and tel e-operated syst ems. Unlike narrow- } \\
\text { range haptic devices that provide only simple tactile } \\
\text { feedback, wide-range haptic devi ces are input-output } \\
\text { devices, meaning that they track a user's physical } \\
\text { manipul ations (input) and provide realistic touch } \\
\text { sens ations coordin ated with on-s creen ev ents (output). } \\
\text { Exampl es include consum er peripheral devices equipped } \\
\text { with special motors and sensors (e.g., force feedback } \\
\text { joysticks and steering wheels) and more sophisticat ed } \\
\text { devices designed for industrial, medical or sci entific } \\
\text { applications (e.g., the PHANTOM }{ }^{\mathrm{TM}} \text { device). }\end{array}$ & $\begin{array}{l}\text { of machines or robots (that is, using sensors on the robot } \\
\text { to allow the operator to "sense" the robot's environm ent } \\
\text { and motions. }\end{array}$ \\
\hline $\begin{array}{l}\text { Head-mounted displays: A display device, worn on the } \\
\text { head or as part of a helm et, that has a small display optic } \\
\text { in front of one (monocular HMD) or each eye (bino cul ar } \\
\text { HMD). }\end{array}$ & Han ds-free op erations, e.g. field work. \\
\hline $\begin{array}{l}\text { Large group-vi ew display (non-interactive): Group- } \\
\text { view display systems allow multiple pers onnel to } \\
\text { simultaneously view the same in form ation when they } \\
\text { are in the CR or distributed throughout the plant. The } \\
\text { most important charact eristic of a group-vi ew display is } \\
\text { supporting team perform ance and not the type of device } \\
\text { used to implem ent the display. (NUREG-0700) }\end{array}$ & $\begin{array}{l}\text { Control room, out age control center, technical support } \\
\text { center, etc. }\end{array}$ \\
\hline $\begin{array}{l}\text { Live speech (radio, cellular devices): A device such as } \\
\text { a radio, telephone, walkie-talkie or intercom that allows } \\
\text { transmission of speech from a speaker to a listener. }\end{array}$ & $\begin{array}{l}\text { Communication between hum ans during field work } \\
\text { (This is not a new application, but enhanced technical } \\
\text { cap abilities such as with smart phones could be } \\
\text { exploited more effectively).. }\end{array}$ \\
\hline $\begin{array}{l}\text { Syn thesi zed speech: The arti ficial production of hum an } \\
\text { speech by m ean s of a speech synth esizer. It can be } \\
\text { implemented in so ft ware or hardware products. }\end{array}$ & $\begin{array}{l}\text { Applications where visual in formation is not av ailable or } \\
\text { accessible by the worker, e.g. feed back from a system } \\
\text { while performing a function. }\end{array}$ \\
\hline
\end{tabular}

Ta ble 4: Device Con text of Use - Input Devices

\begin{tabular}{|l|l|}
\hline \multicolumn{1}{|c|}{ Device Description } & \multicolumn{1}{|c|}{ Typical Context of Use } \\
\hline $\begin{array}{l}\text { Touch screen (soft buttons \& on-screen keyboards): A } \\
\text { display panel that can detect the presence and location of } \\
\text { a touch within the display area and allow the us er to } \\
\text { interact directly with displayed obj ects. }\end{array}$ & Operations, training, mainten ance, etc. \\
\hline $\begin{array}{l}\text { Advanced keyboards: Adapt ation of standard computer } \\
\text { keyboards to allow application-specific functions. Such } \\
\text { keybo ards can be customized and can provide various } \\
\text { types of tactile and visual feedback. Virtual keyboards } \\
\text { that use a laser to project an image of the keys on a } \\
\text { surface are also av ailable. The user interacts with this by } \\
\text { interrupting an in frared beam. }\end{array}$ & \begin{tabular}{l} 
Specialized ap plications where data entry is required. \\
\hline $\begin{array}{l}\text { Voice con trol (sp eech recognition): Systems that } \\
\text { anal yze the person's speci fic voice and use it to fine tune } \\
\text { the recognition of that person's speech, resulting in more } \\
\text { accurate tran scription and control of computer so ft ware. }\end{array}$
\end{tabular} \\
\hline
\end{tabular}




\begin{tabular}{|c|c|}
\hline Device Des cription & Typical Context of Use \\
\hline $\begin{array}{l}\text { Systems that do not use training are called "Speaker } \\
\text { Independent" systems. Systems that use training are } \\
\text { call ed "Speaker Dependent" syst ems. }\end{array}$ & \\
\hline $\begin{array}{l}\text { 3D spatial con troll ers: A device that gen erates three- } \\
\text { dimensional spatial data used to control virtual dat a } \\
\text { objects such as } 3 \mathrm{D} \text { graphics }\end{array}$ & $\begin{array}{l}\text { Dev elopm ent of 3D graphics, manipulation of virtual } \\
\text { reality applications }\end{array}$ \\
\hline $\begin{array}{l}\text { Composite Controllers: Devices that combines buttons } \\
\text { and positional controllers in a single physical device. }\end{array}$ & Complex graphics applications, robot control \\
\hline $\begin{array}{l}\text { Gestu re input: A device that employs data gloves, } \\
\text { cam eras and/or proximity sens ors to dynamically sense } \\
\text { the position, orientation of the user's hand(s). This data is } \\
\text { then translat ed to control inputs to manipulate the } \\
\text { orient ation or status of a virtual object on a displ ay. }\end{array}$ & Manipulation of virtual objects in3 D space \\
\hline $\begin{array}{l}\text { Haptic con trols: A device that uses mech anical } \\
\text { stimulation to control objects on a display and to } \\
\text { enh ance the remote control of machines and devices } \\
\text { (telerobotics). Haptic devices may inco rpo rate tactile } \\
\text { sensors that measure forces exerted by the user on the } \\
\text { interface. }\end{array}$ & $\begin{array}{l}\text { Design of 3D obj ects, medical applications, } \\
\text { manipul ation of virtual 3D obj ects in space }\end{array}$ \\
\hline $\begin{array}{l}\text { Eye tracking / Gaze Control: A device that measures } \\
\text { eye positions and eye movem ent. Used to analyze gaze } \\
\text { patterns of device users. Can be us ed to det ermine areas } \\
\text { of interest of visual displays, situation aw aren ess, } \\
\text { saliency of visual in formation, worklo ad and fatigue. }\end{array}$ & $\begin{array}{l}\text { Analysis and measurem ent of cognitive perform ance, } \\
\text { visual system research, situation awaren ess, product } \\
\text { research }\end{array}$ \\
\hline
\end{tabular}

Table 5: Device Con text of Use - Hybrid Input/Output Devices

\begin{tabular}{|c|c|}
\hline Device Description & Potential Conte xt(s) of Use \\
\hline $\begin{array}{l}\text { Touch screens (soft buttons \& on-screen keyboards): A } \\
\text { display panel that can detect the presence and location of } \\
\text { a touch within the display area and allow the us er to } \\
\text { interact directly with displayed objects. }\end{array}$ & Operations, training, maint en ance, etc. \\
\hline $\begin{array}{l}\text { Hand-held displays and hand-held computers: A } \\
\text { computer built around a form factor smaller than a } \\
\text { stand ard laptop computer. }\end{array}$ & $\begin{array}{l}\text { Maintenance work, inspections, remote in formation } \\
\text { access (e.g. computer-bas ed procedures) }\end{array}$ \\
\hline $\begin{array}{l}\text { Large multi-touch interactive display: A display on a } \\
\text { larg e smart board that has a touch sensing surface } \\
\text { capable of recognizi ng the pres ence of two or more } \\
\text { points of cont act with the surface. The plural-point } \\
\text { awaren ess is offen us ed to implem ent advanced } \\
\text { functionality such as pinch to zoom or activating } \\
\text { pred efined programs. }\end{array}$ & $\begin{array}{l}\text { Collaborative tasks, briefings: Control rooms, outage } \\
\text { control centers, tech support. }\end{array}$ \\
\hline $\begin{array}{l}\text { Large "roll-up" electronic display: Portable wall-sized } \\
\text { TV or computer monitor that can be rolled or folded and } \\
\text { stored when not in use. It can be described as e-paper } \\
\text { book. }\end{array}$ & Field work, maint en ance planning, etc. \\
\hline $\begin{array}{l}\text { Tablet or Laptop: A mobile com puter, typically has a } \\
\text { touch screen, with a finger or stylus replacing the } \\
\text { conventional computer mouse. }\end{array}$ & $\begin{array}{l}\text { Maintenance work, inspections, remote in formation } \\
\text { access (e.g. computer-bas ed procedures) }\end{array}$ \\
\hline
\end{tabular}




\begin{tabular}{|l|l|}
\hline \multicolumn{1}{|c|}{ Device Description } & \multicolumn{1}{c|}{ Poten tial Con te xt(s) of Use } \\
\hline $\begin{array}{l}\text { Virtual/Augmented reality (AR) (multidimensional) } \\
\text { in form ation displ ay: Live, direct or indirect, view of } \\
\text { physical, real world environm ent whos e el ements are } \\
\text { augm ented by computer gen erated sensory input such as } \\
\text { sound, video, graphics or GPS dat a. }\end{array}$ & $\begin{array}{l}\text { Hands-free op erations, e.g. field work requi ring access } \\
\text { to procedural or technical in formation while performing } \\
\text { a task. }\end{array}$ \\
\hline $\begin{array}{l}\text { Wrist-worn display: A small device, similar to a small } \\
\text { tablet that can be mount ed on the forearm. It can display } \\
\text { text and graphical in formation and allow basic selection } \\
\text { methods. }\end{array}$ & $\begin{array}{l}\text { Field work requi ring easy access to real -time } \\
\text { in form ation and SA alerts. }\end{array}$ \\
\hline
\end{tabular}

Table 6: Advan ced Technology Con te xt of Use - Specialized Applications

\begin{tabular}{|c|c|}
\hline Technology Description & Potential Context(s) of Use \\
\hline $\begin{array}{l}\text { Software agents: Can also be called "int elligent agent" } \\
\text { which continuously performs three functions: perception } \\
\text { of dynamic conditions in the environment; actions to } \\
\text { affect conditions in the envi ronment and reason to } \\
\text { interp ret perceptions, solve problems, draw int erfaces, } \\
\text { and det ermine actions. Agents must act autonomously so } \\
\text { as to realize a set of goals. }\end{array}$ & $\begin{array}{l}\text { Adaptive automation systems for dyn amic plant } \\
\text { conditions requi ring variable levels of op erator support. }\end{array}$ \\
\hline $\begin{array}{l}\text { Predictive displays: Display of predictive behavior or } \\
\text { outcome that is based on actions in the past, experience } \\
\text { or empirical data. }\end{array}$ & $\begin{array}{l}\text { Keeping op erators in the loop, improving situation } \\
\text { aw aren ess in advanced control rooms and highly } \\
\text { autom ated process es. }\end{array}$ \\
\hline $\begin{array}{l}\text { Advanced Alarm Processing and Displays: An } \\
\text { intelligent system designed to display in formation rel ated } \\
\text { to monitoring plant performance and al erting operator in } \\
\text { case of abnormalities. Advanced al arm syst em should be } \\
\text { able to pinpoint the root cause and be tied to other plant } \\
\text { intelligent instrumentation systems. }\end{array}$ & $\begin{array}{l}\text { Simplify alarm processing and pres entation in cont rol } \\
\text { rooms }\end{array}$ \\
\hline $\begin{array}{l}\text { Advanced System Performan ce Visualization: } \\
\text { Graphical visualization con sists primarily of line graphs, } \\
\text { pie charts, bar charts, etc., which are us ed to show some } \\
\text { performance charact eristic value or parameter over time } \\
\text { and us es a computerized system capable of storing and } \\
\text { exchanging data. Often displays use color-coded icons to } \\
\text { convey the current overall state of a large collection of } \\
\text { managed objects to help in the comprehension and } \\
\text { analysis of complex large databas e systems. }\end{array}$ & As for Predictive Displays \\
\hline
\end{tabular}




\begin{tabular}{|c|c|}
\hline Technology Description & Potential Con text(s) of Use \\
\hline $\begin{array}{l}\text { Ambien t Contex tual Environment Lighting: Lighting } \\
\text { changes in response to computing in frastructure output } \\
\text { designed to provide intelligent services to the us er by } \\
\text { targ eting so ft ware to wards a speci fic context before } \\
\text { delivery, and adapting it to changing cont ext after } \\
\text { delivery. }\end{array}$ & $\begin{array}{l}\text { Advanced control rooms and other operational areas to } \\
\text { simplify the indication of plant conditions. }\end{array}$ \\
\hline $\begin{array}{l}\text { Adaptive Auto mation: A system that has a means of } \\
\text { monitoring its own perform ance and a means of varying } \\
\text { its own param eters by clos ed loop action to improve its } \\
\text { performance. In a human -cent ered system, adaptive } \\
\text { automation can be us ed to maint ain operat or's } \\
\text { involvem ent in complex systems control to facilitate } \\
\text { situational awaren ess or in task allocation between } \\
\text { human and machine. }\end{array}$ & $\begin{array}{l}\text { Advanced stat e-bas ed process control, linked to } \\
\text { comput eri zed operator support systems. }\end{array}$ \\
\hline $\begin{array}{l}\text { Brain-computer interface (BCI): A direct } \\
\text { communication pathway between the brain and an } \\
\text { external device. BCIs are oft en directed at assisting, } \\
\text { augm enting, or repairing hum an cognitive or sensory - } \\
\text { motor functions }\end{array}$ & $\begin{array}{l}\text { Currently prim arily neuroprosthetics applications that } \\
\text { aim at restoring damaged hearing, sight and movem ent. } \\
\text { Simpler em erging technologies are us ed in gaming, } \\
\text { pers onal brain training, simple comput er applications. }\end{array}$ \\
\hline
\end{tabular}

\subsection{Conceptual Mapping of Functions to HSI Displays and Controls}

Based on known NPP operational scenarios, a number of functions were identified that would be required of the HSI suite. Table 7 shows how these functions can be mapped to the appropriate display/control devices.

An asterisk (*) next to a function indicates that the device or controller is secondary or redundant for that function and that one of the other devices may generally be more suited for that function. For example, if a handheld device that includes some coordination tools such as shared pointers may be acceptable for some cases of team communication and coordination, a larger display wo uld be preferable in most cases. 


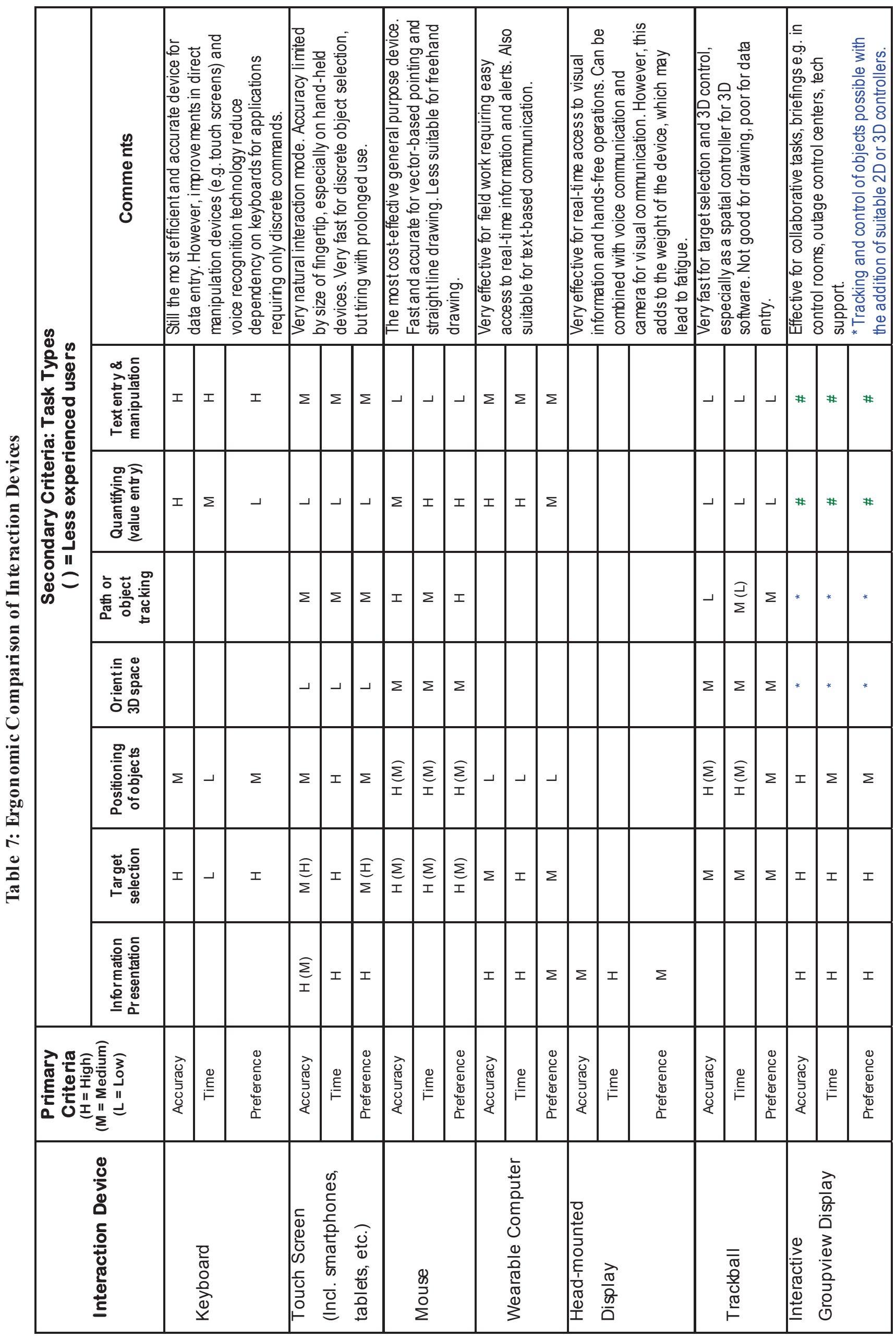




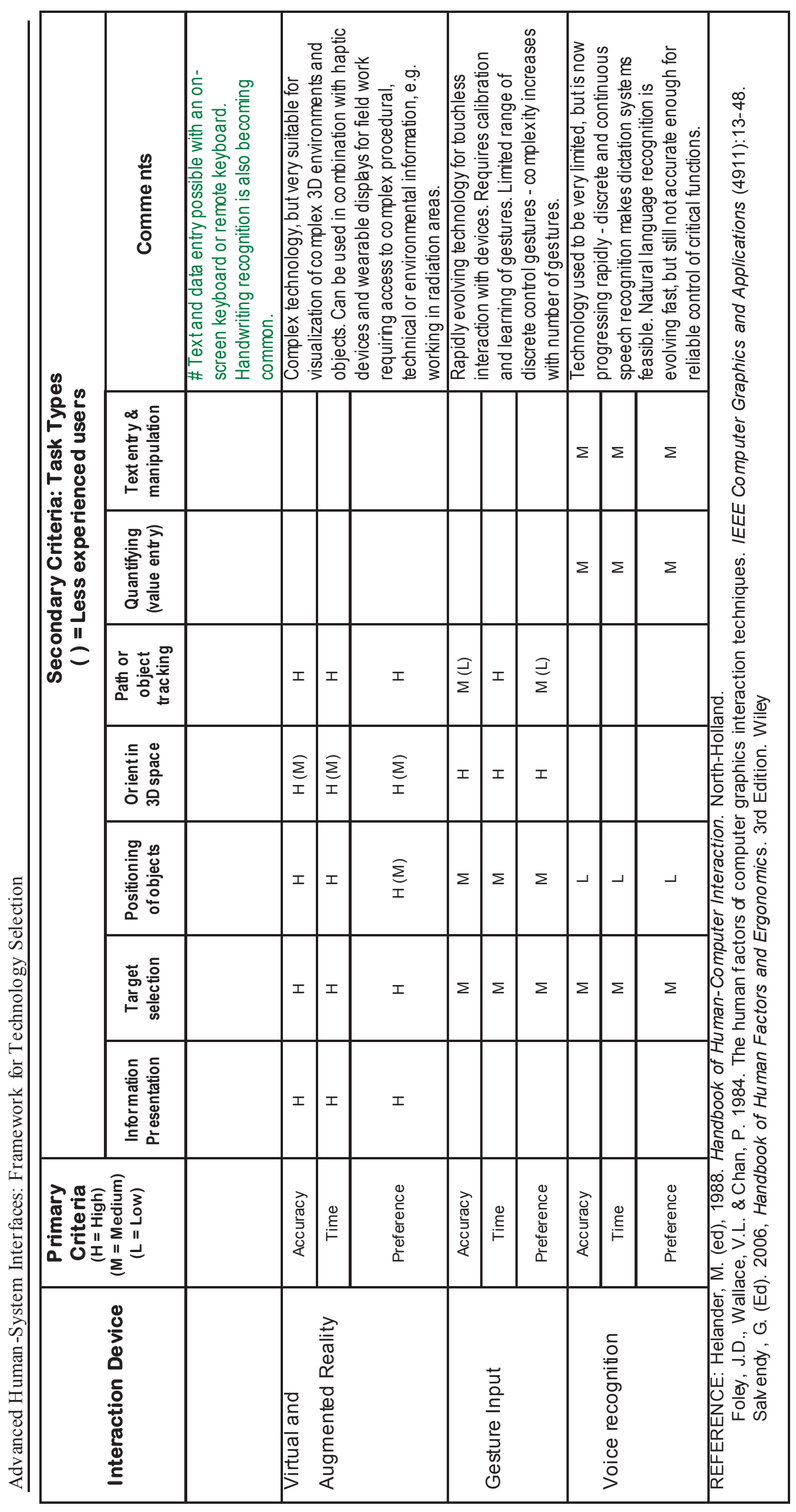




\subsection{HSI architecture and functions}

The HSI in older NPPs has always been a reasonably complex system, but it was possible to describe it in fairly simple terms as consisting of control boards, panels, ga uges, switches, controls, alarm annunciators, and so on. However, with increasing automation and availability of digital I\&C systems, the HSI in newer NPPs has also become progressively more complex. The HSI is now a system with many functions, components and interfaces to other systems and environments. Even a superficial review of its many components will show that the HSI is in fact not only a hierarchy of high - and low-level components, but many of the components at the same level are linked in some way. It is also possible to describe this structure from different viewpoints, depending up on, for example, whether it is a safety-or non-safetyrelated system, whether it is used in operations or in maintenance, and so on. It is also possible to describe it as either an abstract functional or a physical structure.

Because it is easy to get lost in this complexity, an HSI architecture or taxonomy is proposed to guide $\mathrm{I} \& \mathrm{C}$ designers an human factors engineers in their analyses and design $\mathrm{s}$. The easiest way to do this is to provide a reference table that illustrates the various levels of the HSI architecture and the relationships between them.

The table below illustrates the distinction between the functions of the HSI and its physical architecture. The physical architecture consists of the concrete components, which include the operating environment (control rooms and other workspaces described in the Operational Domains section) and all the hardware within it. These physical components in turn make it possible for the operating crew to perform all tasks in the work environment. All of these components could be broken down to several levels of decomposition.

The taxonomy also indicates the Operator Task Support components and functions. The implementation of such functions is a subsystem that does not exist in current NPPs, but it is included here because it is likely to be an important area of research and development over the next ten to twenty years.

Ta ble 8: HSI Taxon om y (Part 1: Function al HSI Architecture)

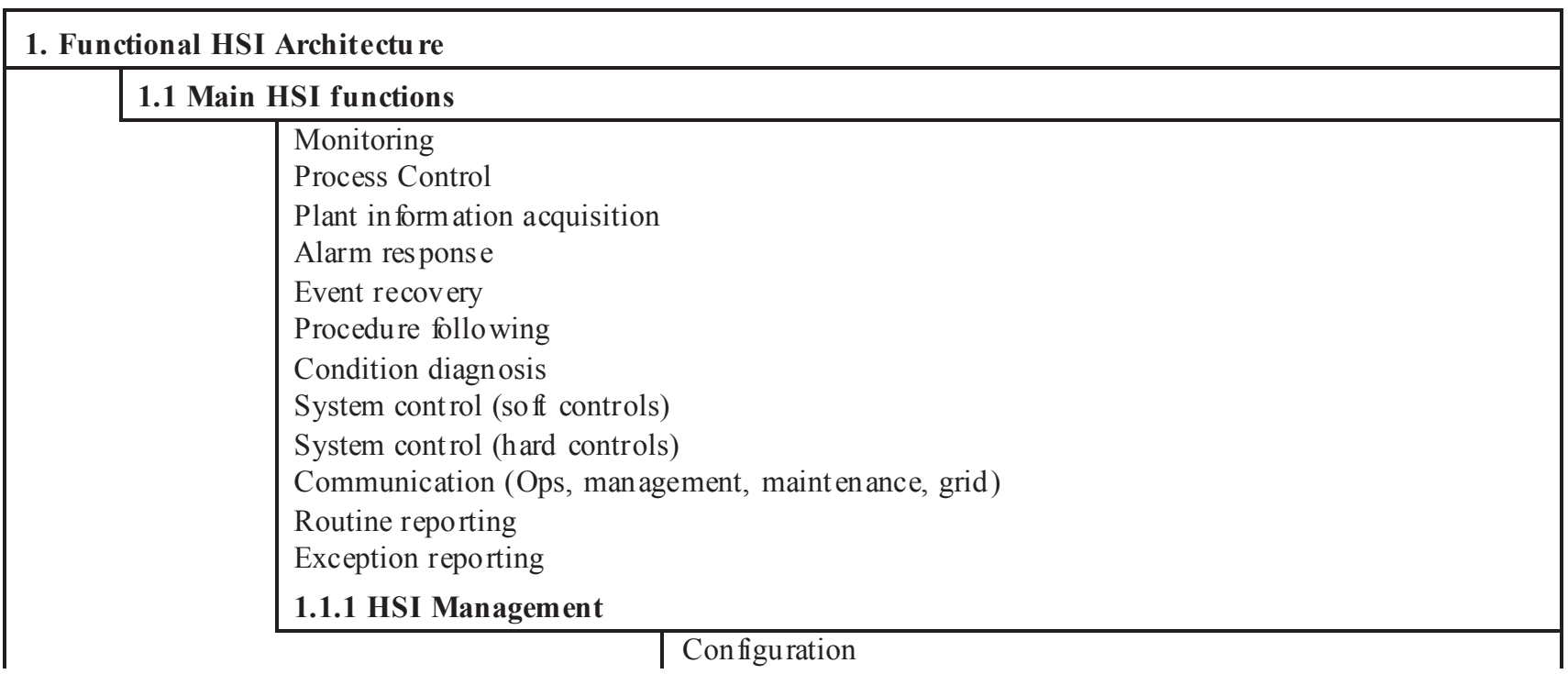




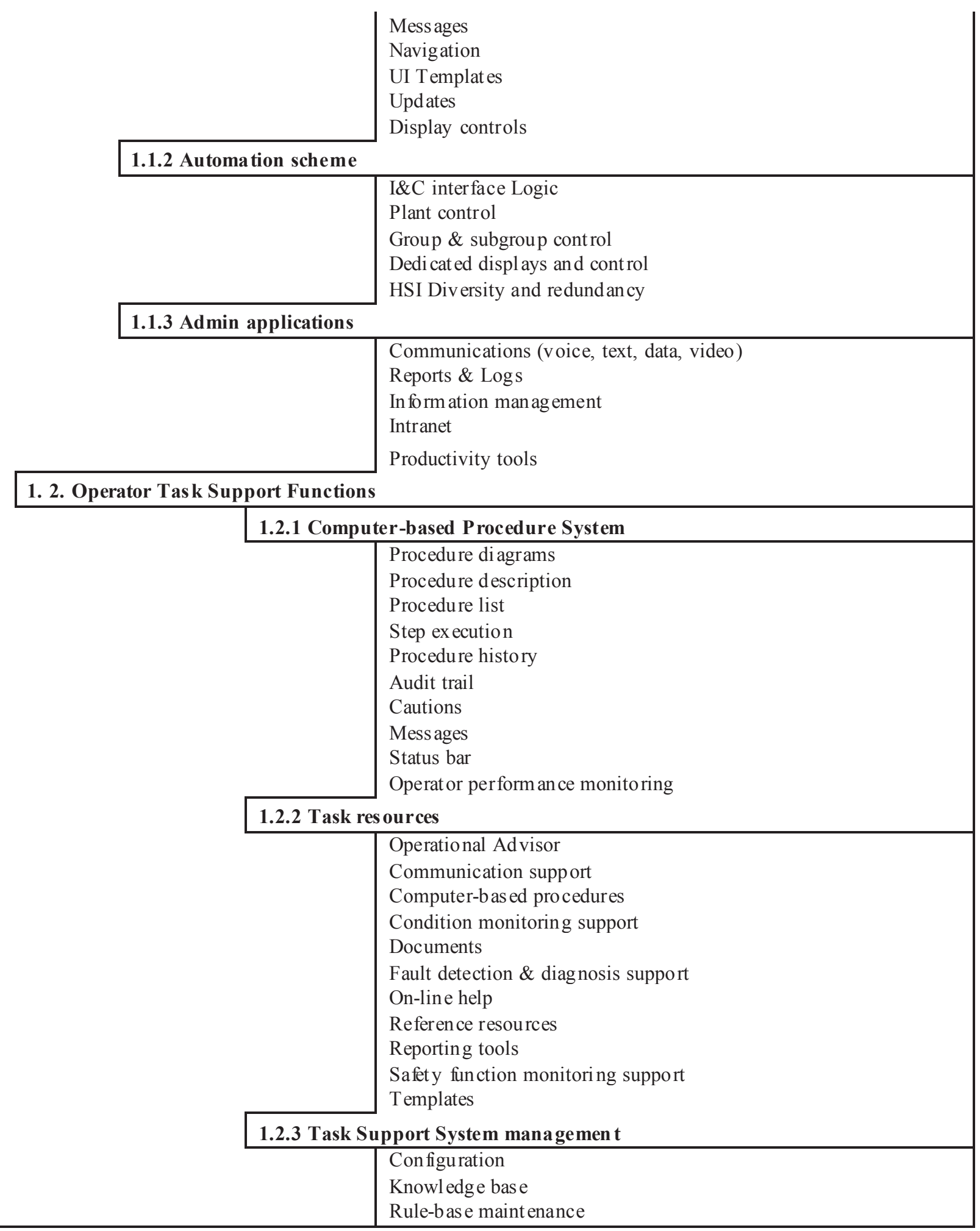


The physical HSI architecture includes the physical workspaces (control rooms and other work areas) and the devices within those areas. Table 2 shows first the typical structure of the Main Control Room with the HSI contained within it, and then the other areas where humans may interact with a range of devices:

Ta ble 9: HSI Taxon omy (Part 2: Physical HSI Architecture)

\section{Physical HSI Architectu re}

\subsection{Physical Work Areas \& Con trol Centers}

\subsubsection{Main Control Room}

Main HSI

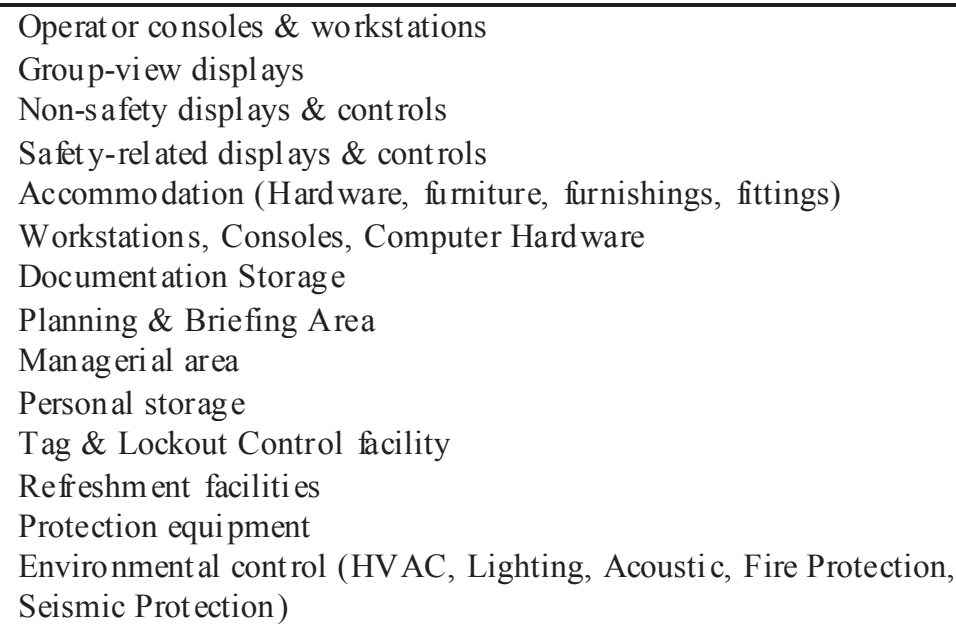

2.1.2 Remote Shutdown Facility

Environmental control

Safety provisions

Hardware

Layout

Workstation s

\subsubsection{Local Control Stations}

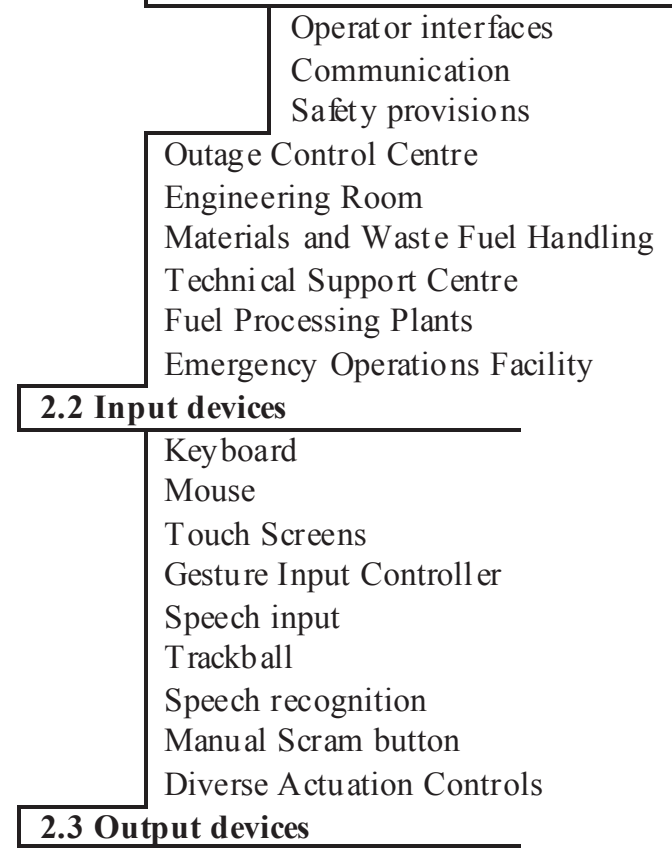




\begin{tabular}{|c|c|}
\hline \multicolumn{2}{|c|}{ 2.3.1 Audio annunciators } \\
\hline \multicolumn{2}{|l|}{ Coded } \\
\hline \multicolumn{2}{|c|}{ Uncoded } \\
\hline \multicolumn{2}{|c|}{ 2.3.2 Visual Display Units } \\
\hline \multirow{5}{*}{\multicolumn{2}{|c|}{$\begin{array}{l}\text { Annun ciat ors } \\
\text { Overvi ew Displ ays } \\
\text { Process Displ ays } \\
\text { Safety-rel ated displ ays } \\
\text { Flat Panel Op era tor Displays }\end{array}$}} \\
\hline & \\
\hline & \\
\hline & \\
\hline & \\
\hline & Alarm Annunciators: \\
\hline & SDCV (Spatially Dedicated Constantly Visible) displays \\
\hline & 'Status-at-a-glance' Overviews \\
\hline & Process Flow displays \\
\hline & Mode/State displays \\
\hline & Sub-process display \\
\hline & Soft Cont rols \\
\hline & Low-level System Status displays \\
\hline & Trend Displays \\
\hline & Faceplates \\
\hline & Diagnostic Displays \\
\hline & Safety Status Displays \\
\hline & Event Log Displays \\
\hline & Dedicated safety-rel ated displays \\
\hline & Post-event Display Panel \\
\hline \multicolumn{2}{|l|}{ Printers } \\
\hline \multicolumn{2}{|c|}{ 2.3.3 Hybrid Input/Output Devices } \\
\hline \multicolumn{2}{|c|}{ Communication equipmen $t$} \\
\hline & Intercom \\
\hline & Touchscreens \\
\hline & Intranet \\
\hline & Radio \\
\hline & Telephone \\
\hline \multicolumn{2}{|c|}{ Portable/wea rable devices } \\
\hline & Tablets \\
\hline & Smartphones \\
\hline & PDAs \\
\hline & Barcode scanners \\
\hline & RFID (Radio frequency identi fication) tags \\
\hline \multicolumn{2}{|c|}{ Augmented Reality devices } \\
\hline & Haptic devices (e.g. vibratory alerts) \\
\hline & Head-mount ed display \\
\hline & Head-mount ed communicators \\
\hline & Head-mounted cameras \\
\hline
\end{tabular}

Note that the 'Safety provisions' and 'Environmental Control' for the Remote Shutdown Facility shown above include provisions for habitability and survivability, such as battery backed-up HVAC (heating, ventilation, air conditioning), communications and personal protective equipment (PPE). 
The table does not show lower-level components for the Outage Management Centre, Engineering Room, Technical Support Centre and Emergency Operations Facility, but they are listed to indicate other areas outside the main control room that operators interact with during different operational, maintenance and emergency conditions. (See also section 4.6.2, Operational domains).

As mentioned before, this architecture is not definitive and could be structured and described in a number of different ways. This is presented as a starting point for engineers and designers involved in the definition of I\&C and HSI requirements.

\subsection{A Typical Suite of Operator Support HSIs}

The description of the Context of Use in section 4.2 included the generic functions of operators in those work domains. It is very likely that some HSIs will be common to all areas, but there will also be unique requirements, based upon the functional requirements of those areas. For example, there will be significant differences in the kind of procedural support devices needed by maintainers, field operators and control room operators.

A typical suite of advanced technologies wo uld have to support operating crews in performing the functions described in this document with effectiveness, efficiency, safety and satisfaction. It is possible to match candidate devices to the operat ors' functional performance requirements, based upon the known advantages and disadvantages of each. As background information, the tables in Appendix A list the advantages and disadvantages considere in generating the following suite of devices:

\section{Han dheld devices}

A handheld HSI device is typically meant for use inside the plant during in spections, walkdown s or maintenance. It would typically be of a size that can be held in one hand and operated by pressing physical buttons on the device with that same hand (probably no larger than 2.5 inches $\times 6-7$ inches). The device would include several physical buttons including a four-way directional controller. A highresolution touch screen forms the biggest portion of the device. A glove-tip-mounted stylus might be included for operation of the touch screen with gloves. The device would also accept simple voice commands for many of the commonly used functions. The device would be optionally mounted on a belt or wrist, worn in a pack or rugge dized to protect against falls and bumps. This device might also include tactile feedback (i.e. a vibrator) for indicating the receipt of critical information.

\section{Large tablet or roll-up display}

A larger display may also be used for operations or maintenance planning. This device is not intended to be carried on fieldwork. Depending on the display form (roll-up vs. tablet), this HSI device may also include physical buttons, an optional keyboard, touch screen input, laser pointer entry and/or gesture (such as head tracking) input. The input method would include functionality for numeric an d text entry. This device wo uld also accept voice control as a redundant method of control and may also allow for speech to text input for reporting functions. 


\section{Virtual reality head/helmet mounted display}

An alternative display wo uld be a head mounted display (HMD) for augmented reality applications, procedure rehearsal and possibly embedded training applications. Some type of directional controller such as a joystick with multi-function buttons would likely be used for control. This device is intende $\mathrm{d}$ to be carried on inspections or manual work. This device would include some type of data storage such as a secure digital (SD) card that would allow for easy updates of information. Because of relatively high power demand, it is expected that this kind of device would be used primarily at sites where recharging facilities are readily available.

\section{Haptic alerts}

A vibratory alert may be integrated into other wearable devices to provide simple environmental cues in noise environments or where the need for hands-free work will limit the ability to manipulate a handheld device.

\section{Bone conduction microph one and listening de vice}

A bone conduction microphone/speaker as part of other wearable devices wo uld be an ideal solution for sending and receiving auditory information without environmental interference.

\section{Gesture recognition controller}

An optional gesture recognition controller could be integrated into the operator's clothing or gloves so that gestures could be used for transmission of simple information to operators who are out of view (via translation to audio, tactile, or visually displayed information). As noted in section 6.1.4, the state-of-theart of this technology is lagging behind other options and may take several more years to become freely available.

\section{Wrist-worn display de vice}

This is a lightweight, low-power, rugge dized device that would provide simple visual cues for in -plant navigation, supervisory notification, system status, and system control functions, as well as time and date display. Ideally this kind of device would support different display modes, for example monochrome graphic day/night displays, vibration haptic displays, GP S or wayfinding displays. Wayfinding and situation alerts in particular would support situation awareness, allo wing the operator to rapidly identify operational conditions and directions of the indicated information with minimal cognitive effort. In addition to these, a RFI component locator may also be integrated with these devices so that the operator can determine information such as range and position of components.

In advanced power plants all of the above devices wo uld be chosen such that they easily integrate with each other. For example, a scenario generated through outage team disc ussions on a larger display could be transmitted at a lower resolution form to handheld displays used by each operator. Similarly, a keyboard, head tracker, or joystick controller might also be used with any of the other display types. 


\section{Technology Evaluation}

The original objective of this phase of the project was to evaluate the usability and human performance aspects of a number of advanced HSIs. However, it was found more beneficial to spend more effort on developing the technology characterization and human performance considerations described in this report. The findings from that part of the effort were subsequently applied in the development of a basic template for the evaluation of the two devices described in this section, the Smart Technologies SMART Board (a large interactive display) and the Emotiv Epoc Neuroheadset (a brain-computer interface - BCI). This template conforms to the principles described in ISO 9241-11 [39].

\subsection{Technology readiness review}

Part of the preparation for the evaluation of the devices was to review their technology readiness levels (TRLs) in terms of the following Department of Energy definition:

- TRL 1. Scientific research begin s translation to applied R\&D - Lowe st level of technology readiness. Sc ientific research begin s to be translated into applied research and development. Examples might include paper studies of a technology's basic properties.

- TRL 2. Invention begins - Once basic principles are observed, practical applications can be invented. Applications are speculative and there may be no proof or detailed analysis to support the assumptions. Examples are limited to analytic studies.

- TRL 3. Active R\&D is initiated - Active research and development is initiated. This includes analytical studies and laboratory studies to physically validate analytical predictions of separate elements of the technology. Examples include components that are not yet integrated or representative.

- TRL 4. Basic technological components are integrated - Basic technological components are integrated to establish that the pieces will work together.

- TRL 5. Fidelity of breadboard technology improves significantly - The basic technological components are integrated with reasonably realistic supporting elements so it can be tested in a simulated environment. Examples include "high fidelity" laboratory integration of components.

- TRL 6. Model/prototype is tested in relevant environment - Representative model or prototype system, which is well beyond that of TRL 5, is tested in a relevant environment. Represents a major step up in a technology's demonstrated readiness. Examples include testing a prototype in a high fidelity laboratory environment or in simulated operational environment.

- TRL 7. Prototype near or at planned operational system - Represents a major step up from TRL 6, requiring demonstration of an actual system prototype in an operational environment.

- TRL 8. Technology is proven to work - Actual technology completed and qualified through test and demonstration.

- TRL 9. Actual application of technology is in its final form. Facilities, structures, systems and components successfully operated for one full cycle. 
In terms of this classification, the SMART Board and the Emotiv Neuroheadset are both TRL 9, but as a BCI the Emotiv device is more complicated. In practice it is generally TRL 8, but in some niche applications it could be considered TRL 9.

\subsection{Evaluation of the Smart Technologies SMART Board}

Table 10: SMART Board Usability Evaluation

\begin{tabular}{|c|c|}
\hline Evaluation Item & Des crip tion \\
\hline Name of Device/System & Smart Technologies SMART Board Int eractive Display \\
\hline Device/System Description & $\begin{array}{l}\text { The SMART Board interactive display op erates as part of a system that } \\
\text { includ es the interactive LCD panel, a computer, a proj ector and software for } \\
\text { collab orative meetings and pres entations. The components are connected } \\
\text { wirel essly or via USB or serial cables. The interactive touch screen accepts } \\
\text { touch input from a finger, pen or other solid object. }\end{array}$ \\
\hline Purpose and Intend ed Use & $\begin{array}{l}\text { Creating an in form ation space that allows personnel to eng age in active } \\
\text { collab oration in a variety of work environm ents, typically con ference rooms, } \\
\text { control rooms, classrooms, etc. }\end{array}$ \\
\hline Context(s) of Us e & $\begin{array}{l}\text { - Normal presentation of operational conditions, with the added ability to } \\
\text { annot ate displays with notes or comments. } \\
\text { - Display of computer-bas ed procedures for group view with the ability to } \\
\text { add comment, an notations and als o to check off completed procedures } \\
\text { ('circle/slash' method of procedure following). } \\
\text { - Crew briefing between control room shifts } \\
\text { - Classroom training } \\
\text { - Interactive in form ation sharing in Outage Control Centers }\end{array}$ \\
\hline Intended Users & $\begin{array}{l}\text { Power plant staff, including operators, maint ainers, fi eld workers, trainees, } \\
\text { etc. }\end{array}$ \\
\hline - - User Characteristics & $\begin{array}{l}\text { The SMART Board is design ed for all literate staff of a work area, including } \\
\text { operators, maintainers, field workers, man agers, etc. A mod erate amount of } \\
\text { training and practice on the user of the device is required. It is assumed that } \\
\text { staff will acquire this knowledge through appropriate orient ation training. }\end{array}$ \\
\hline - - Task Charact eristics & $\begin{array}{l}\text { Typical user behavior and activities using the SMART Board: } \\
\text { - Operate and activate the system by touching the panel by hand or stylus } \\
\text { keyboard and making a number of sel ections from options offered on the }\end{array}$ \\
\hline
\end{tabular}




\begin{tabular}{|c|c|}
\hline & $\begin{array}{l}\text { display; } \\
\text { - Read and und erstand the graphic, textual and auditory (alarms and } \\
\text { messages ) in formation offered on sp eci fic options on the various displays } \\
\text { as sources of prim ary in form ation; } \\
\text { - Observe tran sient in formation (system feedback, tren ds, highlighting, } \\
\text { non-critical audio signals, etc.) as sources of secondary in formation; } \\
\text { - Enter in form ation when prompted by the syst em to do so, using the finger } \\
\text { or stylus; } \\
\text { - Recognize when errors have occurred that must be recti fied, for example } \\
\text { incorrect numbers entered, incorrect param eters, incorrect location, etc.; } \\
\text { - Decide when to consult the us er guide. }\end{array}$ \\
\hline - - Environmental Charact eristics & 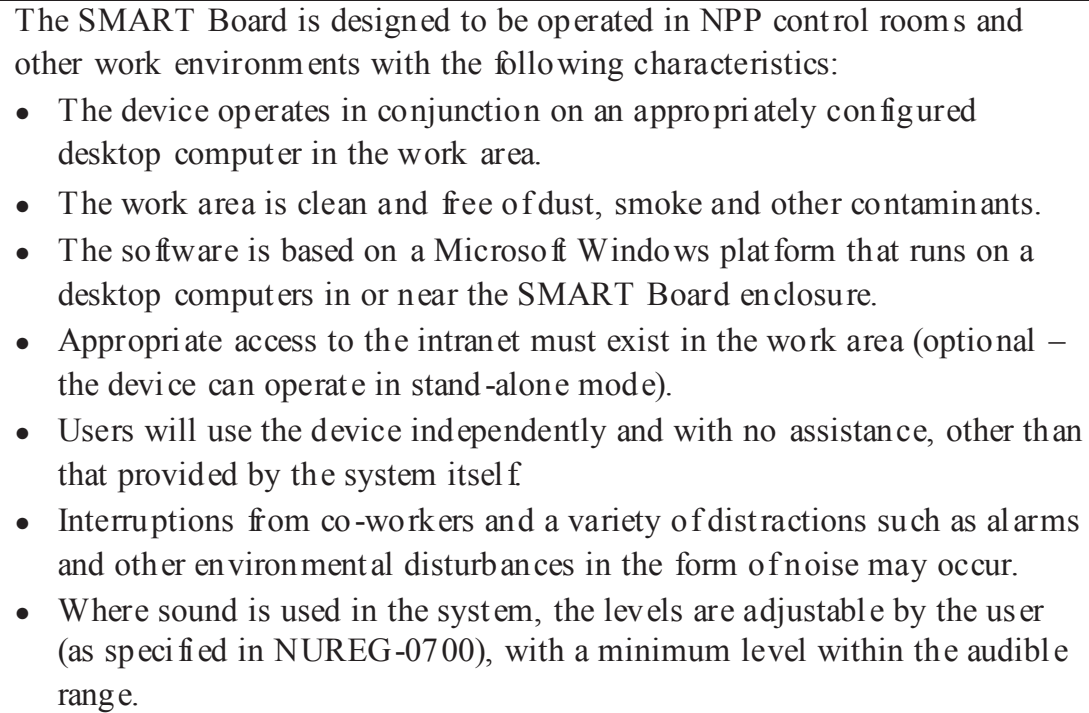 \\
\hline
\end{tabular}

Table 11: SMART Board Heuristic Usability Measures

\begin{tabular}{|l|l|}
\hline \multicolumn{1}{|c|}{ Evaluation Item } & \multicolumn{1}{c|}{ Des crip tion } \\
\hline Devi ce evaluation & $\begin{array}{l}\text { The device should be function ally and physically suitable for the rel evant task, as } \\
\text { determined in terms of effectiveness, efficiency, safety, reliability and user satis faction. }\end{array}$ \\
\hline
\end{tabular}

\begin{tabular}{|l|c|}
\hline Evaluation Criteria & $\begin{array}{c}\text { Rating } \\
\text { Y, N, } \mathbf{?}^{\mathbf{8}}\end{array}$ \\
\hline The size of the devi ce is optimal for the task & $\mathrm{Y}$ \\
\hline Is the display resolution ad equate for the task? & $\mathrm{Y}$ \\
\hline $\begin{array}{l}\text { The operating system (Android, Apple, Windows, etc. ) is optimal for the } \\
\text { task }\end{array}$ & $\mathrm{Y}$ \\
\hline Internal and/or ext ernal device memory is adequate for the task & $\mathrm{Y}$ \\
\hline Portability ofthe device is suited to the task & $?$ \\
\hline $\begin{array}{l}\text { Touch Interaction is effici ent and contributes to the operator's ability to } \\
\text { perform the task effectively without undue strain or error }\end{array}$ & $\mathrm{Y}$ \\
\hline Stylus/Pen Interaction is suitable for the task & $\mathrm{Y}$ \\
\hline Multitasking allowed by the device is suitable for the task & $\mathrm{N}$ \\
\hline
\end{tabular}

8 '?' = someti mes 


\begin{tabular}{|l|c|}
\hline Handwriting input is suitable for the task & $\mathrm{Y}$ \\
\hline Drawing/sketch input is suitable for the task & $\mathrm{Y}$ \\
\hline Keyboard input is effici ent and suitable for the task & $?$ \\
\hline $\begin{array}{l}\text { Navigation between applications and functions is efficient and suitable for } \\
\text { the task }\end{array}$ & $?$ \\
\hline Display in bright light is adequate and supports task perform ance & $\mathrm{Y}$ \\
\hline Display in low light is adequate and supports task perform ance & $\mathrm{Y}$ \\
\hline Touch sensitivity is ad equate and supports task perform ance & $\mathrm{Y}$ \\
\hline Protection from accidental activation is suitable for the task & $\mathrm{N}$ \\
\hline $\begin{array}{l}\text { Rugged construction protects the device from dam age and is suitable for the } \\
\text { task }\end{array}$ & $\mathrm{Y}$ \\
\hline Gloved use is possible with the device and supports task performance & $\mathrm{N}$ \\
\hline Protection from electromagnetic interference is effective & $\mathrm{Y}$ \\
\hline
\end{tabular}

\section{Visibility of system} status
The system should always keep operator in form ed about what is going on, through appropriate feedback within reasonable time.

\begin{tabular}{|l|c|}
\hline Evaluation Crite ria & $\begin{array}{c}\text { Rating } \\
\text { Y, N, ? }\end{array}$ \\
\hline $\begin{array}{l}\text { Is there a consistent sym bol design s cheme and stylistic treatm ent across the } \\
\text { system? }\end{array}$ & $\mathrm{Y}$ \\
\hline $\begin{array}{l}\text { Is a single, sel ect ed symbol clearly visible when surrounded by uns elected } \\
\text { symbols? }\end{array}$ & $\mathrm{Y}$ \\
\hline $\begin{array}{l}\text { Ifovertype and insert mode are both av ailable, is there a visible indication of } \\
\text { which one the operator is in? }\end{array}$ & $\mathrm{Y}$ \\
\hline Is there some form of system feedback for every operat or action? & $\mathrm{Y}$ \\
\hline Is there visual feedback when objects are sel ected or moved? & $\mathrm{Y}$ \\
\hline Are res ponse times appropriate to the task? & $\mathrm{Y}$ \\
\hline $\begin{array}{l}\text { Does the system provide visibility: that is, by looking, can the operator tell } \\
\text { the state of the system and the alternatives for action? }\end{array}$ & $\mathrm{Y}$ \\
\hline $\begin{array}{l}\text { Ifoperators must navigate between multiple screens, does the system use } \\
\text { cont ext labels, menu maps, and place mark ers as navig ational aids? }\end{array}$ & $\mathrm{N}$ \\
\hline
\end{tabular}

Match between system and the real world
The system should speak the operat or's language, with words, phras es and concepts familiar to the op erator, rather than system-oriented terms. Follow real-world conventions, making in formation appear in a natural and logical order.

\begin{tabular}{|l|c|}
\hline Evaluation Crite ria & $\begin{array}{c}\text { Rating } \\
\text { Y, N, ? }\end{array}$ \\
\hline $\begin{array}{l}\text { Does the system allow ad equate flexibility to perform the task eith er in a } \\
\text { sequ en ce appro pri ate to the tas k, or to support the op erator's need to deviate } \\
\text { from sequence wh ere nec essary, while helping the operator to avoid errors? }\end{array}$ & $\mathrm{Y}$ \\
\hline Can the op erator easily rev erse actions? & $?$ \\
\hline Does the system offer a retracing mechanism to allow for multiple undos? & $\mathrm{N}$ \\
\hline Does the system prevent errors from occurring? & $\mathrm{N}$ \\
\hline Can operators can set their own system, session, file, and screen defaults & $\mathrm{N}$ \\
\hline
\end{tabular}




\subsection{Evaluation of the Emotiv Epoc Neuroheadset}

Table 12: Epoc Neuroheadset Usability Evaluation

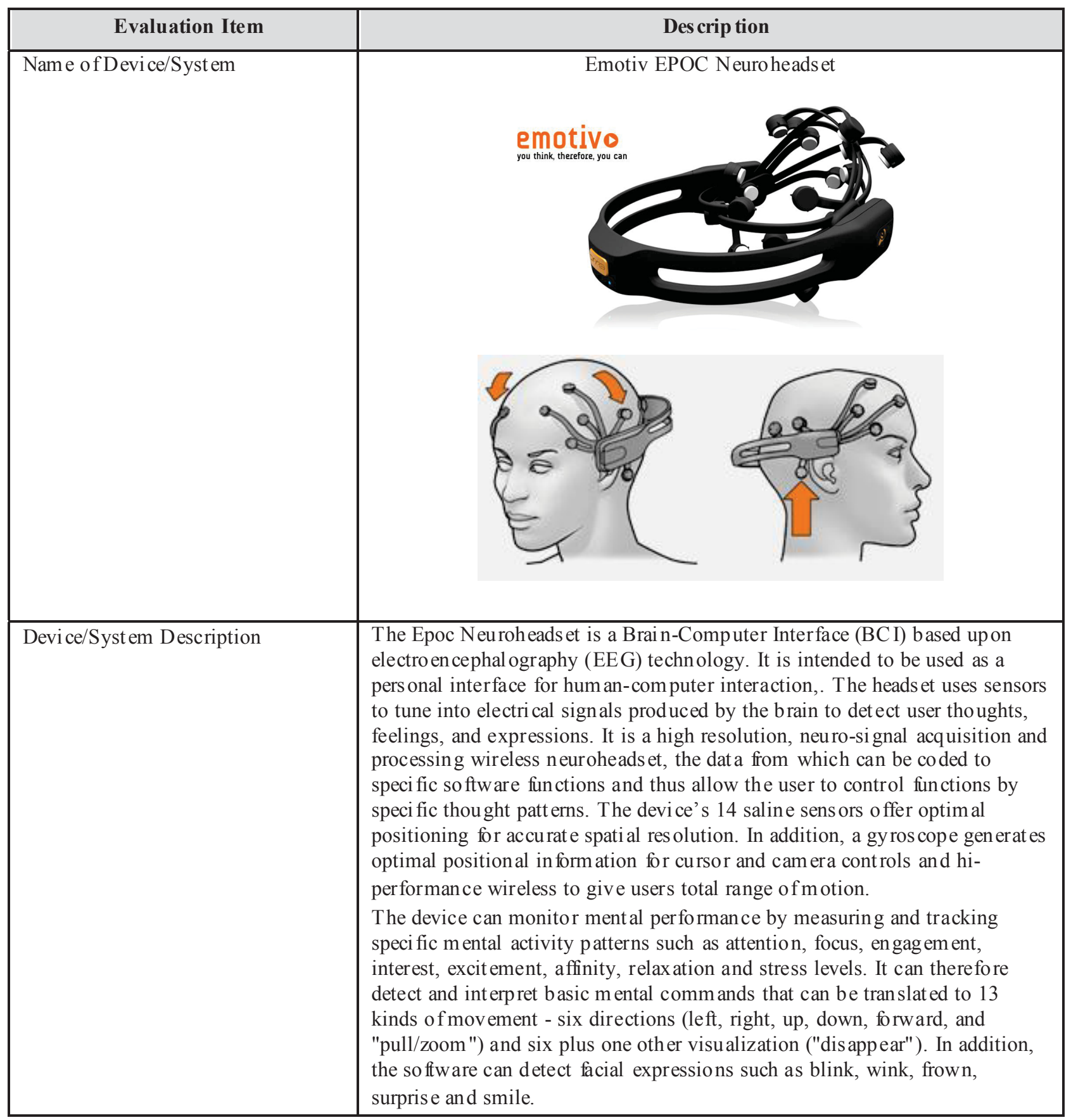




\begin{tabular}{|c|c|}
\hline Purpose and Int end ed Use & $\begin{array}{l}\text { The device is currently promot ed for a range of promising applications: } \\
\text { - Promoting artistic and creative ex pression by encouraging us ers to use } \\
\text { their thoughts, feeling, and emotion to dynami cally creat e color, music, } \\
\text { and art. } \\
\text { - Li fe changing applications for disabled pati ents, such as controlling an } \\
\text { electric wheel chair, mind-k eyboard, or playing a hands-free game. } \\
\text { - Gam es \& Virtual Worlds - to allow us ers to ex perience the fantas y of } \\
\text { controlling and influen cing the virtual environm ent with the mind. } \\
\text { - Market Res earch \& Advertising - new insights into how people res pond } \\
\text { and feel about mat erial presented to them. Res earchers can get real -time } \\
\text { feedback on user enjoym ent and eng ag ement. }\end{array}$ \\
\hline Context(s) of Use & $\begin{array}{l}\text { Because of its ability to detect basic brain activity patterns, a number of } \\
\text { potential advan ced applications in a vari ety of work, play and res earch } \\
\text { applications are em erging, including control of robotic devices, personal } \\
\text { mental training, control of dom estic appliances, control of electronic toys, } \\
\text { measurement of workload in control rooms, etc. }\end{array}$ \\
\hline Intended Users & Researchers, gam ers, artists, athletes \\
\hline - - User Characteristics & $\begin{array}{l}\text { The Epoc Neuroheads et is designed for personal use by normal, healthy } \\
\text { users. }\end{array}$ \\
\hline - - Task Charact eristics & $\begin{array}{l}\text { Typical user behavior and activities using the Neuroheads et: } \\
\text { - Activate the system by positioning the heads et on the head, calibrating } \\
\text { the sensors, and con figuring the det ection param eters; } \\
\text { - Operate the device by consciously forming ment al comm an ds to activate } \\
\text { functions that have been previously defined in the application so ftware. } \\
\text { - Observe the response and make mental adjustments as necess ary. } \\
\text { - Recalibrate functions and sensor sensitivity as necess ary. } \\
\text { Researchers can also record brainwave patterns for lat er analysis. }\end{array}$ \\
\hline - - Environmental Charact eristics & $\begin{array}{l}\text { The device is designed to be us ed in clean office or dom estic envi ronm ents. } \\
\text { In addition, minimal distractions are desirable for best results. }\end{array}$ \\
\hline
\end{tabular}

Ta ble 13: Headset Heuristic Usability Measures

\begin{tabular}{|l|l|}
\hline \multicolumn{1}{|c|}{ Evaluation Item } & \multicolumn{1}{c|}{ Des crip tion } \\
\hline Devi ce evaluation & $\begin{array}{l}\text { The device should be function ally and physically suitable for the rel ev ant } \\
\text { task, as det ermined in term s of effectiven ess, efficiency, safety, reliability } \\
\text { and us er satis faction. }\end{array}$ \\
\hline
\end{tabular}

\begin{tabular}{|l|c|l|}
\hline Evaluation Cri teria & $\begin{array}{c}\text { Rating } \\
\text { Y, N, }{ }^{9}\end{array}$ & \multicolumn{1}{|c|}{ Comments } \\
\hline The size of the devi ce is optimal for the task & Y & $\begin{array}{l}\text { The sensor holders are flexible to fit most } \\
\text { heads. }\end{array}$ \\
\hline $\begin{array}{l}\text { The operating syst em (An droid, Apple, Windows, etc. ) is } \\
\text { optimal for the task }\end{array}$ & Y & $\begin{array}{l}\text { Can be us ed with tablets, smart phones or } \\
\text { PC. }\end{array}$ \\
\hline $\begin{array}{l}\text { Internal and/or ext ernal device m emory is adequate for } \\
\text { the task }\end{array}$ & Y & Data storage directly to the host computer. \\
\hline Portability of the device is suited to the task & Y & Wireless connection allows mobility within \\
\hline
\end{tabular}

$9 \quad$ '?' = someti mes 


\begin{tabular}{|c|c|c|}
\hline & & 30 feet of the computer. \\
\hline $\begin{array}{l}\text { Sensor s ensitivity is efficient and contribut es to the } \\
\text { operator's ability to perform the task effectively without } \\
\text { undue strain or error }\end{array}$ & $\mathrm{Y}$ & $\begin{array}{l}\text { Calibration may have to be repeated after } \\
\text { prolonged use, especially if the sens or pads } \\
\text { become dry and lose conduction. }\end{array}$ \\
\hline Battery life is suited to the task & $\mathrm{Y}$ & $\begin{array}{l}\text { Typical battery life of } 4 \text { hours is suitable } \\
\text { for most trials. }\end{array}$ \\
\hline Device weight and fit on body is suited to the task & $?$ & $\begin{array}{l}\text { The test device is lightweight, but tended } \\
\text { to shift with fast head movem ents or when } \\
\text { bumped by the hand. }\end{array}$ \\
\hline $\begin{array}{l}\text { Navigation between applications and functions is } \\
\text { efficient and suitable for the task }\end{array}$ & $\mathrm{Y}$ & $\begin{array}{l}\text { Users need to face the com puter screen to } \\
\text { monitor the effectiven ess of ment al } \\
\text { commands. }\end{array}$ \\
\hline $\begin{array}{l}\text { Protection from accidental activation is suitable for the } \\
\text { task }\end{array}$ & $\mathrm{N}$ & $\begin{array}{l}\text { Calibration is lost easily when the device is } \\
\text { moved on the head }\end{array}$ \\
\hline $\begin{array}{l}\text { Rugged construction protects the device from damage } \\
\text { and is suitable for the task }\end{array}$ & $\mathrm{Y}$ & $\begin{array}{l}\text { The device is reason able robust and can be } \\
\text { dropped without dam age. }\end{array}$ \\
\hline Protection from electromagnetic interference is effective & Y & $\begin{array}{l}\text { No interference was observed in normal } \\
\text { use in the target environment. }\end{array}$ \\
\hline
\end{tabular}

\begin{tabular}{|l|l|}
\hline $\begin{array}{l}\text { Visibility of system } \\
\text { status }\end{array}$ & $\begin{array}{l}\text { The system should al ways keep operator in form ed about what is going on, through } \\
\text { appropriate feedback within reaso nable time. }\end{array}$ \\
\hline
\end{tabular}

\begin{tabular}{|l|c|l|}
\hline Evalu ation Crite ria & $\begin{array}{l}\text { Rating } \\
\text { Y, N, ? }\end{array}$ & \multicolumn{1}{|c|}{ Comments } \\
\hline $\begin{array}{l}\text { Is there a consistent sym bol design scheme and stylistic treatm ent across } \\
\text { the system? }\end{array}$ & $?$ & $\begin{array}{l}\text { This is dependent on the } \\
\text { application so ftware. }\end{array}$ \\
\hline Is there some form of sy stem feedback for every operat or action? & $\begin{array}{l}\text { All mental commands are } \\
\text { observable in the application } \\
\text { so ffware. }\end{array}$ \\
\hline $\begin{array}{l}\text { Is there visual feedback when objects are sel ected or moved? } \\
\text { Are response times appropriate to the task? }\end{array}$ & As above \\
\hline $\begin{array}{l}\text { Does the system provide visibility: that is, by looking, can the operator } \\
\text { tell the state of the system and the alternatives for action? }\end{array}$ & Y & As above \\
\hline $\begin{array}{l}\text { Ifoperators must navigate between multiple screens, does the system use } \\
\text { cont ext labels, menu maps, and place markers as navigational aids? }\end{array}$ & $?$ & Application dependent \\
\hline
\end{tabular}

\begin{tabular}{|l|l|}
\hline $\begin{array}{l}\text { Match between system } \\
\text { and the real world }\end{array}$ & $\begin{array}{l}\text { The system should speak the operat or's language, with words, phras es and concepts } \\
\text { familiar to the op erator, rather than system-oriented terms. Follow real-world } \\
\text { conventions, making in formation appear in a natural and logical ord er. }\end{array}$ \\
\hline
\end{tabular}

\begin{tabular}{|l|c|c|}
\hline Evaluation Crite ria & $\begin{array}{l}\text { Rating } \\
\text { Y, N, ? }\end{array}$ & \multicolumn{1}{|c|}{ Comments } \\
\hline $\begin{array}{l}\text { Does the system allow ad equate flexibility to perform the task eith er in a } \\
\text { sequ ence appropriate to the task, or to support the op erator's need to } \\
\text { deviate from sequence where necess ary, while helping the operator to } \\
\text { avoid errors? }\end{array}$ & $?$ & $\begin{array}{l}\text { Dependent on the } \\
\text { application software }\end{array}$ \\
\hline $\begin{array}{l}\text { Is the amount of training required appropriate for the compl exity of the } \\
\text { system and its functions? }\end{array}$ & $?$ & $\begin{array}{l}\text { Some users require } \\
\text { extensive training and } \\
\text { practice to become }\end{array}$ \\
\hline
\end{tabular}




\begin{tabular}{|l|l|l|}
\hline & & $\begin{array}{l}\text { pro ficient. Even then } \\
\text { performance can vary due to } \\
\text { mental or envi ronm ental } \\
\text { distractions }\end{array}$ \\
\hline Can the op erator easily reverse actions? & $?$ & $\begin{array}{l}\text { Dependent on the } \\
\text { application soft ware }\end{array}$ \\
\hline $\begin{array}{l}\text { Does the system o ffer a retracing mechanism to allow for multiple } \\
\text { undos? }\end{array}$ & $?$ & As above \\
\hline Does the system prevent errors from occurring? & N & \\
\hline Can operat ors can set their own system, session, file, and screen defaults & $?$ & $\begin{array}{l}\text { Dependent on the } \\
\text { application software }\end{array}$ \\
\hline
\end{tabular}

\subsection{Evaluation Summary}

Of the two devices described above the SMART Board is the most stable technology and has been proven extensively in practice. Its benefits in a variety of work and educational settings are undisputed. While it is already being used in the outage control centers and training centers of some NPPs, it has yet to be accepted for use in control rooms.

Due to the lack of supporting software, the Epoc Neuroheadset BCI is not ready for wide commercial use and is likely to remain in experimental use for the next two to three years. However, it offers exciting potential as a device to help human factors researchers develop new met hods to assess situation awareness and workload in control rooms. This could be achieved by recording the brainwaves of subjects during actual operating scenarios and then matching the resulting patterns to other measures of performance, situation awareness and workload, such as NASA-TLX, SAGAT (Situation Awareness Glo bal Assessment Technique) and SACRI (Situation A wareness Control Room Inventory) [20], [12].

As a general rule, it is not likely that any advanced HSI that has not reached at least TRL 8 would be considere d for use in the nuclear industry, even for experimental purposes. It is possible however that TRL7 devices (that is, prototypes or near-operational systems) would be considered by a national laboratory for research and demonstration purposes. For example, the Motorola Golden-I that was tested at INL in 2012 and the Tobii Glasses eye tracking system that was reviewed in the September 2012 milestone report [34]. 


\section{Future trends}

The only clear thing about the future of HSI technologies is that there will be different development paths for various technologies to support the licensing and commercialization process of new NPPs, and especially SMRs. With more and more devices to choose from, designers may often be forced to adopt a suboptimal design solution by using technologies that are not cutting-edge, but that have already passed the proof-of-concept stage.

Since many advanced SMR designs will only see the light as operating plants by about 2022, it would be realistic to envision the state of technology between now and abo ut ten to fifteen years from now. From current research and trends emerging in consumer, commercial and in dustrial markets we can identify a number of the most significant technologies that might have a greater or lesser impact on fut ure NPPs.

The following table presents a human factors perspective on the likely evolution of HSI technology from $2015-2020$ and beyond: 
Ta ble 14a: Technol ogy Forecast

\begin{tabular}{|c|c|c|}
\hline & $\begin{array}{l}\text { TECHNOLOGY } \\
\text { READINESS }\end{array}$ & NEW NUCLEAR POWER PLANT APPLICATION POTENTIAL \\
\hline Now & $\begin{array}{l}\text { Handheld } \\
\text { communication and } \\
\text { computing }\end{array}$ & $\begin{array}{l}\text { Already available in many commercial and industrial applications, and slowly } \\
\text { finding its way into nuclear. Future applications include remote monitoring and } \\
\text { control for control rooms as well as hazardous environments. }\end{array}$ \\
\hline & Large Touch Screens & $\begin{array}{l}\text { These are becoming more ubiquitous throughout the plant, but especially in } \\
\text { control rooms, technical support centres and emergency operations centres }\end{array}$ \\
\hline 2016 & 3D Displays & $\begin{array}{l}\text { Glasses used to view images. Range from flat panel displays to large virtual reality } \\
\text { displays. Some already available in commercial and consumer devices and will } \\
\text { soon be acceptable for certain nuclear energy applications. Plant personnel can } \\
\text { visualize systems and environments that cannot normally be observed without } \\
\text { exposure to various hazards. }\end{array}$ \\
\hline & $\begin{array}{l}\text { Wearable HSIs and } \\
\text { Gesture Interaction }\end{array}$ & $\begin{array}{l}\text { Wrist-mounted computers are already available in industrial applications, but are } \\
\text { migrating to head-mounted displays and touch-less gesture controllers for a } \\
\text { variety of field operations. In the control room they could replace the } \\
\text { conventional alarm annunciators and other displays that need to be monitored } \\
\text { constantly. }\end{array}$ \\
\hline 2018 & $\begin{array}{l}\text { Flexible and e-Ink } \\
\text { Displays }\end{array}$ & $\begin{array}{l}\text { Can be used in rollable or bendable displays to provide durable information } \\
\text { devices for industrial environments. They could be used for applications like } \\
\text { special instruments, for documents and even large schematics like electrical } \\
\text { drawings, making it unnecessary for workers to carry many documents in the } \\
\text { plant. }\end{array}$ \\
\hline & $\begin{array}{l}\text { Industrial cloud } \\
\text { computing and data } \\
\text { storage }\end{array}$ & $\begin{array}{l}\text { Already widespread in business and domestic applications, but in future would } \\
\text { provide a complete automation system and communication service rather than } \\
\text { the current distributed control system employing programmed logic devices } \\
\text { throughout the plant. The key transition is moving from a fixed client server } \\
\text { architecture, to a distributed architecture with local and global intelligence. }\end{array}$ \\
\hline 2020 & $\begin{array}{c}\text { Augmented Reality } \\
\text { (AR) }\end{array}$ & $\begin{array}{l}\text { Combines real and virtual data to provide an interface between real plant, } \\
\text { operators, technicians and the digital plant. Simple applications are already } \\
\text { available in some niche applications. Maintenance and surveillance tasks will be } \\
\text { improved by AR. In the nuclear plant, technicians can point a camera to an on-site } \\
\text { piece of equipment and the system will match it to the digital map of the plant } \\
\text { and verify it is in its designated location and state, freeing the staff from } \\
\text { cumbersome documents and procedures and also providing contextual } \\
\text { information. }\end{array}$ \\
\hline (Cont & & \\
\hline
\end{tabular}


Table 3b: Technology Forecast

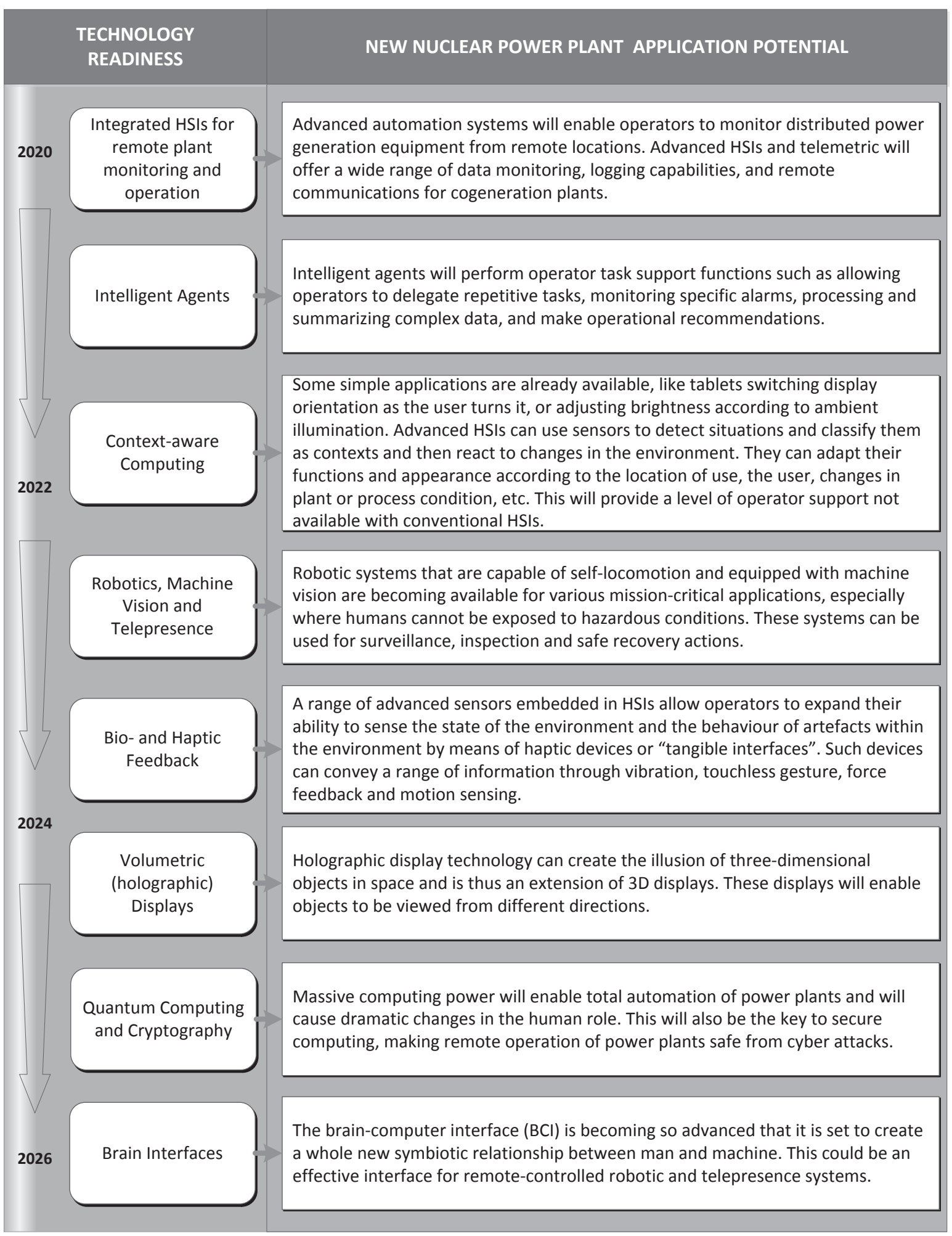

It is easy to see how many of these technologies overlap. As mentioned before, convergence is in fact the one overarching characteristic of current technology trends. Developers have been working on integrating more and more functions into single devices since the $1980 \mathrm{~s}$. What we are seeing now is not only the 
development of different technologies that are able to perform similar tasks, such as voice and video communications and computing, but also for separate technologies such as input and output devices to be combined in the same physical device to enable different interaction modalities. Tablets and smartphones are typical examples of input and output devices that used to be two distinct technologies, like keyboards and visual display units (Cheskin Research, 2002 [10], Silberglitt et al., 2006 [75]). Another growing trend is to develop devices that can adapt to the user's physical location and usa ge context (home, street, office, factory or the great outdoors). Devices like Google's Augmented Reality Glasses is taking this several steps further by interacting with the environment and continually providing users with contextual information.

This convergence is going to be particularly relevant for future SMR operating concepts where changing operator roles will require more powerful means of accessing and manip ulat ing operational information. The discussion of the HSI architecture referred to the future 'operator support system', which wo uld be an ideal application of these hybrid and synergistic technologies.

We can expect improved reliability, resilience, adaptability and information accessibility offered by the HSI technology convergence and functional synergy to be one of the strongest driving forces in design decisions for future control rooms and HSIs. The ability of these technologies to deliver text, audio, a nd video material over the same wired, wireless, or fiber-optic connections is rapidly making the conventional HSI devices of today's power plants obsolete. We can expect the operator of the future to be surroun ded, inside as well as outside the control ro om, by a multi-level, convergent, media-rich world where all mo des of computation, information presentation and communication are available to adapt to normal as well as emergency operating conditions.

Most I\&C engineers assume implicitly that future plants will be highly automated. If we accept that technology advances (for example large-scale integration of networked intelligent sensors and control systems) will force higher levels of automation, then we can safely assume that the role and function of the operator will ultimately change. As explained else where in this report, we can safely assume that operators will perform more supervisory functions and less hands-on control tasks. Human factors engineers would be wise to plan ahead to avoid technology dictating this change. They should work more closely with systems engineers than ever before to ensure that automation decisions are not based solely on the capability of advanced I\&C technologies, but on a productive collaboration between humans and systems. In principle this means that functions should be automated only if it will improve reliability, efficiency and safety without compromising the operator's situation awareness and ability to intervene when necessary. This ability to intervene should be designed into the system in such a way that it will exploit those complex phenomena and capabilities that still make humans superior to machines: coping with uncertainty and conflicting indications, applying rules of thumb, rapid visual recognition of objects, or identifying and matching complex visual or auditory patterns and translat ing it into action. In contrast, operators should not be expected to perform complex mathematical calculations, to perform functions that humans perform poorly or with increased workload, or tasks that are too expensive or dangerous for human operators. 


\section{Discussion and Conclusion}

The first two years of the project focused primarily on developing an understanding of the current state of human-system interface technology. This included identifying and prioritizing key issues in humansystem interaction, identifying and defining the attributes of the state-of-the-art in HSIs, reviewing their potential impact for NPP control rooms, and determining the key technologies to be investigated in forthcoming project activities.

This phase of the project has established the basic principles involved in characterizing advanced HSI technology and identifying the human factors and contextual aspects that would influence its selection for NPPs. However, the human factors guidance for technology selection and deployment is incomplete and more research is needed to translate the concepts described in this report into practical guidance and implementation plans. In addition, the review of technologies and emerging literature on new development has reinforced the general impression of significant gaps in the way advanced HSI technology is used in the nuclear industry:

- There is no coherent HSI technology classification for the nuclear industry.

- There is no classification of operational contexts and the human factors requirements for specific work domains.

- There are no formal guidance and decision criteria for technology selection, including guidance on representation of plant performance data.

- Existing human performance criteria and measures of human performance are limited primarily to the control room and conventional devices. No criteria exist for human performance with advances technologies in other work areas in the plant.

These gaps offer ample opportunity for groundbreaking research over the remainder of this project. In support of the need to develop formal human factors guidance for HSI technology selection, two topics were identified that have never been investigated in the nuclear industry before.

1. How an understanding of trends in technology adoption would help to inform technology selection and implementation plans

2. How a formalized technology acceptance model could be linked to the DOE Technology Readiness Levels and organizational maturity and used to develop a prioritization scheme for technology deployment plans.

These topics are described briefly below.

\section{- Technology adoption trends}

The technology adoption lifecycle model had its origin with the work of Everett Rogers, who generalized the use of the technology adoption curve that describe d how new ideas and technologies spread in different cultures. Others have since used the model to describe how innovations spread between states in 
the U.S., including Geoffrey Moore (1991) in "Crossing the Chasm" [52]. The model describes the adoption or acceptance of a new product or innovation, according to the demographic and psychological characteristics of defined adopter groups.

The process of adoption over time is typically illustrated as a classical normal distribution or "bell curve." The model indicates that the first group of people to use a new product is called "innovators," followed by "early adopters." Next come the early and late majority, and the last group to eventually adopt a product are called "laggards." When graphed cumulatively, the rate of adoption forms the S-curve of technology diffusion and adoption that shows a cumulative percentage of adopters over time - slow at the start, more rapid as adoption increases, then leveling off until only a small percentage of laggards have not adopted:

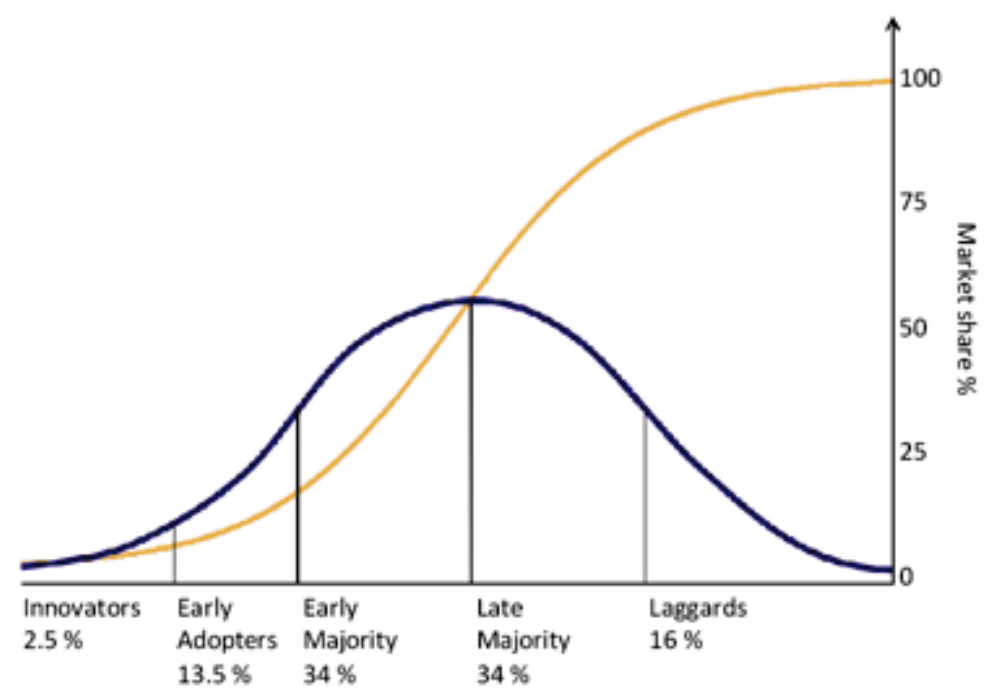

Figure 3: Technology Adoption Curve

Note that this theory and corresponding cycle for product adoption does not describe the effect of the specific domain where technology is to be adopted, or the influence of regulatory and institutional inertia that also can inhibit the adoption of new technologies. What this means for the adoption of advanced ASI for the nuclear industry is that some plants (1-2\%) will lead in the adoption of a new technology and that after $50 \%$ of operating plants have adopted an advanced technology, the other $40-50 \%$ can be expected to follow suit. An example of adoption of advanced technologies in NPP control rooms could be the use of crew identification biometrics as part of the hold-point approval process for automated plant operation sequences. One of the activities proposed for further research is examine the adoption of biometric devices and touch screen interface for feedwater and digital turbine control and to determine the phases associated with adoption and implementation across US plants. From this we will establish a predictive model that can be used to support DOE, industry, and NRC planning for technology adoption. Further research will also review of the applicability of this model and theory to predict the time frame for acceptance of such phenomena as industry and regulatory acceptance of reduced crew size. 


\section{- Technology Acceptance Model}

The Technology Acceptance Model (T AM) is an information systems theory that models how users come to accept and use a technology. The model suggests that when users are presented with a new technology, a number of factors influence their decision about how and when they will use it, notably:

Perceived usefulness (PU) - This was defined by Fred Davis as "the degree to which a person believes that using a particular system wo uld enhance his or her job performance".

Perceived ease-of-u se (PEOU) - Davis defined this as "the degree to which a person believes that using a particular system would be free from effort" (Davis, 1989 [15])

There is a relatively large body of cross-cultural literature related to the technology acceptance model (T AM) found in Davis (1989). Most supporting studies have reviewed facets of informat ion technology: the acceptance of cellular devices, computer usage, distance learning, and broadband on the basis of technology acceptance. Venkatesh et al. (2003 [80]) have also extended the theory to include aspects of performance expectancy and facilitating conditions. There has even been some attempt to apply the underlying theory as an input to cross-cultural human reliability analysis methods that can be used to predict decision choices and failure rates for high technology environments. (Gertman, Novack \& Marble 2006 [21]). The method is scalable and can be used on a national basis, and or an occupational basis, e.g., US procurement specialists versus NPP control room operators. However, many of the studies are not focused on a specific sub-group such as operators within the nuclear industry. These data would have to be developed. In developing a predictive model of technology acceptance, it may be possible to combine Moore's theory of innovation acceptance with the technology acceptance attributes of a particular industry; groups with higher TAM scores would be expected to have a different cumulative innovation profile than technology neutral industries.

Developing training strategies for new technology may require more than simply presenting the functionality of the technology, but may have to address attitudes that figure in technology acceptance. Bagozzi, Davis and Warshaw (1992 [1]) state: "Because new technologies such as personal computers are complex and an element of uncertainty exists in the minds of decision makers with respect to the successful a doption of them, people form attitudes and intentions toward trying to learn to use the new technology prior to initiating efforts directed at using. Attitudes towards usage and intentions to use may be ill-formed or lacking in conviction or else may occur only after preliminary strivings to learn to use the technology evolve. Thus, actual usa ge may not be a direct or immediate consequence of such attitudes and intentions." (ibid.)

Earlier research on the diffusion of innovations also sugge sted a prominent role for perceived ease of use that figures prominently in Davis's T AM model. Tornatzky and Klein (1982 [79]) analyzed the adoption of technology, finding that compatibility, relative advantage, and complexity had the most significant relationships with adoption across a broad range of innovation types. Eason studied perceived usefulness in terms of a fit between systems, tasks and job profiles, using the terms "task fit" to describe the metric (quoted in Stewart 1986 [78]). 
Criticisms of T AM as a "theory" include its que stionable heuristic value, limited explanatory and predictive power, -, and lack of any practical value. (Chuttur 2009 [11]). We feel that one of the reasons that criticism has been harsh is that the model is of value in terms of characterization and limited retrospective analysis but it suffers from not having been paired with a predictive, if global, model such as the one proposed by Geoffrey Moore. Benbasat and Barki (2007 [3]) suggest that TAM "has diverted researchers' attention away from other important research issues and has created an illusion of progress in knowledge accumulation. to the model was also not designed to be applied to - the constantly changing IT environments, has lead [sic] to a state of theoretical chaos and confusion". This is because the model currently does not, but could be, directed to gather information on the number of IT or HSI changes across time. Once a threshold has been crossed, personnel having recently experienced a number of technology changes can build resistance to further change. In the case of the n uclear industry, the pace of change for control rooms has been relatively slow and resistance to change on the basis of frequency is not expected. 


\section{Path Forward - FY 2014 and beyond}

The gaps describe above present a large number of opportunities for syst ematic research and the plan to address these gap s requires several activities to develop and finalize the human factors guidance and technical basis for HSI technology selection and deployment. These are listed in terms of their importance, ease of access to information, and near term achievability:

- Task 1: Formalize the technology selection framework and technical basis, including selection criteria, guidance on context of use methods and tools to support designers, regulators, engineers, and decision makers in the development and evaluation of a new generation of NPP control rooms and related workplaces.

- Task 2: Determine a quantitative model for technology innovation and adoption. This would include several subtasks:

- Development of a risk-informed approach to technology selection that takes into account the vulnerabilities and failure modes associated with technology implementation. For this purpose, a limited set of DBAs or BDBAs wo uld be selected to determine how the implementation of various technology strategies would either increase or decrease.

- To the extent necessary, determine a taxonomy of new failure modes associated with advanced technology.

- $\quad$ Document the failure rates, if available, for use in PRA and HRA.

- Gather the data and theory necessary to support prediction and adoption of advanced technology at various nuclear operating facilities.

- Task 3: Perform a field benchmark study and gap analysis with an industry partner to evaluate the use of advanced technologies in other industries.

- Task 4: Develop a methodology and process for the integration of human factors principles for technology selection as part of the joint Human Factors Engineering/Systems Engineering Process. This includes a cross-mapping of this process with the twelve elements of the human factors engineering program de scribed in NUREG-0711 Rev. 3 as well as a definition of the relationship to existing international standards, such as IEEE 1220-2005 [37], IEEE 1023 [36] and the INCOSE Handbook [38].

- Task 5: Develop a technical basis and human factors guidance for HSI technology classification. Submission to an international standards organization would be a future consideration. 


\section{References}

[1] Bagozzi, R. P., Davis, F. D. \& Warshaw, P. R. (1992), Development and test of a theory of technological learning and usage. Human Relations, 45(7): 660-686.

[2] Ballard, J. W., Hessin ger, R. W. Ballard, J. W., \& Hessinger, R. W. (1954). Human-engineered electromechanical tactual sensory control system. Electrical Manufacturing, 54, 118-121.

[3] Benbasat, I.; Barki, H. (2007), "Quo vadis, T AM?", Journal of the Association of Information Systems, 8 (4): 211-218

[4] Boring, R.L. (2010) Human Reliability Analysis for Design: Using Reliability Methods for Human Factors Issues. Seventh American Nuclear Society International Topical Meeting on Nuclear Plant Instrumentation, Control and Human-Machine Interface Technologies NPIC\&HMIT 2010, Las Vegas, Nevada, November 7-11, 2010, American Nuclear Society, LaGran ge Park, IL.

[5] Braseth, A.O., Nihlwing, C., Sven gren, H., Velan d, O., Hurlen, L. and Kvalem, J. (2009). Lessons learned from Halden Project Research on Human System Interfaces. OECD Halden Reactor Project, Halden, Norway.

[6] Brown, W.S., Higgins, J.C. and O'Hara, J.M. (1994) Local Control Stations: Human Engineering Issues and Insights. NUREG/CR-6146. US Nuclear Regulatory Commission, Washington, DC, 2011.

[7] Butter, C.M., Buchtel, H.A. \& Santucci, R. (1989) Spatial attentional shifts: further evidence for the role of polysensory mechanisms using visual and tactile stimuli. Neuropsychologia. 1989, 27(10):1231-40.

[8] Buxton, B. (2011). Haptic Input. (Chapter 14, Gesture-based Interaction). eBook, http://www. billbuxton.com/input 14.Gesture.pdf, Accessed February 10, 2013.

[9] Chapman, C.E., Bushnell. M.C., Miron, D., Duncan, G.H. \& L und J.P. Sensory perception during movement in man. Experimental Brain Research. 1987, 68:516-524. [PubMed]

[10] Cheskin Research (2002) Designing Digital Experiences for Youth, Market Insights Series, Fall 2002 pp. 8-9.

[11] Chuttur, M.Y. (2009), Overview of the Technology Acceptance Model: Origins, Developments and Future Directions, Indiana University, USA, Sprouts: Working Papers on Information Sy stems

[12] Collier, S. G. \& Follesø, K. (1995). SACRI: A mea sure of situation awareness for nuclear power plant control rooms. Proceedings of an International Conference: Experimental Analysis and Measurement of Situation Awareness (pp. 115-122). Daytona Beach, FL.

[13] Czerwinski, M., Ro bertson, G., Meyers, Smith, G., Robbin s, D. and Tan, D. (2006). "Large Display Re search Overview", In: Proceedings of CHI 2006, Montreal, Canada, Association for Computing Machinery, 2006.

[14] Davenport, W. G. (1969). Vigilance for simultaneous auditory and vibrotactile signals. Australian Journal of Psychology, 21(2), 159-165.

[15] Davis, F. D. (1989), Perceived usefulness, perceived ease of use, and user acceptance of information technology, MIS Quarterly, 13(3): 319-340.

[16] Davis, F. D., Bagozzi, R. P.\& Warshaw, P. R. (1989), User acceptance of computer technology: A comparison of two theoretical models, Management Science 35: 982-1003 
[17] Diederich, A. (1995). Intersensory facilitation of reaction time: Evaluation of counter and diffusion coactivation models. Journal of Mathematical Psychology, 39,197-215

[18] Ehlert, P. A. M. (2003). Intelligent user interfaces: Introduction and survey. Technical report. Delft Technical University.

[19] Endsley, M . R. (1996) Situation awareness measurement in test and evaluation. In T. G. O'brien and S. G. Charlton, (Eds.) Handbook of human factors testing and evaluation (pp159-180) Larence Erlbaum Associates, Mahwah, NJ.

[20] Endsley, M. R. and Garland, D. J. (2000) Situation Awareness Analysis and Measurement. Lawrence Erlbaum Associates, Mahwah, NJ.

[21] Gertman, D., Novack, S. \& Marble, J. (2006). Culture Representation in Human Reliability Analysis. Interservice/Industry Training, Simulation, and Education Conference (I/IT SEC) 2006.

[22] Gilliland, K. and Schlegel, R. E. (1994). Tactile stimulation of the human head for information display. Human Factors, 36(4), 700-717

[23] Guida, G. and Lamperti, G. (2000), “AMMETH: A Methodology for Requirements Analysis of Advanced Human-System Interfaces”, In: IEEE Transactions on Systems, Man, and Cybernetics-Part A: Systems and Humans, Vol. 30, No. 3, May 2000.

[24] Hale, K.S.D (2006). Enhancing situation awareness through haptic interaction in virtual environments training systems. PhD Dissertation, University of Central Florida.

[25] Hameed, S., Ferris, T., Jayaraman, S. \& Sarter, N.B. (2009). Using Informative Peripheral Visual and Tactile Cues to Support Task and Interruption Management, Human Factors: The Journal of the Human Factors and Ergonomics Society, April 2009, 51: 126-135.

[26] Hoffman, R.R. and Elliott, L.R. (2010) Using Scenario-Based Envisioning to Explore Wearable Flexible Displays. Ergonomics in Design: The Quarterly of Hum an Factors Applications 2010 18: 4 .

[27] Hoffman, R.R., Feltovich, P.J., Ford, K.M., Woods, D., Klein, G., and Feltovich, A. (2002) 'A Rose by Any Other Name...W ould Probably Be Given an Acronym.' IEEE Intelligent Systems, vol. 17, no. 4, pp. 72-80, July-Aug. 2002.

[28] Hollifield, B., \& Habibi, E. (2010). The Alarm Management Handbook (2nd ed., p. 261). PAS, Inc.

[29] Hugo, J. (2004) Design Requirements for an Integrated Task Support System for Advanced Human-System Interfaces. In Fourth American Nuclear Society International Topical Meeting on Nuclear Plant Instrumentation, Controls and Human-Machine Interface Technologies. NPIC\&HMIT 2010, American Nuclear Society, LaGrange Park, IL.

[30] Hugo, J. (2006) Human Factors Challenges for Multi-module Control Rooms. International Workshop on Future Control Station Design and Human Performance Issues in Nuclear Power Plants. Halden, Norway, 2006.

[31] Hugo, J. (2012) Towards a unified HFE Process for the Nuclear Industry. Proceedings of the Eighth American Nuclear Society International Topical Meeting on Nuclear Plant Instrumentation, Control, and Human-Machine Interface Technologies. NPIC\&HMIT, San Diego, CA, 2012.

[32] Hugo, J. (2013). Human-System Interfaces for a new generation of nuclear power plants. In Handbook of Small Modular Nuclear Reactors. Carelli, M. and Ingersoll, D. (Eds). Woodhead Publishing: London. (In press). 
[33] Hugo, J., Boring, R., Hanes, L. and Thomas, K. (2013) A Reference Plan for Control Room Modernization: Planning and Analysis Phase. INL/EXT/13-30109. Idaho National Laboratory, Idaho Falls, Idaho, USA.

[34] Hugo, J., Fikstad, C., Forester, J., Gertman, D., Joe, J., LeBlanc, K and Persensky, J. (2012) Draft Framework for Human-System Interface Technology Selection Research. INL/EXT-12-27242. Idaho National Laboratory, Idaho Falls, Idaho, USA.

[35] Hurlen, L., Sven gren, H., Strand, S., Kaarstad, M. and L und-Hanssen, L. S. (2013). Human System Interfaces for near-term applications: Proposed design philosophy and concept. Halden Work Report HWR-1067, OECD Halden Reactor Project, Halden, Norway.

[36] IEEE 1023 (2004). Recommended Practice for the Application of Human Factors Engineering to Systems, Equipment, and Facilities of Nuclear. Power Generating Stations and Other Nuclear Facilities. IEEE Power Engineering Society.

[37] IEEE 1220 (2005). IEEE Standard for Application and Management of the Systems Engineering Process. IEEE Computer Society.

[38] INCOSE. (2010). Systems Engineering Handbook - A Guide for System Life Cycle Processes and Activities, Version 3.2.

[39] International Standards Organization ISO 9241-11 (1998) Ergonomic requirements for office work with visual display terminals (VDTs) - Part 11: Guidance on usability (1998).

[40] International Standards Organization ISO 9241-210 (2010) Ergonomics of human-system interaction, -Part 210: Human-centred design for interactive systems (2010).

[41] Jones, L. A., and Sarter, N. B. (2008). Tactile displays: Guidance for their design and application. Human Factors, 50, 90-111.

[42] Juang, B.H. \& Rabiner, L.R. (2004) Automatic Speech Reco gnition - A Brief History of the Technology Development. Elsevier Encyclopedia of Language and Linguistics (2005)

[43] Kirman, J. H. (1986). Vibrotactile frequency recognition: Forward and back ward masking effects. Journal of General Psychology, 113(2), 147-158

[44] Korsah, K., Holcomb, D.E., Muhlheim, M.D. and twelve others. (2009) Instrumentation and Controls in Nuclear Power Plants: An Emerging Technologies Update. NUREG/CR-6992 US Nuclear Regulatory Commission, 2009.

[45] Kunjachan, M. A., Evaluation of Usability on Mobile User Interface, Belleview Washin gton

[46] Lehto, M. R., Landry, S.J. and Buck, J. (2007). Introduction to Human Factors and Ergonomics for Engineers, Second Edition. CRC Press.

[47] Lewis, R., Commarford, P., Kennedy, P. and Sa dowski, W. "Handheld Electronic Devices", In: "Reviews of Human Factors and Ergonomics", Chapter 4. Human Factors and Ergonomics Society, 2008.

[48] Lintern, G. (2007) What is a Cognitive Sy stem? Proceedings of the Fourteenth International Symposium on Aviation Psychology, (pp. 398-402). Dayton, OH.

[49] Manjoo, F. (2012-06-19). "You Will Want Google Goggles | MIT Technology Review". Technologyreview.com. Retrieved 2013-06-14.

[50] Metz, Rachel. Augmented Reality Is Finally Getting Real, Technology Review, 2 August 2012. http://www.technologyreview.com/news/428654/augmented-reality-is-finally-getting-real/. Accessed 9/15/2013. 
[51] MIL-ST D 1472G(2012) Department of Defense Design Criteria Standard Human Engineering, US Army Aviation and Missile Command, Redstone Arsenal, AL.

[52] Moore, G. (1991). Crossing the Chasm. HarperCollins: New York, NY.

[53] Ni, T., Schmidt, G. S., Staadt, O.G., Livingston, M.A., Ball, R., and May, R. (2006) A Survey of Large High-Resolution Display Technologies, Techniques, and Applications. Proceedings of VR '06 Proceedings of the IEEE conference on Virtual Reality, p.223-236, IEEE Computer Society, Washington, DC.

[54] NUREG-0696 (1981). Functional Criteria for Emergency Response Facilities. US Nuclear Regulatory Commission, Washington, DC.

[55] NUREG-0700 (2002). Human-System Interface Design Review Guidelines. U. S. Nuclear Regulatory Commission, Washington, DC.

[56] NURE G-0800 (2007). Standard Review Plan for the Review of Safety Analysis Reports for Nuclear Power Plants. US Nuclear Regulatory Commission, Washington, DC.

[57] O'Hara, J., Brown, W.S., Lewis, P. M., and Persensky, J. J. (2002) Human System Interface Design Review Guidelines, (NUREG 0700 Rev2). US Nuclear Regulatory Commission Washington, D.C. 2002.

[58] O'Hara, J., Brown, W.S., Lewis, P. M., and Persensky, J. J. (2002) Human System Interface Design Review Guidelines, NUREG 0700 Rev2. US Nuclear Regulatory Commission Washington, D.C. 2002.

[59] O'Hara, J., Higgins, J, and Brown, W. (2008), Human Factors Considerations with Respect to Emerging Technology in Nuclear Power Plants, NUREG/CR-6947. NRC.

[60] O’Hara, J., Higgins, J. and Pena, M. (2011) Human-Performance Issues Related to the Design and Operation of Small Modular Reactors, BNL -96654-2011, (NUREG/CR-7126) US Nuclear Regulatory Commission, Washington, DC, 2011.

[61] O’Hara, J., Higgins, J.C., Fleger, S.A and Pieringer, P.A. (2012) Human Factors Engineering Program Review Model, NUREG-0711, Revision 3, US Nuclear Regulatory Commission, Washington, DC, USA (2012).

[62] Oviatt, S. (2003) Multimodal interfaces. In Jacko, J. and Sears, A. (Eds.), Handbook of humancomputer interaction (pp. 286-304). Erlbaum: Mah wah, NJ.

[63] Persensky, J.J., Szabo, A., Plott, C., Engh, T. and Barnes, V. (2005) Guidance for Assessing Exemption Requests from the Nuclear Power Plant Licensed Operator Staffing Requirements Specified in 10 CFR 50.54(m). NUREG-1791. US Nuclear Regulatory Commission Washington, D.C.

[64] Post L. J. and Chapman CE. (1991)The effects of cross-modal manipulations of attention on the detection of vibrotactile stimuli in humans. Somatosens. Mot. Res. 8:149- 57.

[65] Robbe-Reiter S., Carbonell, N., Dauchy P. (2006) Expression constraints in multimodal human computer interaction. Proceedings of the 5th international conference on Intelligent user interfaces, pp. 225-228, ACM New York, NY.

[66] Robles-De-La-Torre, G. (2006). The Importance of the Sense of Touch in Virtual and Real Environments. International Society for Haptics. http://www.roblesdelatorre.com/gabriel/GRIEEE-MM-2006.pdf. Accessed 9/15/2013.

[67] Rogers, E.M. (1983) (2nd Ed). Diffusion of Innovations. The Free Press: New York, NY. 
[68] Rogers, W. A., Fisk, A. D., McLaughlin, A. C., and Pak ,R. (2005)Touch a Screen or Turn a Knob: Choosing the Best Device for the Job, Human Factors, Vol. 47, No. 2, pp. 271-288.

[69] Salthouse, T. A. (1992). Reasoning and spatial abilities. In F.I.M. Craik \& T.A. Salthouse (Eds.), The handbook of aging and cognition, (pp. 167-211). Hillsdale, NJ: Erlbaum.

[70] Sarter, N. B., and Woods, D. D. (1995). How in the world did we ever get into that mode? Mode error and awareness in supervisory control. Hum an Factors: The Journal of the Hum an Factors and Ergonomics Society, 37(1), 5-19.

[71] Sarter, N.B., Mumaw, R.J., and Wickens, C. D. (2007). Pilots' monitoring strat egies and performance on automated flight decks: an empirical study combinin g behavioral and eyetracking data. Human Factors: The Journal of the Human Factors and Ergonomics Society, 49(3), 347-357.

[72] Sheridan, T. (2002) Humans and Automation: System Design and Research Issues. Wiley Interscience: New York, NY.

[73] Shiffrin, R. M., Craig, J. C., Cohen, E. Shiffrin, R. M., Craig, J. C., \& Cohen, E. (1973). On the degree of attention and capacity limitation in tactile processing. Perception and Psychophysics, 13(2), 328-336.

[74] Shneiderman, B. (2002). The limits of speech recognition. Communications of the ACM. Volume 43 Issue 9, p. 63-65, Sept. 2000.

[75] Silberglitt, R., Anton, P.S., Howell, R. and Wong, A. (2006) The Global Technology Revolution 2020: In-Depth Analyses: Bio/Nano/Materials/Information Trends, Drivers, Barriers, and Social Implications, Santa Monica, CA: RAND Corporation, T R-303-NIC, 2006. Online at www.rand.org/pubs/technical_reports/TR303/.

[76] Sklar, A. E., and Sarter, N. B. (1999). Good Vibrations: Tactile feedback in support of attention allocation and human-automation coordination in event-driven domains. Human Factors, 41(4), 543-552.

[77] Stanley, R. M., \& Walker, B. N. (2009). Intelligibility of bone-conducted speech at different locations compared to air-conducted speech: Evaluation of bone-conduction transduc ers for use in radio communications. Proceedings of the Annual Meeting of the Human Factors and Ergonomics Society (HFES2009), San Antonio, TX (19-23 October).

[78] Stewart, T.(1986), Task fit, ease-of-use and computer facilities, Norwood, NJ: A blex, pp. 63-76 In N. Bjørn-Andersen, K. Eason, \& D. Robey (Eds.), Managing computer impact: An international study of management and organizations.

[79] Tornatzky, L. G. \& Klein, R. J. (1982), Innovation characteristics and innovation adoptionimplementation: A meta-analysis of findings, IEEE Transactions on Engineering Management, EM-29: 28-45

[80] Venkatesh, V., Morris, M. G., Davis, G. B. \& Davis, F. D. (2003), User acceptance of information technology: Toward a unified view, MIS Quarterly, 27(3): 425-478

[81] Verrillo, R. T. (1985) Psychophysics of Vibrotactile Stimulation, Journal of the Acoustical Society of America.

[82] Wallace, J.R., Scott, S.D., Lai, E. and Jajalla, D. (2011), "Investigating the role of a Large, Shared Display in Multi-Display Environments", In: Computer Supported Cooperative Work, 2011, 20:529:51, Springer.

[83] Wood, R.T. et al . (2003), "Emerging Technologies in Instrumentation and Controls", NUREG/CR-ORNL/TM-2003 
[84] Woods, D. and Hollnagel, E. (2006). Joint Cognitive Systems: Patterns in Cognitive Systems Engineering. Taylor and Francis, NY.

[85] Wright, P., Dearden, A. and Fields, B. (2000) Function allocation: a perspective from studies of work practice. International Journal of Human-Computer Studies. Volume 52, Issue 2, p. 335 355 February 2000.

[86] Zlotnik, M. A. (1988). Applying electro-tactile display technology to fighter aircraft - flying with feeling again. Proceedings of the IEEE 1988 National Aerospace and Electronics Conference, pp.191-197. 


\section{APPENDIX A: CLASSIFICATION OF HSI DEVICES}

The following tables describe four classes of HSI devices (see Section 6.1 HSI technology Classification):

- Output devices, that is, technologies that present visual, auditory or tactile information to the user, but do not accept any input.

- Input devices, that is, technologies that allow the user to perform a control action by means of direct (e.g., touch, etc.) or indirect manipulation (push button, lever, joystick, pedal, etc.)

- Hybrid input/output devices that combine more than one interaction modality in the same device

- Specialized Applications that use one or more of the previous three technologies in combination with advanced software to allow the user to perform advanced functions, to reduce the burden on the user, or to augment the user's natural abilities.

Each device in the tables is classified in terms of the following criteria:

- Device Category

- Interaction modality

- Advantages and disadvantages

- Potential Context of Use

- Assess Technology Readiness Level

- Examples of technologies with literature references (where available)

- Opportunities for further research (only for Specialized Applications) 


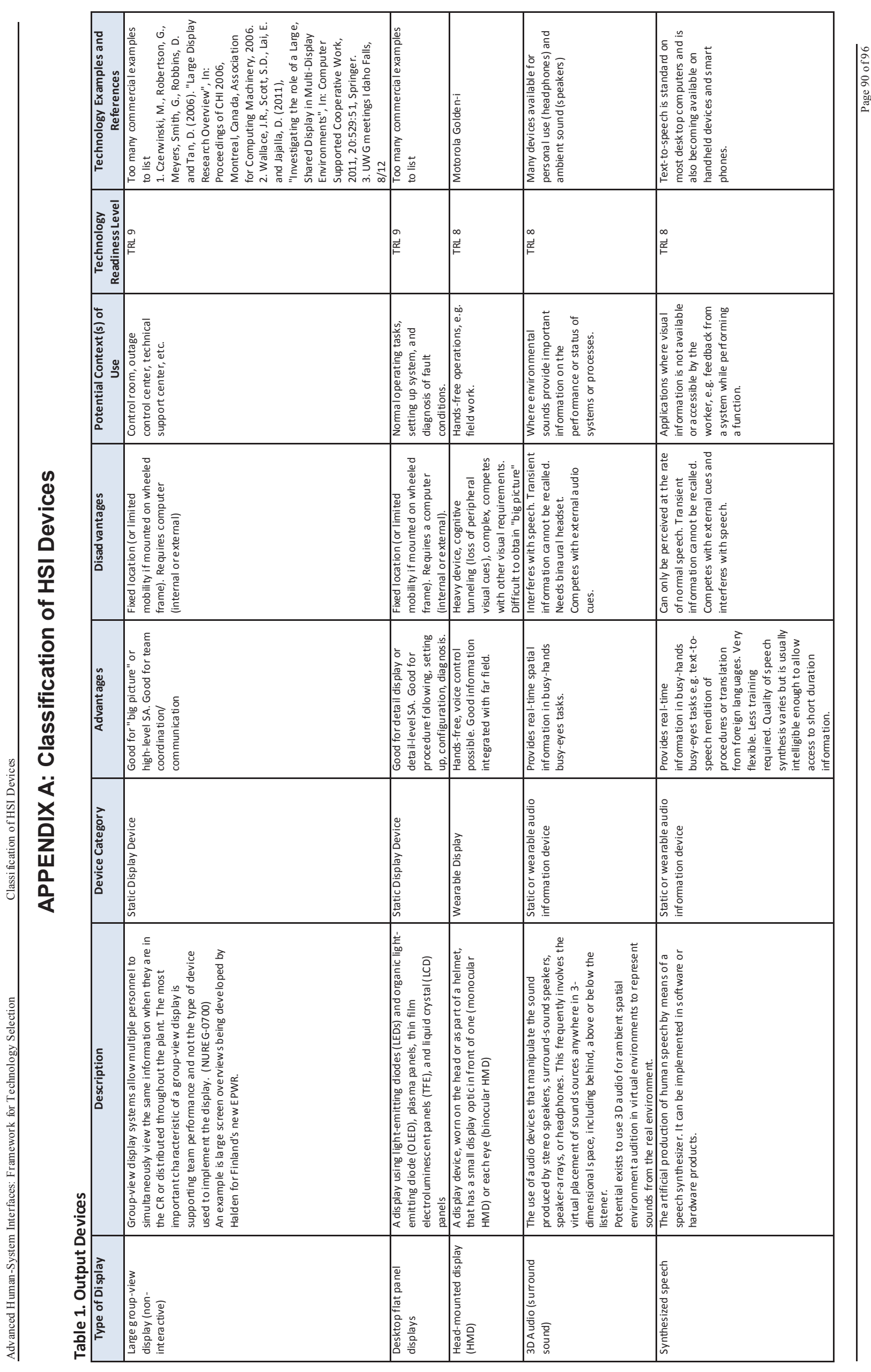




\begin{tabular}{|c|c|c|c|}
\hline 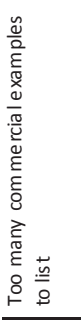 & 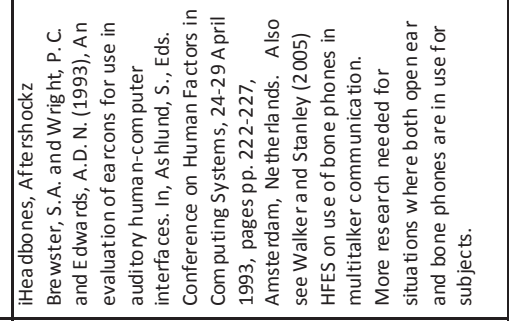 & 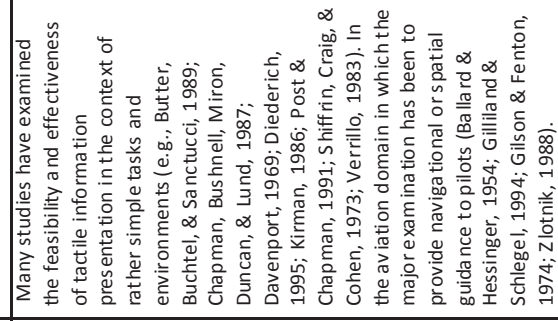 & \\
\hline$\underset{\vec{\mu}}{\vec{\mu}}$ & $\mid \begin{array}{l}\infty \\
\overrightarrow{\underline{\mu}}\end{array}$ & $\mid \begin{array}{l}\infty \\
\overrightarrow{\underline{x}}\end{array}$ & 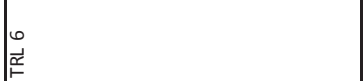 \\
\hline 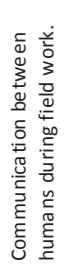 & 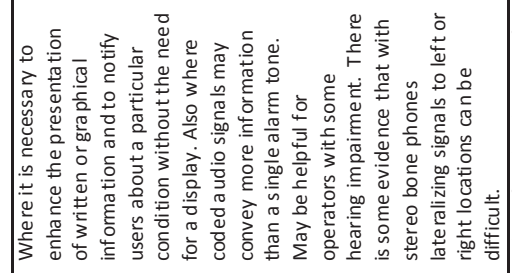 & 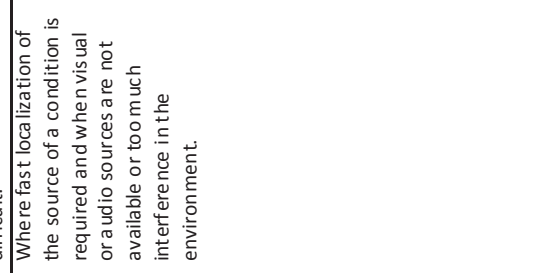 & 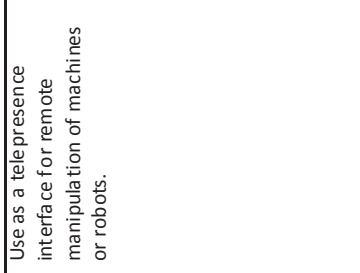 \\
\hline 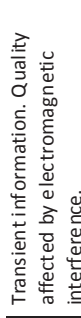 & 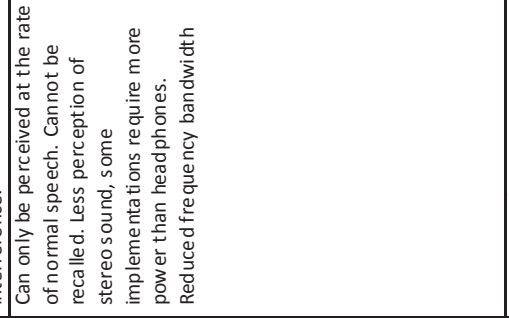 & 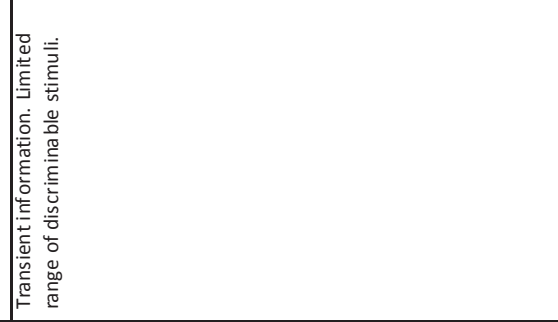 & 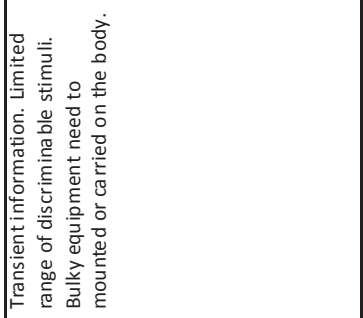 \\
\hline 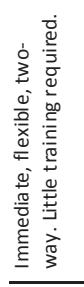 & 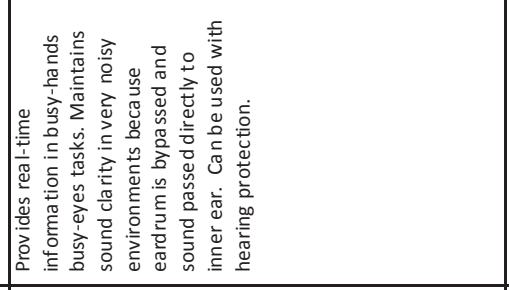 & 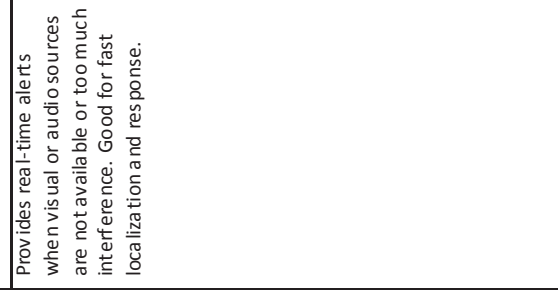 & 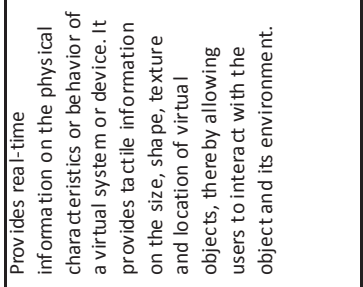 \\
\hline 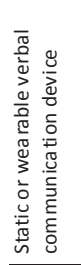 & 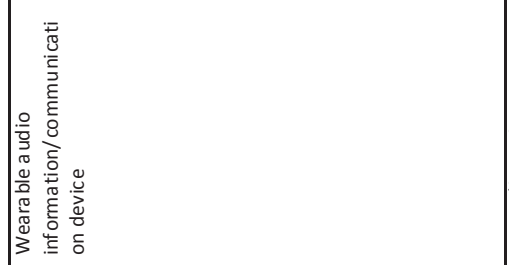 & 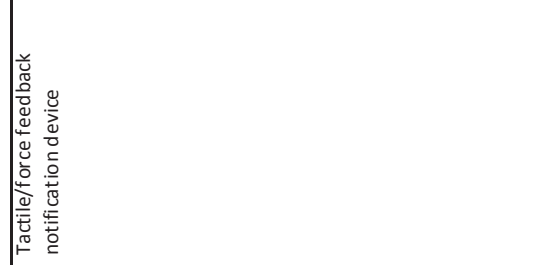 & 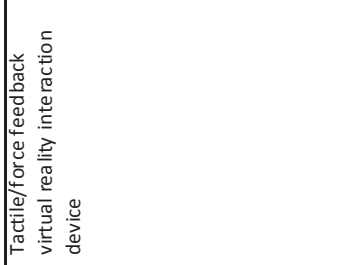 \\
\hline 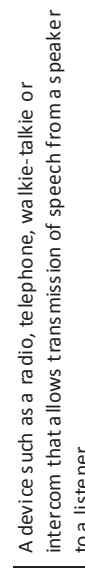 & 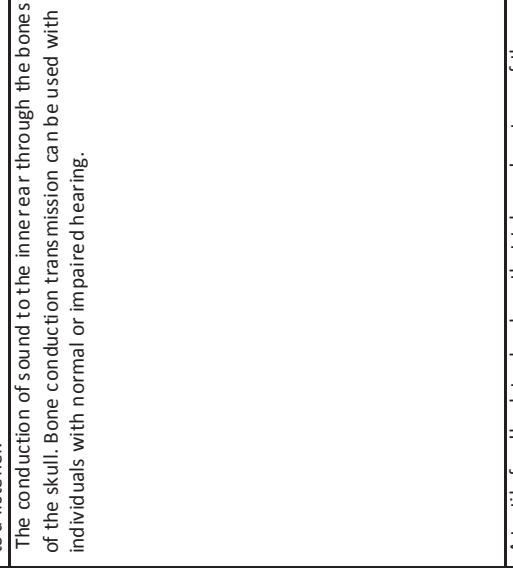 & 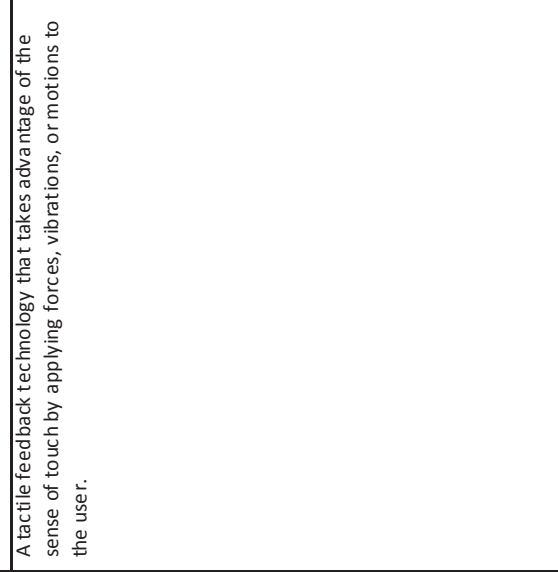 & 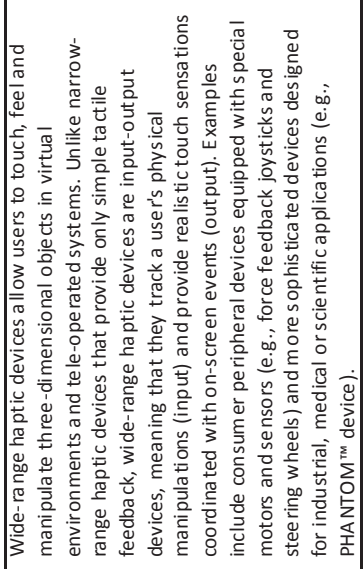 \\
\hline 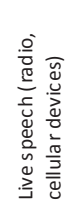 & 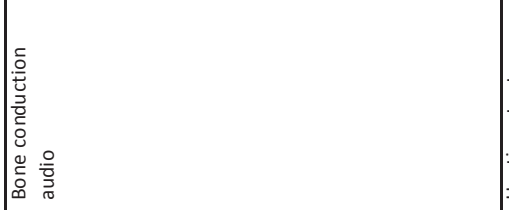 & 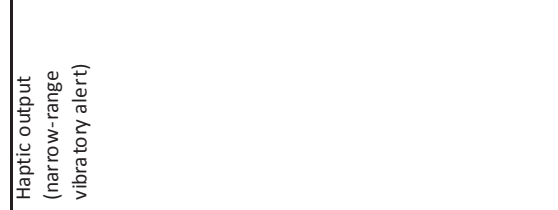 & 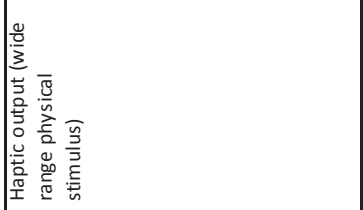 \\
\hline
\end{tabular}




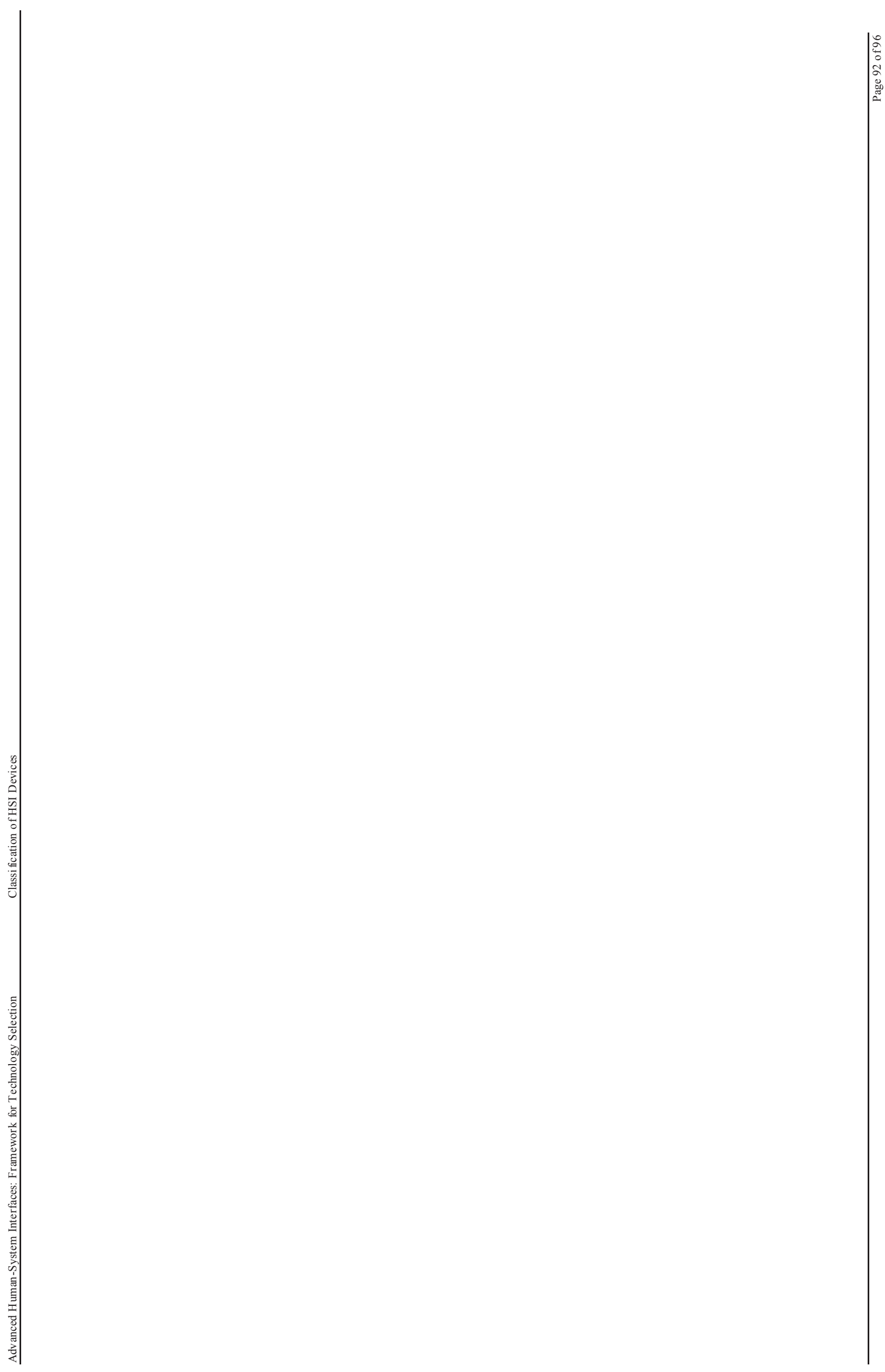




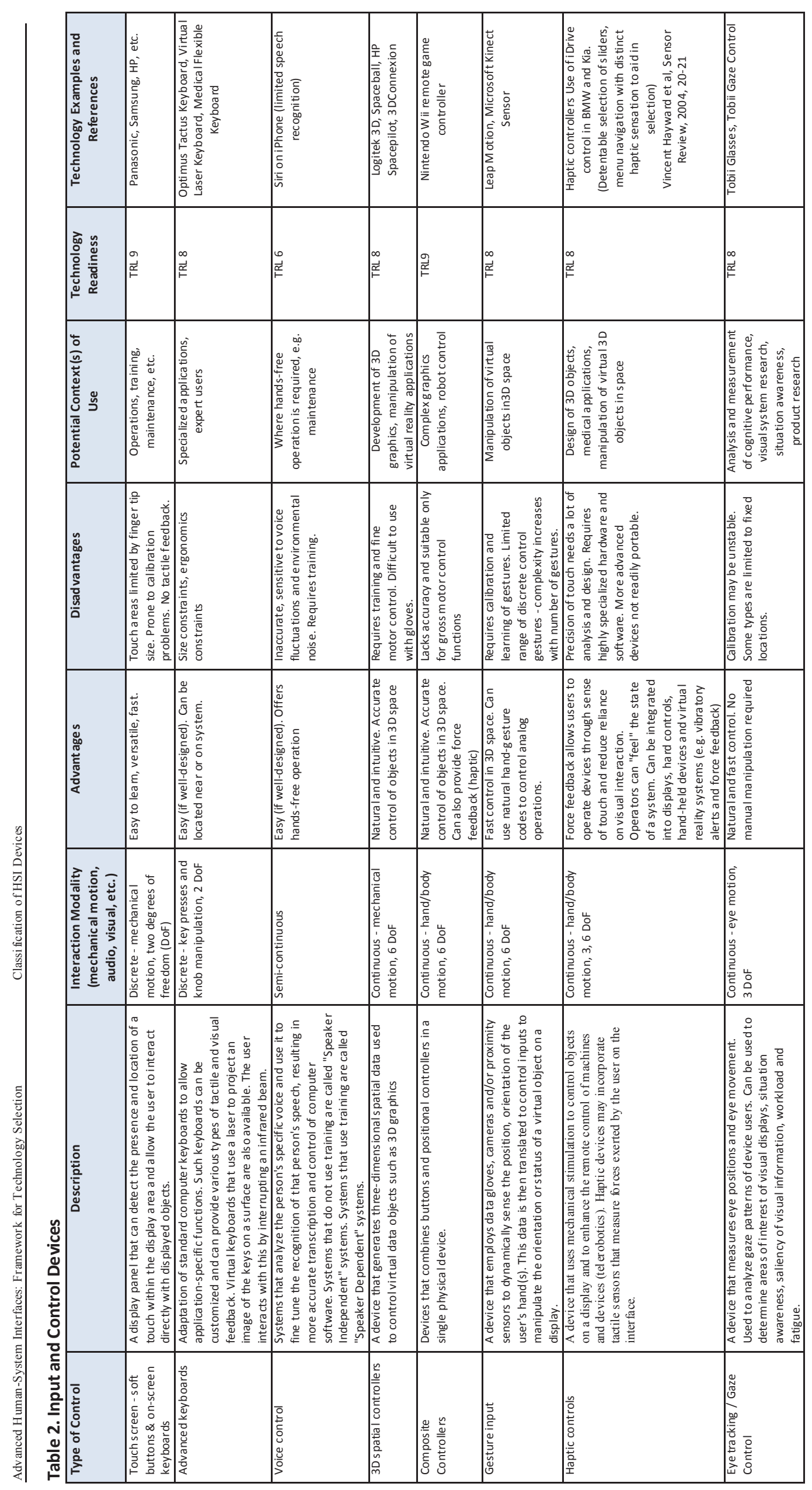




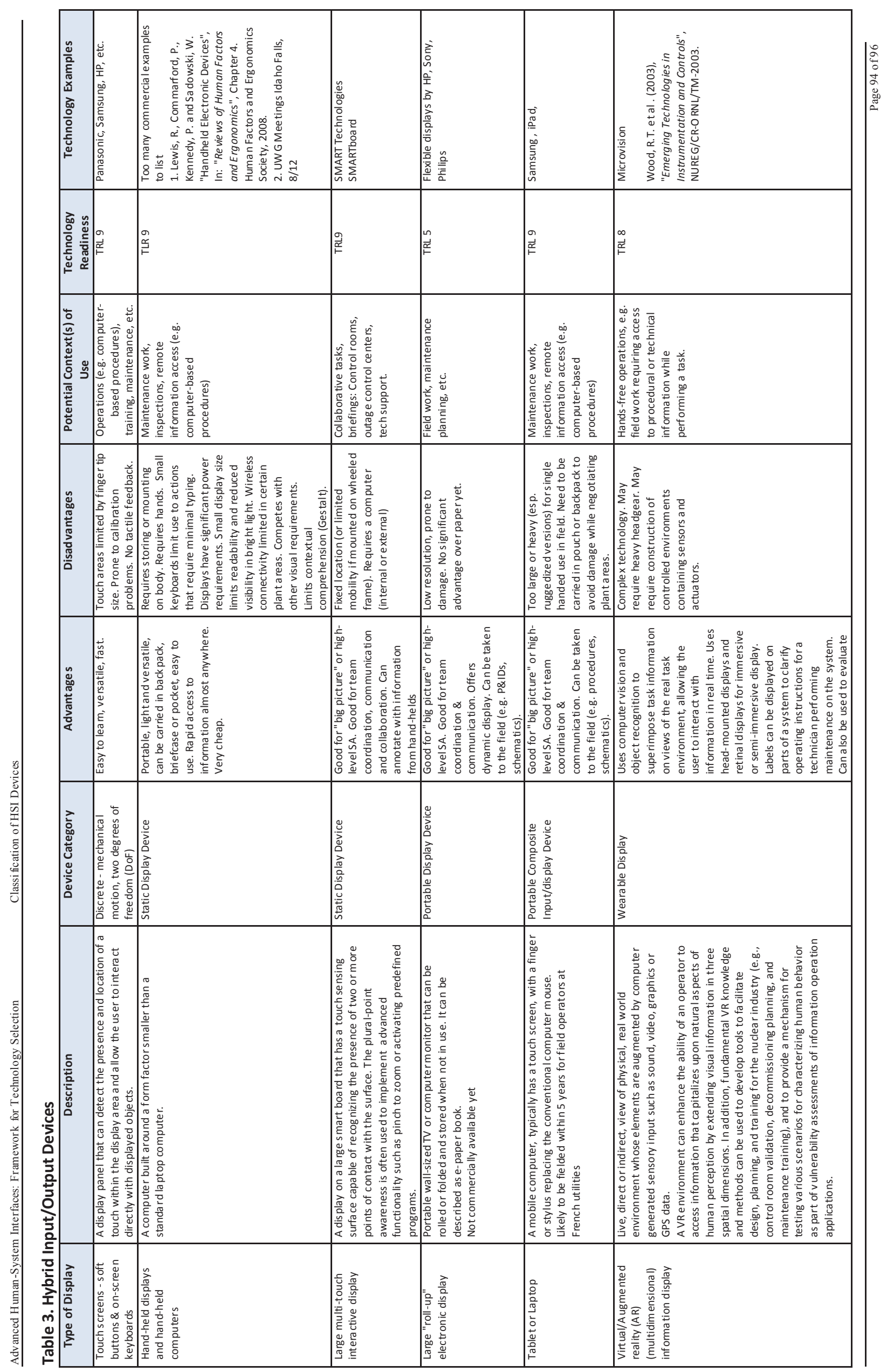




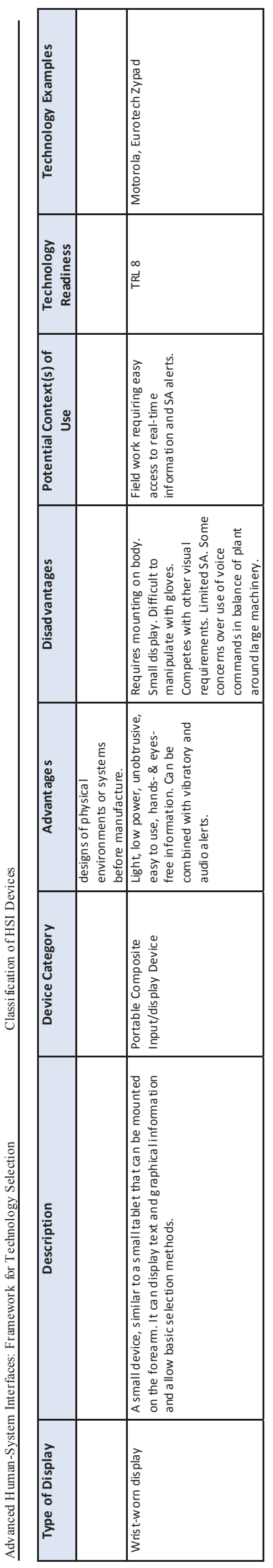




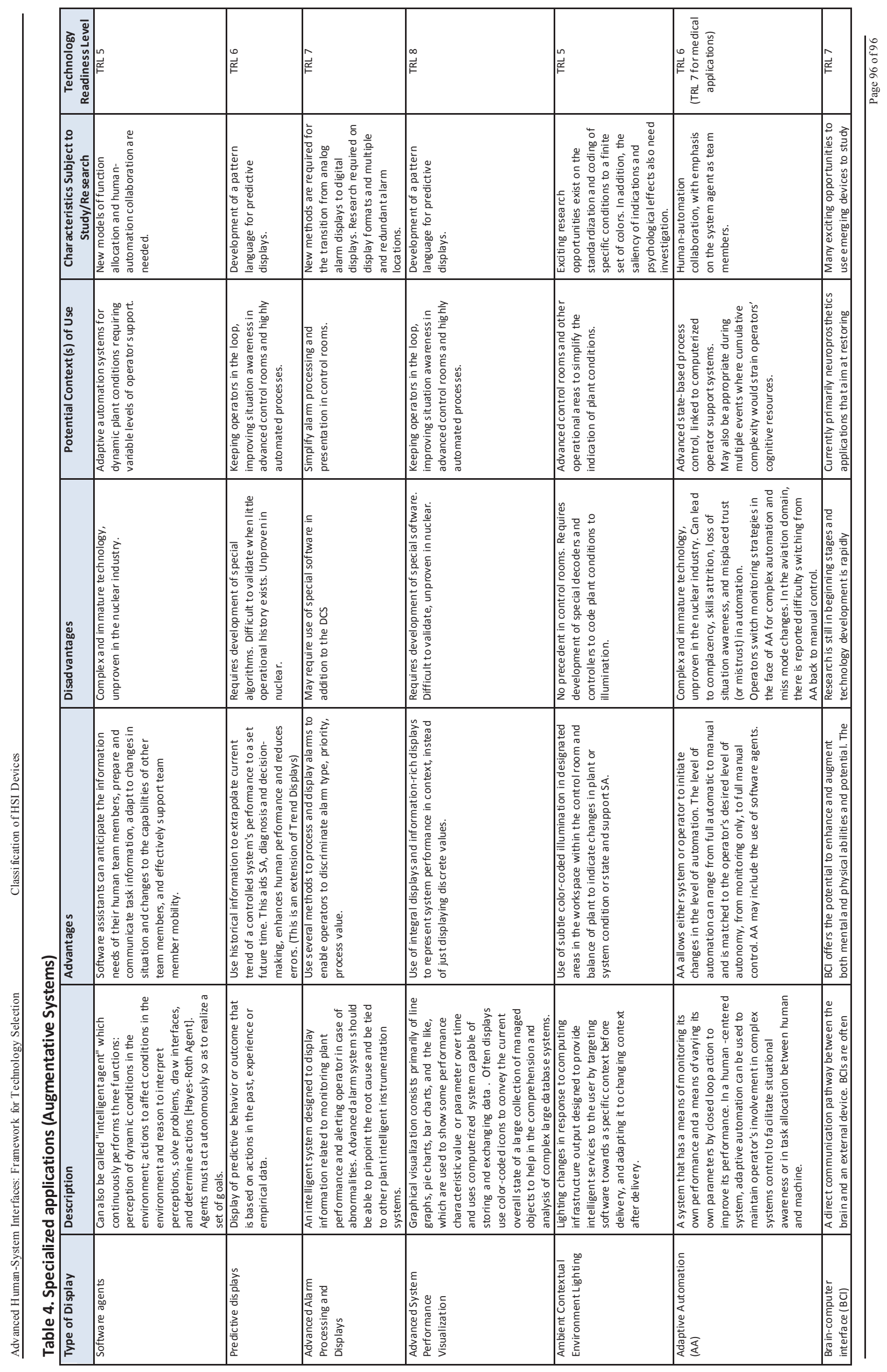




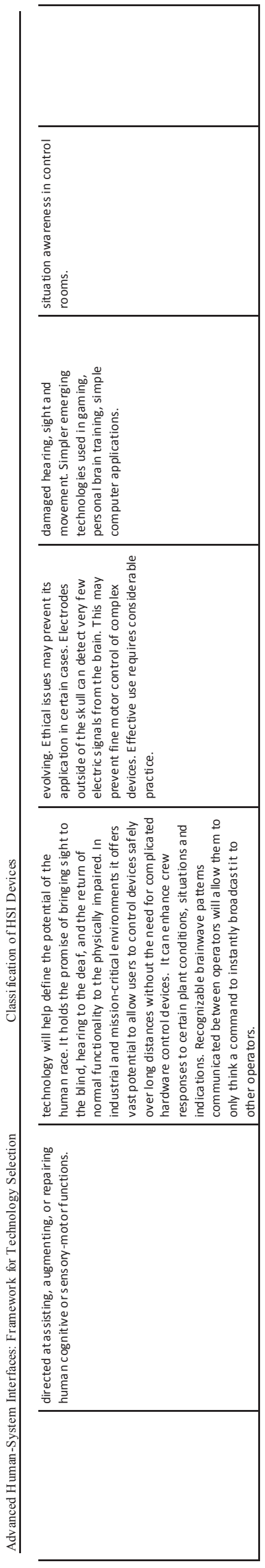

